



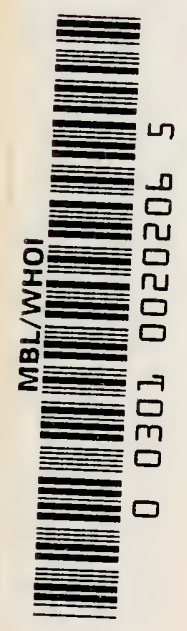



$f$ 


\section{B OOKS \\ BY \\ PERCY G. STILES}

Nutritional Physiology

I 2 mo of 275 pages, illustrated.

Cloth. Si.25 net.

The Nervous System and Its

Conservation

I2mo of 229 pages, illustrated.

Just Out. 


\title{
THE NERVOUS SYSTEM AND ITS CONSERVATION
}

\author{
BY \\ PERCY GOLDTHWAIT STILES \\ INSTRUCTOR IN PHYSIOLOGY IN HARVARD UNIVERSITY; \\ INSTRUCTOR IN PHYSIOLOGY ANI) PERSONAL HYGIENE \\ IN THE MASSACHUSETTS INSTITUTE OF TECHNOLOGY; \\ FORMERLY ASSISTANT PROFESSOR OF PHYSIOLOGY IN \\ SIMMONS COLLEGE, BOSTUN
}

I L L USTR A T ED

PHILADELPHIA AND LONDON

\section{W. B. SAUNDERS COMPANY 1914}


Copyright, 1914, by W. B. Saunders Company

$$
7023
$$

PAINTED IN AMERICA 
TO

\section{EDITH ARTHUR BECKLER}

Co-worker and Friend:

My colleague in developing the instruction in Hygiene in Simmons College 


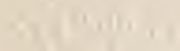

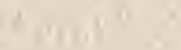

$1+21$ 


\section{PREFACE}

There are several excellent books devoted to the anatomy of the nervous system, there are others which treat of its physiology in an illuminating way, and others still which deal with its hygiene. If the present volume is not to be an impertinence, it must be justified by its attempt to combine some elements of the three. The intention has been to present no more anatomy than is essential to an appreciation of the correlated physiology and to subordinate the physiology, in its turn, to the teaching of hygiene.

In the chapters which deal with structure and function the writer has tried to gather his material from authoritative sources. In those occupied more largely with hygiene, personal judgments have doubtless found expression. But the desire has been not so much to dictate in a dogmatic spirit as to open important mat. ters to fuller discussion.

Many associates have contributed to the making of this book. From the number it is just to mention Professor Elnest G. Martin, of Harvard, whose suggestions have been numerous and valuable.

$$
\text { P. G. S. }
$$

November, 1914 



\section{TABLE OF CONTENTS}

CHAPTER I

PAGE

INTRODUCTION ........................... 11

CHAPTER II

The Mindte Structure of the Nervous Tissues..... 22

CHAPTER III

The Elements of Nerve Physiology ............... 36

CHAPTER IV

Reflexes................................ 49

CHAPTER V

The General Anatomy of the Nervoes System..... 60

CHAPTER VI

The Afferent Part of the Nervous System........ 75

CHAPTER VII

The Neuromuscular Mechanism ................. 85

CHAPTER VIII

The Neuromuscular System: Neuromuscular Fatigue.. 101

CHAPTER IX

Tine Autonomic Nervous System 
C'HAPTER X'

The Cerebrum .............................. 127

\section{CHAPTER XI}

The Cerebrem and Human Development............ 142

CIIAP'TER X̃II

The Cerebrua and the Life of the Individual...... 15:3

CHAPTER XIII

Emotiox ............................... 164

CHAP'TER XIV

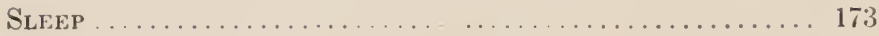

CHAPTER XV

Dreams .....................................

CHAPTER XVI

Cacses of Nervot's Impalbment.... ............ 192

CIIAPTER XVII

Neurastuenia

CHAP'TER XV'HI

Some Matters of Cieneral hygiene. 216

INDEX. 22.5 


\section{THE NERVOUS SYSTEM AND ITS CONSERVATION}

\section{CHAPTER I \\ INTRODUCTION}

\section{TISSUES}

Before the modern microscope was available, anatomists and physiologists recognized in the make-up of the human body various types of constituent substance or fabric. The different kinds of material recognizable were few in number and easily assigned to certain large classes. Comparison of one part of the body with another showed that the same forms of organized substance were found over and over again. The several varieties of material distinguished came to be known as tissues.

In the hand, for example, we find the skin, the muscle, and the bone, representatives of kinds of tissue contrasted in function, in physical character, and in chemical composition. Closer study of the hand would add other members to the list. When we consider the tissues with regard to the intensity of the life-processes taking place in them it is clear that this is anything but a constant quantity. In some cases we have to do with structures which are essentially passive in their nature and which might conceivably be replaced by non-living substitutes. This is true of those tissues which are described as connective. Their service is mechanical; they unite and support other tissues. Bone is a conspicuous example of 
this class, and very much as the skeleton determines the general form of the hody, so each organ is to be thought of as possessing a minor framework of material which behaves for the most part as though it were not really alive.

It is usial to place the tissues in four large groups. Besides the connective, to which reference has just been made, we speak of the epithelial, the muscular or contractile, and the nervous. Epithelial tissues are those which form surface layers, either internal or external. They are the linings and the coverings of the organs. The skin, or at least its superficial portion, is an obvious example. While all the epithelia an-wer to the description of "coverings or linings," they vary widely in other respects. Under the general term are included structures as unlike as the calloused sole of the foot, the exquisitely clear cornea of the eye, and the excessively thin partitions interposed between the blood and the air in the lungs. Judging the epithelial tissues by their share in the total of the life-procesises, we may say that they have both passive and active parts to perform. In some places their function is merely protective; in others they have well-marked (hemiceal activity. Secretion and absorption are epitlielial duties, and neither the one nor the other could be sarried out in its fulness by membranes not living.

Contractile tissues are those which originate the movements of the parts of the body. Organized into large masses, they form the familiar muscles. The heart is mainly composed of a peculiar contractile material which is responsible for its beating. The same property is manifested by elements fonmd in the walls of the alimentary canal, the blood-vessels, the urinary bladder, the uteris, and other bollow viscera. It is evident that the contractile tisisues are eninently "alive"-that no lifeless substances could be expected to behase as they do. Three principal varieties are recognized, conveniently distingnished at the skeletal, the cardiace, and the visceral 
-names which go far to denote the region where each is discovered.

The nervous tissues are far less conspicuous in an anatomic sense than the three orders just enumerated. Let us imagine for a moment that each of the four divisions in which we have placed the tissues could be presented separately to view. Four human figures would appear before us. That one composed wholly of comnective tissue would consist of the skeleton as a basis, and would show, in addition, an indication of each organ in outline, with an internal system of interlacing strands. It would include the ligaments which join bone with bone, the cartilages which also occur about the joints as well as in some other localities, and the tendons uniting muscles with bones. The muscles themselves would be blocked out in this picture by the surface membranes which they possess and by webs of non-contractile material within.

The second figure would retain the complete contour of the human form, inasmuch as it would have the skin. If it were transparent enough the cavities and external surfaces of the viscera would be seen defined in their entirety, but with spectral lightness. The alimentary canal would be traceable as a winding tube of great delicacy within another still more diaphanous. The blood system would be mapped in similar fashion. The interior arrangement of each gland would show a tree-like pattern of bewildering intricacy.

The third figure, consisting of the contractile lissues, would be fragmentary and discontinuous. To conceive of this apparition as keeping its shape calls for an extra stretch of the imagination. It would supply the chief bulk of the muscles and a fraction, missing in the other manikins, of the alimentary, circulatory, and reproductive systems. In a scattering way contractile tissue occurs even in the skin, where its presence makes possible the "goose-flesh" reaction. Although this third figure would be less colerent than the others, it would greatly exceed them in weight. 
What would remain for the fourth member of this uncanny series? It has been reserved for a reconstruction of the nervous tissues. A distant view of it would give the impression of a ghostly form with a more substantial axis expanding above into a bulbous mass in the head. On closer approach the axis would prove to be the spinal cord, the enlargement above would be recognized as the brain, and the filmy haze which completed the figure would resolve itself into many nerves, branching strancls proceeding from both brain and cord and terminating in a cloud of finest filaments. These filament: would be found to reach almost every pitrt of the body (Fig. 1). A large proportion would be seen to end near the external surface; a great many could be followed to localities previously determined to correspond with the skeletal muscles; still others would be manifestly adapted to make connections with blood-vesseh, glands, and the contractile elements of the viseeril.

By way of recapitulation the following statements may now be made: The human body-or the body of any animal of a highly organized type-owes its relative constancy of form to an inactive supporting system, the connective tissues. It owes its ability to move to the contractile tissues. The epithelial tissues are those which establish the boundaries between the organism and the envirnment; through them exchanges of gaseous and dissolverl substances take plare. The service of the nervolis tissues remains to be indieated. The task is to oceupy us throughout the present volume. But at condemser proliminary discussion is desirable.

If a word is sought which shatl convey a general idea of the work of the nervous system, it is probable that the term coürdination will suggest itself. The nerves serve to place various parts of the borly in communication. This statement mast be followed at once with the note that the ammmunication afforeded is never directly from organ to organ, but always by way of the axial part of the system. Thus, there is no mbroken nervons high- 


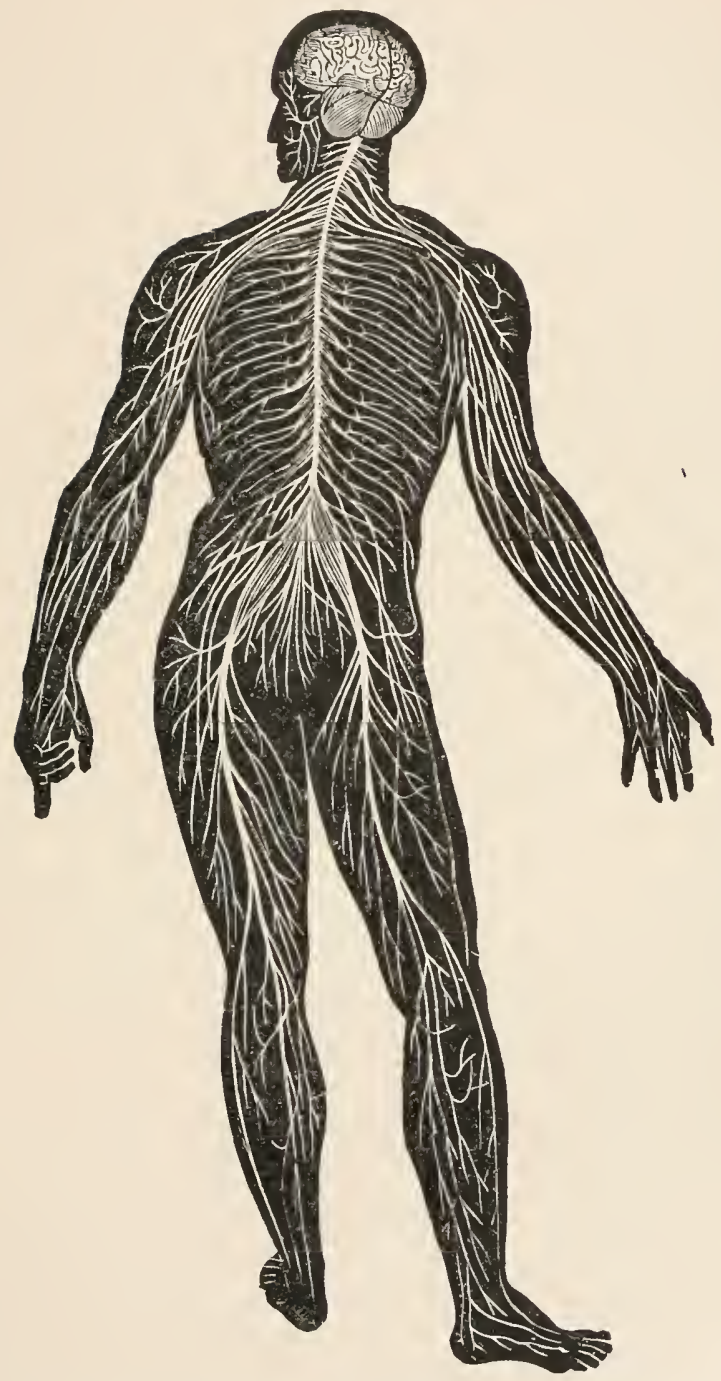

Fig. 1.-Diagram illustrating the general arrangement of the nervous system (Martin, "The Human Body"). 
way from the stomach to the heart, nor from one hand to the other. Yet the stomach may influence the heart, the central part of the mechanism transmitting the effect. The fundamental plan of the structure involved is that of a tree, and just as an ant cannot pass from one of the main branches to another without visiting the trunk, so all physiologic reactions employ a rentral link.

Coördination implies order, efficieney, and timeliness in the operation of a machine. These desirable qualities rould not be realized in the living machine if it were not for the nervous system. Coördination is akin to coöperalion, and the purposeful working together of all the parts for the advantage of the whole is accomplished through the aid of nerves and nerve-centers. A word which is now frequently heard in this connection is integration. The nervous system may be saicl to confer integrity upon the organism. This is to say that the unity or omeness of the animal is almost wholly depenclent mpon this feature. It is not entirely so, for we are realizing more and more that chemical products passing from organ to organ have much to do with the coördinating of activities. If the nervous tissues could be instantly eliminated from the body of a (log without domg other injury, the life processes would not immerliately rease, but they would become local and partial. They coukl no longer be conbined to the advantage of the animal. The nervous system confers upen the associated tissues the right to rank as an indiriduul.

It is scarecely posithle to use the word "individual" without introchuring the iclas of a self-comscious being. Ono's own nervous system is, in part, demonstrated to one thromgh persomal eonserousness. This is the field of prechology. The pleysiologist is more properly a student of the objective thin the subjective, and he is oceapied for the nost part with observing the reactions mediated loy mervous systens other than his own. Yet it may be chamed that there is a ensiderable borderland common to the two branches of science within which it behooves 
both the psychologist and the physiologist to make ventures. It is fortunate, nevertheless, that a great many facts can be noted and discussed without any reference to supposed mental states in animals.

IVe can deal with all the reactions brought about through the nerve-centers in the simpler animals without assuming psychic accompaniments, and the same method carries us very far with our attempted analysis of nerve physiology in the higher forms. A man cannot regard his own brain in quite the same way in which he regards his liver, but when he is bent on studying the living nervous system in a frog, a cat, or even in another human being his immediate concern is with what it does - not with what is felt while the action is in progress. Eventually he is obliged to consider sensation in connection with his other problems, but it is well to defer as long as possible the admission of psychologic elements.

In accordance with what has been said, an objective treatment of the nervous system will be pursued for the present. The nerves will be looked upon as conductors of energy. The chief source of this energy will be recognized in the external forces which are brought to bear upon the organism and which are termed stimuli. The destination of the currents of energy will be found in the contractile and secreting tissues whose activities they modify. Life that is not one's own is manifested through movement, heat production, and secretion; it is very rarely that we are obliged to take other responses into account. Attention must be directed to the fact that nervous tissues separated from others can scarcely give clear evidence of their internal changes. Muscles and glands are required to testify to what is passing in the governing mechanism. (Except for certain electric symptoms of very slight intensity we should not be able to decide whether a detached portion of a nerve-trunk were living or lifeless.) 


\section{RECEPTORS; AD JUSTORS; EFFECTORS}

These three words have recently been used to develop a most simple and helpful outhe of the general work of the nervous system. Whether we consider a worm, an insect, a reptile, or a mammal, three departments of organization with functions of three orders 'an be indirated. The receptors, as the name implies, constitute that department of the system which is subject to external influenees. Receptors are wrought upon by pressure, by changes of temperature, by chemical agents in solntion. In the more highly (leveloped animals they include particular sense organs like the eye and the ear. Such organs translate vibratory energy of the ether and the air respectively into the form of energy which nerves conver.

It is to be noted that receptors may be strictly part of the nervous system, as where naked endings of the fibers lie exposed to contacts, or they may be mechanisms made of other tissues serving to transmute and apply the energy of the stimulus. Where the receptor does not eonstitute a part of the nervous system the path from it to the centril axis must be given a special name, ancl it is spoken of as a sensory or afferent path.

The efferetors upon which the nervous system pliys include the contractile and ghandular tissues. The effectors are always distinct from the nervous system, and the fibers stretching out to them form efferent paths. The third rass of working units, the adjustors, are those within the nervous system which nediate between the receptors and the effectors, or, more acemately, between afferent and efferent pathways. It is in the reahn of the adjustors that the utmost complexity of organization is posisible. 'The variety of reaction so typical of animals which we "all "high in the scale" has its physical basis here.

Parker, of Harvard, has written most suggestively of

1 ( . H. P'arker, "The Origin and Signifieanee of the Primitive Norvous system," P'roceedings of the American Philosophieal Society, 1911, vol. 1, No. 199. 
the probable sequence in which the three orders of elements have acquired their position in relation to the nervous system of standard type. According to his hypothesis there may have been a certain lowly condition-possibly realized in sponges - in which contractility was displayed only in response to distinct and direct stimulation brought to bear from the outside world upon tissues having the power of movement. No separate and definitely nervous tissue would be requisite to apply the stimuli, but if such a transmitter should be evolved it would be evident that an efferent element had come into existence. Parker thus conjectures that the efferent is the most primitive feature of the three.

In the course of development the submergence of the contractile tissues below the exposed surface of the body would make it necessary that a receptor should be added. Its function would be to maintain relations between the exterior and the hidden effector. One receptor joined with one effector would form a sufficient means for bringing about one, and only one, reaction. The arrangement does not admit of any flexibility. It is the simplest example of what is called a reflex arc. With the addition of intermediate links between the receptor and the effector departments the reaction becomes less and less predictable. This is equivalent to saying that it becomes more and more like the actions of the higher animals-subject to reinforcement, suppression, or modification under the influence of changing circumstances. Many illustrations will be given later which will serve to clear up this matter.

Excitation and Inhibition.-The common conception of the function of nerves is that they arouse activity. This is essentially true of those which stretch out from the central axis to the skeletal muscles, and which call forth the evident movements of the limbs, the play of facial expression, etc. The muscles involved in such movements are relaxed and paralyzed when their nervous connections are interrupted. It is because this fact is so prominent that one may easily fall into the error of sup- 
posing that no process of contraction or secretion takes place save as the nervous system initiates it. This is very far from being the case.

All the branches of the nerves which enter the substance of the heart may be cut, but the heart will continue to beat. Hence, we annot believe that each beat of the heart is dictated by the efferent elements of the coördinating system. The power to make rhythmic contractions is resident in the organ itself; we say that it is automatic. In a less striking, but still positive, way other organs clisplay a tendeney to activity when removed from central command. This is demonstrable for the stomach, the intestine, and the urinary bladder. The contractile tissues which enter into the make-up of these viscera must be said to have a degree of automaticity.

When an organ has this disposition to be active on its own account it will be seen that the nervous system may exert a twofold influence upon it. The native, local process may be accelerated beyond its average rate of progress, or it may be restrained more or less radically. We say that tissues which possess the automatic property may exhibit either excitation or inhibition when the nervous system modifies their inherent tendency. It is probably just to claim that both with the heart and with the alinentary tract inhibitory effects are more frequently witnessed than are those which are clearly excitatory. If one is inclined to question this, on the ground that quickening of the heart-beat in excreise is a claily experience, it may be answered that this quickening is known to be to a ureat extent the withdrawal of an inhibition previously operative. Withdrawal of inhibition is a form of rounterfrit stimulation which will repeatedly call for consideration in later paragraphs. The slowing of the heart after exercise may be a more positive instance of nervous intervention than the hastoning of its atom, which soems so much more impresive.

As for the alimentary anal, it has become neell resengnized that its movements are actually observed to better 
advantage when it is removed from the reach of central influences than when its nervous connections are intact. It is not unlikely that there are a good many human beings suffering from indigestion of nervous origin who would have less trouble if their stomachs and intestines could be placed quite out of reach of brain and cord and left to work as determined by their own intrinsic properties. According to this view, suspension of the motor activities of the canal is a possibility easily realized. Acceleration may also be effected, but cannot be held to be so common and striking an occurrence.

When the first clear instance of inhibition-the case of the heart-was brought to the attention of scientists in the year 1845 it was received with surprise and, at first, with incredulity. All sorts of explanations were offered for the phenomenon, with the intention of proving that it was not a true suppression of activity. In course of time, however, inhibition had to be recognized as a power of the nervous system fully as direct and characteristic as excitation. It is now fair to say, as a concise statement of all which has gone before, that the duty of the nervous system is to translate the energy of external stimulation into nerve-impulses, to carry these to the central axis, and to apply them through the efferent paths either to arouse or to restrain the action of the contractile and secreting tissues. The nature of the energy which is transmitted along the nerves can best be discussed after we shall have cbtained some insight into the microscopic organization of the nervous mechanism. 


\section{CHAP'TER II}

\section{THE MINUTE STRUCTURE OF THE NERVOUS TISSUES}

OuR Introdnetion began with references to the existence of a few types of tissue in the hmman body. These types have been familiar to anatomists for more than a century. A large share of the credit for their recognition and definition belongs to Bichat, a French worker, whose short life of only thirty vears (17\%1-1801) was extraordinary for the extent of its achievements. Forty years after the death of Bichat an important step had been taken toward a more comprehensive knowlerge of the way in which living matter is constructed. The doctrine declared at that time is known as the Cell Theory. Its establishment was directly due to a noteworthy improvement in the lenses made for mieroscopes.

The Cell Theory is to the effect that all forms of life can be demonstrated to exist as single or associated mits of a rertain standard kind. These mits of strmeture continue to bear the name of eedls, though the word became fixed upon them at first as the result of a misconception. It is not logical to nse a word which properly means a cavity to stand for a more or less solid mass of material, but this is the actual practice. The biologic eetl maty be regarded ats having the same relation to a cell in the procise sense of the term that a cast has to the molel. In short, the cell is a small pareel of living matter, the smallest which can contime long to have the behavior which we associate with the living state.

An average cell is nieroseopic in size. Many of these in the body would be found to measure less than $1 \frac{1}{100}$ inch in diameter; the resl corpusseles of the blood, for example, 
are only $\frac{1}{3200}$ inch across their circular faces. If there can be said to be a standard of form for the cell, it is the sphere. But this primitive form is merely the point of departure for the widest variations. The units in contractile tissues are always greatly elongated, those of epithelia are flattened, cubic, or prismatic, those of connective tissue are irregular and often quite freely branched. The

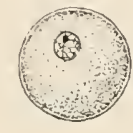

a

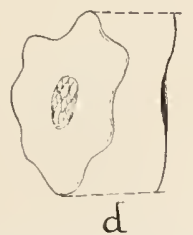

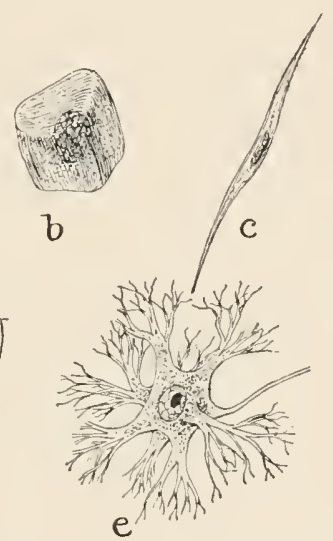

e

Fig. 2.-Drawings like the above are ahmost always made from tissues which have been prepared and colored by special means to make clear, minute features. a represents an ovum or egg-cell, the typical cell may be assumed to tend toward this spheric form; $b$ is a cell from a compact tissue, to show how mutual pressure produces a faceted or polyhedral form; $c$ is a contractile element such as occur: in the walls of the alimentary canal, it illustrates an elongated cell; $d$ is an epithehial or lining cell of the order found on the inner surface of blood-vessels; this is an example of extreme fattening; $e$, from the nervous system, exhibits the possibility of a branching development.

cells in nervous tissues are most peculiar of all, and must presently be described at some length (Fig. 2).

When such diversity of form is considered the student is disposed to ask: What have these differing packets of organized substance in common that the same name should be applied to them all? It is hard to say that any single feature is always to be found in them. One 
which is prominent in the great majority is the mucleus. This is a body within the cell, seemingly more lense than the remainder and unlike the rest in its chemieal character. The last fact is proved by the inclividual reactions of the nucleus toward selected stains or dyes. When tistues are treated with such solutions, the nucleus, which may have been quite invisible in the uncolored specimen, appropriates the stain and stancls out in striking contrast to the pale substance which envelops it. Exceptionally there may be more tham one nucleus to a ecoll or, again, none may be discernible. Cells are said to be composed of protoplasm, and the word is often used as synonymons with living matter. Huxley called it the physical basis of life. The particular word cytoplasm will be found useful to designate the portion of the cell which is external to the nucleus.

The statement that tissues are composed of cells is open to some objection. 'Tisisues are made by cells, but in the course of their development they commonly eome to contain material of a sort which camnot be described as cellular. Such material is conveniently termed "intercellular substance" and it is probably always lifeless. Sometimes it is scarcely recognizable, while at the other extreme it may be so abunclant as to constitute the main bulk of the tisiue and to determine its physical properties and its value to the animal. Thus, bone is serviceable because of the interellukar lime salts which give it rigidity. The rells hatre come to oceupy a very inconspienous position, and though they continue to exert a needed influcuce upon nutrition, they are not at all conecrued from moment to moment in the mechannical function fulfilled by the bone as a part of the skelefon. All connective tissue is astinguished hy the ligh proportion of intereellular substanere containerl in it. The relear, glassy concrete of artilane, the tough, white fibers in tenclons and liganents, the notwork hetween the skin and the muscles- these alle examples of matrial which is not mate of cells, though it was made by them. 
It has proved far more difficult to gain a satisfactory knowledge of the intimate strueture of the nervous system than to master the minute plan of other tissues. Students at the present time are by no means agreed in their interpretation. Fortunately, even an imperfect picture of the microscopic arrangement throws much light upon the physiologic processes observed. From one point of view it may be claimed that the chicf office of the nervous system is conduction. We shall do well to attend first to the elements which are known to carry on this particular duty. These elements are the nerve-fibers; collected in bundles they make the nerves.

A nerve is usually assumed to be a strand directly or indirectly connected with the central system and large enough to be followed by the naked eye as the body is dissected. The fiber is too small to be traced in this way. Fibers bear a relation to nerves like that which wires bear to cables in which they are bound up. It follows that the number of the nerves is of a moderate order, while that of the fibers is expressed in millions. ${ }^{1}$ Nerves are often seen to subdivide, but when such branching occurs the fibers are merely assorted; they do not fork where the nerve does, but are found in equal numbers in the trunk and in the sum of its branches. This does not mean that nerve-fibers never do subdivide, for there are important instances of such behaviol, but subdivision is usually met with either in the central axis or near terminal structures rather than in the nerve-trunlis (Fig. 3).

A nerve-fiber consists of a core surrounded by one or two sheaths. The double covering is the more common arrangement, at least outside the brain and cord. The suggestion of an insulated wire is strong. Here, as in the wire, it is certainly the core which is the essential conductor; the sheaths can scarcely be regarded as insulating material in the ordinary meaning of the word, but they are rather calculated to support and nourish the axis-

1 Between 3,000,000 and 4,000,000 has been estimated. Donaldson, "The Crowth of the Brain," Scott, London, 1895, p. 196. 
cylimler or axon, as the enclosed transmitter is ealled. Investigation by refined methods has made it probable that the axon can be resolyed into a number of very small fibrils. The idea that there may les conducting units finer and more numerous than the filores as usually recognized opens interesting possibilities.

The protective sheaths are broken into segments at intervals of a millimeter or less and thus present a jointed arrangement. These joints are known as the nodes of Ranvier, and the fact is to be emphasized that they do not interrupt the continuity of the axis-eylinder. This goes on unbroken like the thread in a necklace. Nerve-fiberattain a great lengtlı; the longest are not much shorter

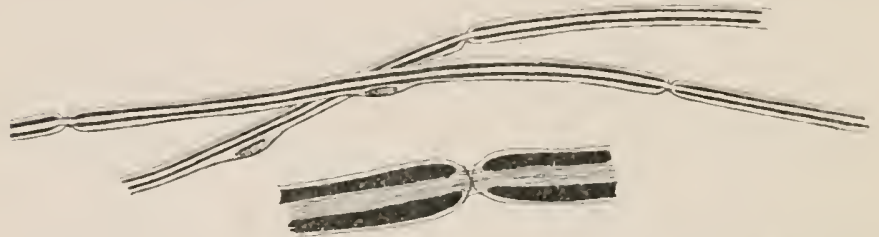

Fig. 3.-Two nerve-fibers shown diagrammatically especially to emphasize the continuity of the axon. A detail, further enlarged, to suggesi tibrils in the axon.

than the entire body. They may in other cases be so short as hardly to pass outsicle a single microscopic fichl. We must now consider the manner of their beginnings: and enclings.

In sturlying the nervous tissues without the aid of the microseope anatomists long ago began to refer to two types which they ralled respertively gray and white

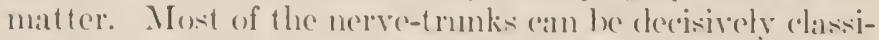
fied as white matter, and when we find substance of a simikar appearance in the cord or the brain we may conclude that its oreanization is monch the same as that of the ordinary nerves. Wo have ahready seen that nerves are bundles of filers kind closely together and having a parallel direction. The microseope shows that this is coputlly the 
case with other white matter. It is always and exclusively devoted to conduction.

Gray matter is far more intricate in structure and its physiology is less easily defined. It is massed for the most part in the central nervous system. Small detached collections, the ganglia, exist in other localities. An inspection of typical gray matter gives, first of all, the impression of looseness of texture. Nerve-fibers are seen straying through the field, but never in a compact formation. Attention is quickly attracted by the curious bodies which

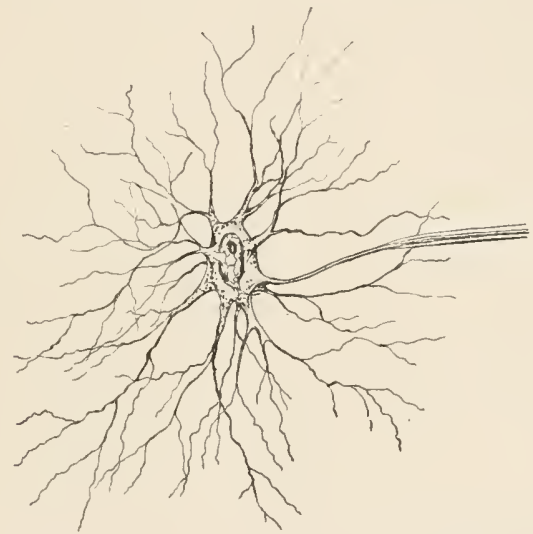

Fig. 4.-A common type of nerve-cell (or perikaryon) giving rise to the axon of a nerve-fiber.

are most characteristic of this tissue, the so-called nervecells. These vary widely in size, but probably have, on the average, about the same dimensions as other cells. In each one a conspicuous nucleus can be demonstrated. But the most remarkable features of most nerve-cells are the numerous processes which extend from them (Fig. 4).

It has been said that the cells in connective tissue sometimes show a highly irregular outline. The cells of the nervous system, however, surpass all others in this respect. Their protoplasm is spun out into prolongations 
which become more and more slender as they branch until their ultimate sublivisions defy observation. Each nervecell, as a rule, has many of these brush-like extensions, and since other cells are near at hand the processes interlare in a bewildering fashion. A recent writer has likened the resulting situation to that prevaling in a forest where the branches of each tree penetrate among those of its neighbors, looking among the foliage from a little distance one cannot tell to which tree individual twigs belong.

Keeping for the moment the illustration just introduced, it may be said that the observer could harlly tell whether the ends of the small branches ended freely or ran together. His infomation would enable him to decide that each tree is really quite without connection with any other, but he might not be able to determine this by his distant inspection. This represents with entire justice the difficulties encountered by workers who have tried to interpret the appearance of the eray matter. They have not been able to agree as to whether the processes of one nervecell are continuous with those of others or whether they merely mingle closely. Fortunately, the physiology of the nervous tissues can be discussed without the adoption of one view to the exchnsion of the other. The prine fact has to be accepted that effects are produced by certain rells upon their neighbors.

A term which it is most important to understand is synapse. A synapse is said to exist wherever the branching processes of a nerve-cell transmit stimulating energy to the processes of a second unit. If there is no continuity between the two, the synapse is a place of contart or of elose approach. If the arjacent units of the gray matter are really bomel together, the synapse is the region of the finest subdivision of the protoplasmic bonds between them. If we speak physiologically, the syllapse is a functional junction; it is not absolutely neressary to decirle whether it is an anatomic junction. One doetrine implicity held with reference to the symapse is that transmission across it can take place in only one direction. 
The property involved has been spoken of as a "valveaction" (Fig. 5).

Most of the processes which spring from nerve-cells are of the branching character which has been described. They are called dendrites or dendrons. But certain processes are found to be of an entirely different order. These can be followed often for long distances from the cells which give rise to them, and are presently found to acquire the sheaths previously mentioned as enveloping the axis-cylinders of nerve-fibers. Just here we reach a most fundamental conclusion as regards the constitution of the nervous system: that each nerve-fiber-or,

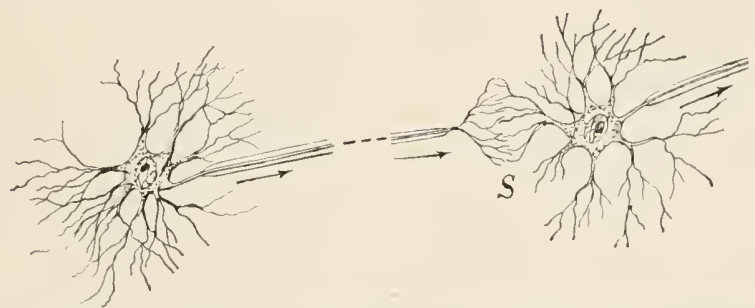

Fig. 5.-To illustrate a synapse $(S)$, which is the functional junction between the terminal arborizations-i.e., fine branchingsof the left-hand neuron and certain dendrites of the one to the right. Effects are secured only in the direction of the arrows.

more accurately, its central core-is the outgrowth of a nerve-cell. This defines the relations existing between the gray and the white matter. In the gray matter are the cell-bodies; in the white matter run their long processes, the conductors of energy in the form which we have called nerve-impulses. However far nerve-fibers may stretch from the situation of their presiding cells, their axons are to be recognized as continuous with the protoplasm of those microscopic elements. The axon in a long fiber may contain many times as much substance as the cell-body in which it originates.

A question of terminology now arises. If the axiscylinder is part and parcel of the structural unit which 
has its nucleus in the gray natter, do we do well to call the portion about the nucleus the ecll and to imply that the erore of the fiber is not to be reckoned as belonging to it? It is reasonable to claim that the ecll should be held to inchule all its extensions, no matter how prolongerl. Histologists have appreciated the foree of this argument and have proposed words to denote more preciscly the features under discussion. What we have gencerally called the nerve-cell may better be called the perilaryon, which means specifically "around the nucleus." When we adopt this we find ourselves in need of a word for the combination of perikaryon, dendrites, and axon (or axons) -in short, for the nerve-cell in the best sense. The word supplied is neuron.

The Neuron Theory.-It is now time to outline the conception of the anatomy and physiology of the nervous system which for twenty-five years has been the foundation of most presentations of these subjects. To rlo this will be, in part, to restate what has gone before, but we shall be led also to fresh considerations. The ideas to be explained are not to be received as surely demonstrated, but they have probably not seriously misled students in the past, however they may have to be modified in the future. New views are now urged by many skilled investigators and we must not ignore them. Nevertheless, the traditional picture of the nervous elements and their relationships remains convenient for teaching and diagranmatic punposes.

The neuron theory assmes that the whole system is capable of resolution into highly specialized eells of the nature already indicated. These neurons are said to be "concatenaterl," which moans enchained. The individual neurou is commonly supposed not to be continuous with any of its follows, but it is supposed to afferet and to be affereterl by them through symapses. The valve action emplatsigulabove gives each neuron a certain regularity of performance; it can rereive stimuli at rertain points, but it camnot remmunicate them at the same plares. So also 
it can despatch impulses to other neurons, but they cannot react upon it. What follows is most important: axons are nearly always channels for the conveyance of impulses away from the perikaryon-dendrites are receptive in function. It is probably a fact that the majority of neurons are of the type having numerous dendrites and only one axon. The arrangement makes stimulation from many directions a possibility, but gives a fixed course to the resulting outflow of energy. Vast numbers of neurons are to be found in the central gray matter which have only short processes and which do not easily admit of distinguishing dendrites from axons, yet the distinction is assumed.

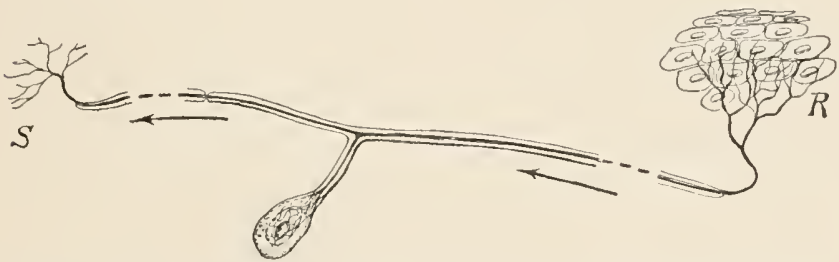

Fig. 6.-To show how in an afferent neuron the transmission is from the endings subject to stimulation $(R)$ to a synapse $(S)$ in the central nervous system. The perikaryon has an intermediate position and its functions other than that of maintenance are problematic.

One kind of neuron stands somewhat in contrast with all the other varieties, inasmuch as it has a smooth perikaryon without sign of dendrities. A single axon runs for a short distance away from the perikaryon and is then found to fork and to be traceable for a long way in either direction. This type of unit is peculiar to the afferent department of the nervous system. It is marked physiologically by the fact that it is not adapted to be stimulated by other neurons, but by energies acting from sources external to the nervous mechanism. In such a neuron the perikaryon is usually buried far from the normal operation of external stimuli. If it bore the ordinary short dendrites and lay open to stimulation within the 
gray matter, this could only result in confusion of reaction and, in case sensations were aroused, in hallucinations. This assertion can be justified later (Fig. 6).

Iet us consider in what various ways nerve-fibers may teminate. Those which serve the receptors are called afferent, those which act on effectors are said to be efferent. Most afferent fibers are parts of neurons like those described in the paragraph above; the perikaryon in each one is neither at the beginning nor at the end of the course traversed by the impulses. It is most often placed on what might be called a "spur-track," nearer the central than the peripheral limit of the neuron. It was long a question whether the passing impulses entered the perikaryon or left it quite at one side as they ran inward. There is some reason to think that they actually visit it. By a rather arbitrary stretehing of our terms we may regard the section of such a neuron that lies between the periphery and the perikaryon as an elongated dendrite, and the portion central to the perikaryon as the axon. But it is not customary to eall a fully developed and (nsheathed nerve-fiber a dendrite, and this is the character of the conductor in question.

When we think of the limits of neurons in an anatomic sense it is well for us always to have their physiologic action in mind. If we (lo si) we (an speak intelligibly of beginnings and endings, the first being the receptive processes, and the second the terminals which transmit effects to other nemrons or to tissues not belonging to the nervous system at all. The afferent or receptor neurons which we have been diseussing begin, in this sense, where they lie exposed to stimulation by pressure, hat or eold, or chemical ancencies. 'They end where they form synapses with other neurons in the gray matter of the rentral axis. To refer to beginnings and endings: with this meaning is an entirely different thing from using the same expressions with respect to origin and growth. IVe cannot deal here with the embryologic facts. 
The neurons belonging in the class of adjustors far outnumber the others in any system which can be said to be highly organized. Such neurons are, by the necessities of the case, intermediate between other neurons. They are stimulated through their dendrites and they are assumed to discharge through their axons. A single adjustor neuron may have a long axon and thus span a wide space, or it may be restricted in its reach to a microscopic scale. When the processes are short a large number of neurons in series may be concerned in carrying inpulses for a very limited distance. Probably this kind of transference from cell to cell is measurably slower than the uninterrupted flow through the white matter.

Efferent neurons receive through their dendrites stimuli which may have been furnished directly from receptor elements or which may have arrived by way of the adjustors. The efferent fibers extend usually to a considerable distance from the seat of their origin and terminate by making connections with contractile or secreting cells. When mention is made of efferent fibers one is most apt to think of those which excite the skeletal muscles-motor fibers as commonly understood. Neurons serving this purpose run an unbroken course from cells in the lower part of the brain to muscles in the head and neck; others similarly pass from the spinal cord directly to muscles in the trunk and limbs. Efferent fibers of other classes are usually, if not always, arranged in tandem fashion, with a synapse in their course, so that two orders have to be traversed by impulses bound from the brain or cord to many peripheral structures.

We have pictured the nervous elements in the way which has been considered acceptable until quite recently. But, as we have already hinted, the neuron theory is under a fire of criticism. We must take pains to suggest possible departures from the doctrine which may come to be established in time. It has been said before that continuity of protoplasm from neuron to neuron is assumed by many. The view that a synapse is a bridge 
rather than a place of contact impairs the supposed individuality of the units. A more important change. in our conceptions may have to be arlopted if the observations of certian students are confirmed.

The statement that the axon of a nerve-fiber may contain a number of fibrils, perhaps to be regarded as independent carriers of impulses, will be recalled. It is claimed that in some eases fibrils like these are to be demonstrated within the perikarya and extending out into the dendrites. The suggestion has, therefore, been made that everything else in the nervous system is subordinate in importance to a continuous network, slender

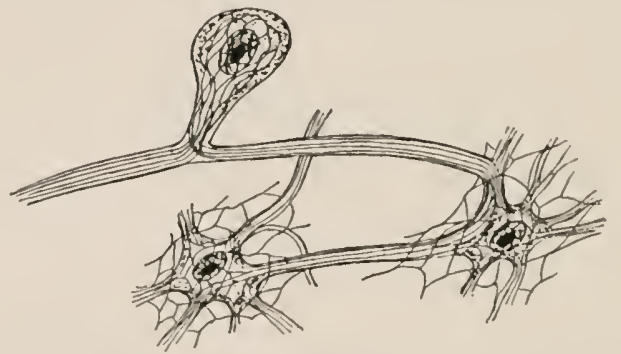

Fig. 7.-To illustrate the coneeption of the neuropile which subordinates the cells of the nervous system to a eontinuous network of fibrils sometines within and sonetimes without the eell boundaries.

and intricate. This it is proposed to call the neuropile. A synapse, in the light of this interpretation, is merely the place where fibrils pass from the sphere of influence of one perikaryon to that of another (Fig. 7).

The chicf result of these recent discoveries will probably be to lessen the prominence given to the perikarya in descriptions of nervous activity and to emphasize the part played by the fibrillar conductors. One interesting function of the perikarya remains undisputed. This is the responsibility for the maintenance of normal nutrition through all the processes of the neuron. No matter how far an axon may stretch from the cell-body to which it 
belongs, its most distant portion is yet dependent upon the influence of the perikaryon for its preservation in good condition. Cut off from its perikaryon it inevitably degenerates. This is a fact which has proved most helpful to the investigators who have sought to unravel the tangled fabric of the nervous system.

Regeneration.-When a nerve has been cut and degeneration has taken place, regeneration remains a possibility. This requires months for its accomplishment. New axons from the old perikarya grow along the track of the former set. It seems marvellous that they should push through to make appropriate connections, but they often do. Of course, this may be prevented by obstacles in the path; if the two ends of the cut nerve were displaced laterally instead of remaining in end-to-end contact the outgrowth of the fresh fibers would not occur. Unfortunately for the human race, the reconstruction of nerve-fibers which we observe outside the cord and brain does not take place in the central axis. Injuries which result in degeneration within the confines of the central nervous system are anatomically irreparable. Physiologically, the accompanying losses are sometimes made good by the substitution of other paths for those which have suffered interruption. 


\section{CHAPTER III}

\section{THE ELEMENTS OF NERVE PHYSIOLOGY}

IT was impossible to discuss the structure of the nervous tisives without anticipating to some extent an exposition of their working. We can now proceed further with this subject. We have chosen the word "coördination" to express the broad function of the system, and we have said that the chief property of its clements is conductivity. The simplest statement of the duty discharged has been said to be something like this: The receptors lie exposed to extemal stimulation, thence the effects of this stimulation are conveyed to the adjustors in the central axis, the adjustors distribute to efferent neurons, and by these the responses of muscles and glands are secured. It is now time to inquire into the nature of the external stimuli and the transmitted energy.

Stimuli.-A stimulus is a change, physical or chemicat, which is calpable of producing physiologic reactions. Raising the temperature of a selected area of the skin is a means of stimulation. Lowering the temperature may have equally positive results. The application of pressure at any spot whenee it may be condueted to moderlying receptors is an instance of mechanical stimulation. There are in the surface of the tongue receptors which ("an be excited by various dissolved substances. Here we have an example of ehenical stimulation. When the retina is acted on by light and impulses flow along the optic nerve to the brain there are probably two steps in the process: first, the light causes a chemical change, ats it does in the photographic plate; secend, some product 
of the reaction behaves as a chemical stimulant. Electric currents-or, more correctly, changes in electric condition-are among the most valuable forms of stimuli for experimental purposes, though they do not play any considerable part in the natural course of events.

The power of a stimulus to elicit responses depends upon the magnitude of the change from previous conditions. This might be confidently predicted, but another equally important fact might easily be overlooked. Stimuli are effective not only in proportion to their amplitude, but also in proportion to the rate at which the change takes place. In other words, changes sufficiently gradual may fail of stimulating effect even though they are most extensive. Demonstration of this is secured most conveniently when the stimuli observed are electric; it is found that rapid shifting of potential is far more exciting than a slower change, while the alteration may be made so gradual as to lose all efficacy.

One more fact concerning stimuli deserves emphasis at this point. The withdrawal of an influence which has been operating upon the living mechanism may be as truly a stimulus as would the application of a new form of energy. Cold, which is to the physicist a negation, must be counted a positive means of physiologic stimulation. The same may be said of sudden darkness or silence. When the baby has gone to sleep the parent must not break off his lullaby too abruptly. He should rather employ a judicious diminuendo, when, if successful, he will have illustrated more than one biologic law. At sea we wake from sleep when the regular throb of the engine ceases.

In the early speculations of philosphers respecting the manner of action of nerves the picture frequently presented is that of tubular conduits giving direction to spurts or pulses of fluid. One is reminded of the pneumatic appliances sometimes used in church organs to transmit the effect of pressure upon a key to a distant valve. All such comparisons are wholly faulty and we 
must utterly discard then. The nerves are not tubes, but cables, and even the axons give no evidence of any progressive movement of their substance. We have to do with conductors in which the material is stationary; this is an important limitation as we strive to conceive of the propagated impulse.

If we think of instances of conduction outside the nervous system we shall be attracted by the figure of a fuse. The spark which runs along the train of powder is the visible sign of a destructive chemical change. A protoplasmic strand might be imagined through which a similar chemical change should make its way, leaving behind it a track barren of further possibilities in the line of conduction. Of course, this does not correspond elosely with what we know to be true of the nerves; they are adapted to carry impulse after impulse without showing impaiment. The extreme resistance of white matter to fatigue has made it hard to believe that its axis-cylinders are in any sense "burnt out" in the perfolmatnce of their function. We camnot think that there is any extensive waste of material as the unseen impulses travel along the paths laid for them.

Conductors of physical changes are not necessirily altered in the least by their service. An iron wire is not worn out by the passage through it of the electric current. It has not contributed energy from its own stores, as has the fuse, to reinforce that which rin from one end of it to the other. All the energy has come from outside the conductor, and when that energy is gone the wire is left sensibly unaffected. In the sime way the harp-string, which is pheked near one end and is swept throughout its length by the resulting vibrations, comes to rest nuchanged except for a trifling wear and tear. Here again the energy came from ontside and the conductor gave up none of its own. The nerve-fiber serms much more like the wire that rarries the ("urent or the musieal string set in vibration than like the fuse consumerl in cloing its duty. Yet we must not hastily conclude that a nerve- 
impulse is an electric current, nor that it can be called a vibratory disturbance. We must not hastily abandon the idea that it has chemical features.

A chemical change occurring in white matter need not be destructive in character. It may take place in one instant and be reversed in the next with the restoration of the initial condition. Something like this must be true of the retinal cells in which the light-waves are momentarily causing photochemical reactions which are almost, though not perfectly, neutralized by the recuperative changes which accompany them. It may be that when a nerve-impulse passes there is a disruption of molecules and an almost instantaneous recovery. It has been suggested that upon the passage of each impulse a slight contribution is made to the axon by the enclosing sheaths and that in this way the conductivity is maintained almost indefinitely. If there is any consumption of substance attendant on the transfer, we should expect to obtain evidence of the formation of waste-products in nervetrunks which have been functioning for a long time. The fact that no conclusive evidence of this sort has been secured shows that the conduction process is one of extraordinary economy of material. ${ }^{1}$

One is constantly tempted to present the plan and working of the nervous system in terms of an electric plant like that of a telephone exchange. Nothing made by man is so like the nervous mechanism, with its channels leading in and out, and shifting connections to mediate between them. Moreover, as we have hinted, there is an electric change-slight, but definite and characteristicwhich betrays the passage of each nervous impulse. The flying energy is, nevertheless, not to be regarded as an

${ }^{1}$ Even while these statements stand in manuseript comes the statement of the Japanese, Tashiro, that he has demonstrated an augmented discharge of carbon dioxid from a nerve-trunk conveying impulses. His method is one of remarkable delicacy (American Journal of Physiology, Proceedings of the American Physiological Society, 1913, xxxi, 22). 
ordinary electric rirrent. It has no such inconceivable velocity. Abont the middle of the last century Helmholtz reported that he had measured the rate at which the impulses pass in the nerves of frogs and that he had found it to be less than 100 feet per second. Recent studies have marte it probable that it is eonsiderably higher in man, but it is not by any means equal to the speed of sound-waves in the air.

A most important question, and one which is proving difficult to answer, relates to the part played by the periliarya when impulses are passing. Do these spend their own substance to reinfore the transmission? If they do they are like the relay cells in telegraphic systems. Wires are not worn out with carrying electric currents, but batteries are used up in generating them. It has been the common belief that the perikarya of the gray matter do suffer disintegration when the neurons to which they belong are active. It is usual to say that when a neuron is stimulated through its dendrites there is a discharge, meaning by this an evolution of fresh energy at the cost of material oxidized or otherwise degraded. Assuming this to be true, we shall have an outflow of energy greater than that applied as a stimulus.

Wo could, perhaps, imagine a nervous organization such that no conergy save that originally applied by the external stimulus should be observed to flow from it. This would be economic to the last degree. But it seems mlikely that any tissuc ram ever become so specialized as to lose all trace of its primitive tendency to molergo some decomposition as a neesesary part of its activity. When contractile elements are stimulated they respond

1 Two investigators, (rohore and Willinns, of New York, have recently attracterl much notier by their contention that nerveimpulases are actually (recetrie in their nat ure. By taking into aceount the dimensions of the fibers and assigning eertinin plysical properties to the sheaths they put forth an argument to prove that cleetric disturlanneres should not pass very rapuilly in nerves, hut rather at about the velocity foumel to hold for the nerve-impulses. It is too seon to say whether physiologists will generally be won to this conecption 
by a display of energy utterly out of proportion to that which was brought to bear to excite them. We say that the force they exert had its source in the chemical changes that took place in their protoplasm, changes that must have left the tissue in an altered condition and with a lessened potency for further performance.

A mechanical analogy suggests itself. Consicler the operation of the lock of a gun. The trigger is pulled and the hammer falls, but not with the slight force applied to the trigger. It comes down with the power represented by the previous tension of the strong corled spring. The "stimulus" released an internal store of energy. This is representative of the conditions exhibited by muscles, and it is probable that with the neurons there is only a difference in degree, not in kind. When we think of the trifling amount of those forces which often prove sufficient to produce extensive reactions of the organism we can hardly doubt that the currents which are started from the receptors receive a very marked reinforeement at the cost of the gray matter.

We have some definite evidence bearing upon this point. If the perikarya make contributions from their own stores to forward the nerve-impulses we may expect them to show fatigue and structural change in connection with long-sustained action. Changes associated with activity have been frequently described. Some years ago Hodge announced that there is a clear difference between the outline and internal appearance of the perikarya in the gray matter of animals killed after a night's sleep and the corresponding features as seen in specimens from animals killed at the close of the day. He obtained his material from birds whose intense life-processes might be expected to make them most favorable subjects. The statements of Hodge have been widely confirmed. We must discuss this important matter again in connection with the topic of fatigue.

We shall assume provisionally that nerve-impulses may be set going in the conducting pathways either by the 
direct effect of extermal stimuli or by the chemieal changes occurring in the perikarya. The impulses that run along the afferent (receptive) channels are originated in at relatively direct manner by external fores. Those that traverse the adjustors and run out to the effectors may be thought of as the afferent eurrents which have contimued through the symapses of the central axis, but we shall probably do well to regarel them rather as relays, that is, impulses started anew from perikaryat excited to "discharge." This view, aceording to which the energy of the transmission is reinforeed by each neuron in the series, is the older doetrine and is still dominant.

Attention must now be ealled to the relative ease with which neurons will respond to stimuli applied at different points. It is most necessary for the orderly and purposeful working of the nervous system that nerve-fibers shall not be easily excited save at their specialized begimings or endings. It is, in fact, difficult to stimulate a nerve at any intermediate point in its course. When we do use sufficiently positive means to make the stimulation effective the result is such as to remind us that it would be undesirable to have it a common incident. A blow on the elbow may be forcible enough to start impulses in the afferent fibers of the nerve which lies near the surface at that spot, and it instantly seems to the sulject that he has sensations pertaining to the wrist and fungers. He has excited to activity the axoms which have habitually brought impulses from the hand, and they still awaken the same associations as though they had come over the whole distance. This is a very significant matter and it will be wise to place further emphasis upon it.

When an electric door-bell rings, the householder is usually justified in the assumption that some one is outside ringing it. Yot it might happen that a short-cirenit at some point along the course of the wires should cause the signat. The ringing of the bell when oceasioned in this abnormal way womlel have the same qualities to the 
ear that had previously become familiar. So it is with our sensations; we rely on the regularity of their external causation, but we are always liable to be misled by an experience like that of the tingle that follows the rap on the elbow. Impulses started anywhere between the periphery and the central stations have the same consequences for us as though they had been initiated at the remotest terminal structures. The more one reflects on this fact, the more one marvels at the freedom from confusing hallucinations which we usually enjoy.

Are nerve-impulses all alike? This is a most interesting question. The first disposition will be for one to say that they must vary widely in nature to produce such dissimilar effects. But most of our physiologic progress has been found consistent with the idea that they vary chiefly in intensity and frequency and not in the more subtle ways which might be conceived. The reader must be reminded that two electric currents precisely alike in themselves may cause utterly unlike phenomena if they are led through different fixtures. The closing of one circuit, for example, may ring a bell; the closing of another may light a gas-jet. It is, for the most part, quite as unnecessary to suppose that different nerves carry impulses of contrasted character as to assume that the electric currents are mysteriously differentiated in the (ase cited. The clarifying view that they are essentially similar throughout the whole system is one which we owe primarily to the great physiologist, Johannes Müller (1801-1858). The theory encounters many difficulties, but is not to be prematurely abandoned.

Teaching experience shows that students find it exceedingly hard to believe that the impulses passing along various nerve-trunks are of one unvarying character. The instructor is at great pains to dissuade them from speaking of "messages" or "sensations" in this connection. Messages and sensations are evolved from nerve-impulses only by a process of translation; these highly colored words cannot properly be applied to the energy in transit. 
Psychologists have cntertained and disciplined their pupils by suggesting what would be the result of diverting the impulses from one sense organ so that they should enter the brain over a route normally belonging to a different receptor system. The favorite proposition is to demand that impulses originating in the eye be switched to the auditory path, and that those generated in the ear be lod into the brain along the fibers of the optic nerve. The subject must then hoar all that he used to see and see all that he formerly heard. The lightning will be for him a short, sharp sound, and the thunder a prolonged, flickering light. At a concert he will hear the lights, the decorations, and the costumes, but he will have the extraordinary privilege of secing the progressions of the music. We cannot anticipate at all how it will look.

Unprofitable as such flights may appear, they at least afford a clear recognition of the "Miillerian principle." According to this the diverse effects produced ly nerveimpulses in various cases are due entirely to the direction which these impulses are made to take within the nervous system, and not at all to their own variability. Moreover, the effects of stimulation must be determined far more by the choice of fibers to be acted upon than by the kind of stimulation employed. The optic fibers are usually made to bear impulses which lave been initiated in the retina moler the influenee of light, but it is posibible to start impulses along these same fibers by other means. 'Thus, it is recalled from the old days of surgery without anestheties that the cutting of the optic nerve-a form of mechanical stimulation-was not productive of pain beyond that alroaly lecing ondured, but of the sensation of a flash of light. It is not certain that we can always adliere strictly to the doetrine of the uniform character of the nerre-impulses, but to do so as far as possiblo makes for clearness.

It is well just here to refer to a phenomenon often hald to be mystorious, thomgl readily explained. This is the 
persistence, after amputation, of sensations long associated with the member that has now been lost. The experience is said to be vivid and distressing. Spiritualistic theories have been advanced with regard to it. But, after all, it is just what we ought to expect. The stump contains all the fibers that were formerly concerned in bringing the impulses from the missing limb. If certain ones are subjected to unusual tension or pressure in the readjustment of the tissues attendant upon the healing process, impulses may be started along the old channels. All the associations of the resulting sensations will be with the peripheral localities from which impulses used to arrive over these routes.

Summary.-We are now in a position to sum up the substance of the last few pages. The white matter of the nervous system serves to conduct impulses-which can usually be considered quite lacking in individualityto and from places in the gray matter. The paths in the white matter are permanent. For the most part, at least, they exist from infancy and are changed only by gross pathologic processes. Conductivity, the course a fixed one, is the distinctive property of the fibers as it is of electric wires. If this is true, what shall we say of the gray matter? We shall be inclined to credit it with the power of reinforcement, as already pointed out, but here too we must continue to emphasize the duty of conducting. A most important difference between the contrasted kinds of nervous tissue is found in the varying direction taken by impulses traversing the gray matter at different times as compared with the inflexible behavior of the white. If we liken the nerve-fibers to wires, as we have just done, we may find in a switch-board a partial analogy to the gray matter. Wires and switchboards both serve to conduct currents, but the latter permit the interruption and the resumption of the consluction and the most extensive shifting of connections between channels of entrance and exit. Similarly, we are brought to recognize that an inflowing stream of im- 
pulses of a certain intensity may under some circumstances be blocked in the gray matter, while under other conditions it may emerge to reach the effectors more or less strikingly. 'This property of the gray matter is spoken of as variable resistance. Often it is denominated synaptic resistance, on the basis of the assumption that it is the spmapses as previously defined which so greatly change their conductivity from time to time.

A little reflection will convince one that resistance to the passage of impulses through the gray matter must have everything to do with the behavior of the organism. If it is temporarily lowered to a certain extent, reactions will be readily produced by stimuli of slight intensity. If it is lowered still further, the responses will become exaggerated, confuscrl, and exhausting. Increase of resistance, on the other hand, will render it more and more difficult to eroke reactions. Life itsclf has been defined approximately as a continued "adjustment of internal to extcrnal relations," and the biologic term, "irritability," stands for the eapacity to make such adjustments. Evidently the resistance of the central nervous system must be maintained between limits not too widely separated if the good of the organism is to be served.

Not only does the resistance of the central gray matter vary under the influence of drugs and of the rlrug-like products of the body's own activity, but, what is of yet greater interest, it is modified by the prolonged use of the structure in question. In gencral, repeated reactions are secured with more and more case. This is a fact of the utmost import; it will be foreseen that it must be the starting-point for any discussion of habit formation and even of education. Wr say that paths of rasy transmission tend to berome estalblished in the nervons system in connection with its employment in a routine. These paths are the "ruts" of creryday speech. The evidenes that they come to exist is found in physiology rather than anatomy, that is, in observed behavior rather than in visible structural features of the gray matter, but we 
cannot doubt that there are actual material changes in the tissue, though it is not likely that the most refined microscopic technic will ever make them recognizable.

It will now be apparent that while conductivity is the most conspicuous property of all nervous systems, it has associated with it, though in a varying degree, the capacity to be modified by use. The power to conduct impulses along fixed pathways with fixed reactions ensuing is highly characteristic of those forms of life which we regard as lower and simpler. The second power is obviously proportional to the rank which we involuntarily assign to animals. So far as they possess it, they have the chance to profit by individual experience. This would seem to be the same thing as intelligence objectively viewed. Complexity of action does not necessarily imply such an endowment. We marvel at the community life of bees, and we are inclined to endorse Darwin's assertion that the brain of the ant is the most wonderful particle of matter in the universe, but upon reflection we are led to give cats and dogs credit for immeasurably superior organization.

An old ant is probably little better than a young one in meeting the exigencies of its environment. Maturity in the insect is a matter of size and strength rather than any acquirement of profitable responses to stimulation. But maturity in the $\log$ means an acquirement of just such responses and it also means that dogs have individuality. The inherited nervous mechanism in the one case is all but rigid; in the other it is plastic in a high degree. We cannot deny to the ant some trace of this capacity for modification through experience; the ability to return to the nest seems to demonstrate it, but we do not expect to find it impressive. It will be noted that the plastic property is met with in those nervous systems which in the beginning of the animal's life are most inadequately fitted to meet the demands made upon them. We might conceive of a nervous system, as well prepared 
4 THE NEROLS SYSTLM AND ITS CONSERVATION

to make the necessary adjustments as is that of the ant, which should nevertheless record the unique history of the single life, but such a combination is unknown. Our chief interest is in the human being, and it is self-erident that the nervous system of man is, at the outset, the farthest from being reacly to cope with the environment as it is the best adapted to register individual contacts. 


\section{CHAPTER IV}

\section{REFLEXES}

$W_{E}$ have said repeatedly, in one form and another, that it is the duty of the nervous system to produce timely adjustments to changing environmental conditions. These adjustments are called reflexes. The statement has already been made that a receptor neuron linked to an effector is the simplest possible "reflex arc." It is now time to enlarge upon these matters.

The word "reflex" readily suggests the word "reflection." The elementary conception is of an influence brought to bear upon the central nervous system from without and rebounding to contractile or glandular structures which are aroused to activity. This is a decidedly crucle notion and must be dismissed in favor of a more accurate description. Descartes, in the seventeenth century, attempted to account for the familiar reactions of animals to stimuli in terms like the following: "Nerves are made up of fine tubular conductors connected with reservoirs of a peculiar fluid in the brain. These tubes contain slender threads which are attached to valves controlling the outflow of this fluid. When there is a disturbance at the exposed ends of some of these conductors the threads are pulled and the valves opened. Thereupon the energizing fluid runs down the same tubes and enters the substance of the muscles, which are at once thrown into contraction."

This is not a correct exposition of the mechanism, but it is a crecitable effort. It can be paraphrased in such a way as to lose much of its fantastic aspect. We can recognize

${ }^{1}$ Foster, "Lectures on the History of Physiology," Cambridge University Press, 1901, chap. x. 
here the afierent fibers conveying a form of energy from the outlying region to the central organs, the resulting release of fresh energy there, and the conveyance of the returning impulses to the contractile tissues. We do not now believe that the incoming and outgoing energies (liffer in any such qualitative fashion as Descartes sup)posed, but we can recognize in his description the important truth that the efferent flow is much more voluminous than the afferent. If we consider typical cases we shall come to appreciate the striking disproportion between the two.

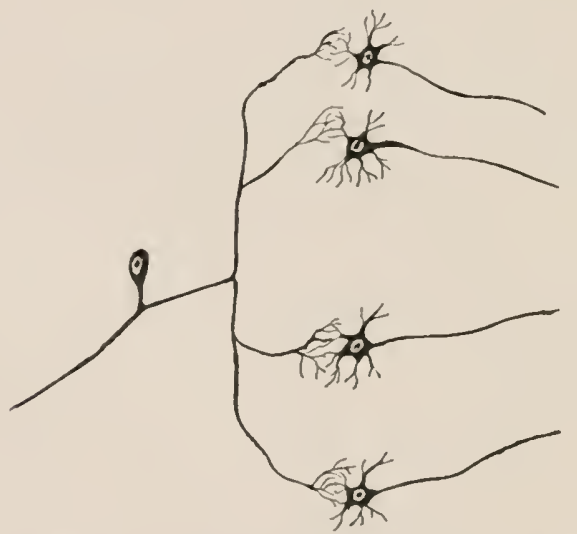

Fig. 8.-The afferent neuron influenees directly four efferent neurons.

Take, for example, the wink which is caused by the contact of a minute particle with the surface of the eye. The area stimulated maty be so small that we cam seareely think that more than a single nerve-fiber is concerned in the afferent transmission which follows. Yot to produce the muscular response a very large number of fibers must be made to bear impulses io the muscles involved. Perhaps the coughing reflex will serve our purpose even better. Here an irritating particle hardly larger than that required to cause the wink may act upon the central 
nervous system from the larynx, with the result that most of the conspicuous trunk muscles are made to share in the convulsive response. It is easy to account for this spread of the impulses in the light of the apparent anatomic organization of the gray matter.

The general rule seems to be that one afferent neuron makes connections with a number of efferent elements. A diagram (Fig. 8) will be helpful. It is possible by an

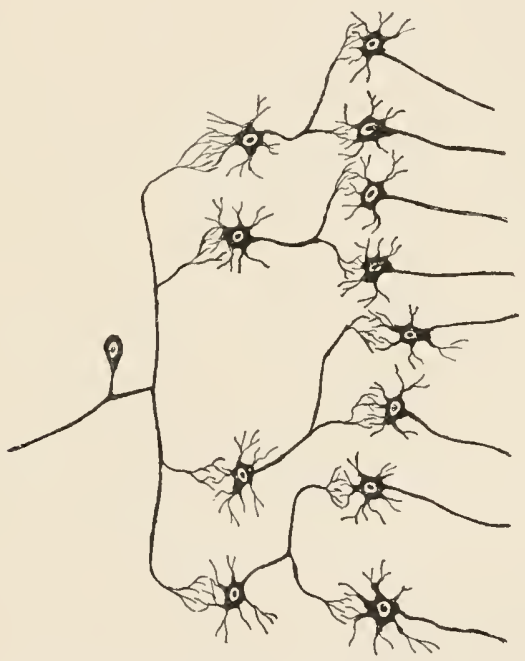

Fig. 9.-The adjustors extend the effect to a greater number of efferent paths.

extension of this principle to visualize a mechanism which will insure the most multifarious discharge of impulses after a solitary afferent conductor has been excited. But the painstaking histologists who have done most to interpret the finer structure of the gray matter believe that the spread of the process is accomplished largely through the interposition of neurons of a third order between those which are clearly afferent and those which are definitely efferent. These, according to our 
preliminary classification, may be called adjustors. Another diagram (Fig. 9) may be introduced to show the relation of the arljustors to the reflex act.

There is an evident economy in this arrangement. It brings large clusters of efferent neurons under the control of single afferent units. Moreover, there is no doubt that adjustors such as we have pictured are often dominated by others of a still higher order. Thus we see in the nervous system an organization like that of an army, in which generals are placed over colonels, colonels over (aptains, etc. In the army the number of officers holding a given rank is greater than the number of their superiors, but less than the number of their subordinates. In the nervous system this is probably true of the units in many of the particular mechanisms, but it may not hold invariably, since, quite unlike the military conclition, a neuron may be under the sway of a number of others of the next grade above. This statement introduces the idea that now one and now another element may be responsible for the activity of the same inferior group. It also suggests that there may, in some sense, be a strife among the interlocking neurons. We slaall have future oceasion to dwell upon the conception that inhibitory as well as excitatory influences may be exerted by certain neurons upon others.

The following illustration is instructive: A man had climbed out of a sixth story window which he was to clean. He stood with his toes ujon a narrow ledge, holding meanwhile to the upper sish. A gust of wind took off his hat and both his hands went instantly to his hearl. At once his body began tilting out into space. His lands fell with great sperel and forece upen the sash, which, fortumately, latel not pasised ont of reach. Here a simple roflex, nomil moler most aireumstances, would have proverel disistrous, and was overruled ly another making for solf-preservation. In all probsbility no reasoning process preserted the sereond adjustment. But the train of reflections that followed was sufficiently vivid, and the 
window-washer crawled back into the room and lay for a while upon the floor.

As we are constantly speaking of nerve-centers, it is time to define what is meant by that expression. A center is usually assumed to be a collection of perikarya mediating a definite action which may be either motor or secretory. The center is a station to which impulses flow from different sources at different times, but which transmits impulses always to a common path. When mention is made of a center one thinks naturally of a circumscribed spot in the nervous system-an anatomic conception. But it is necessary to bear in mind at the same time that widely separated neurons may have such connections that they will be unified in their activities. In other words, centers may have a physiologic existence where there is no focal assembling of the coopperating units.

When we try to draw the line between those actions of the nervous system which can unhesitatingly be called reflexes and others not to be called so, we find ourselves in the midst of difficulties. In elementary presentations of the subject it is usual to distinguish between reflex and "voluntary" action, but the more we observe the facts, the less satisfactory this attempted distinction appears. It is certainly true that in most of those movements which we are accustomed to call voluntary we can still recognize the directing influence of external conditions. This is a way of saying that such acts partake of the reflex character. We find it most clearly the case in monotonous serial movements like those of walking. We say that we walk because we will to do so, but we can hardly claim that the formation of a conscious purpose prececles the taking of each step. At another time we may analyze more fully what can be baldly stated here: that each position assumed by the body and limbs of the walker establishes stresses within and contacts without of such a nature as to dictate the appropriate succeeding contraction. 
In the human subject the acts which are seen to be (anried out by the newborn are always classed as reflexes. Sucking, coughing, sneezing, liccups, vomiting, erving. (lutching, drawing up of the legs, and other examples will occur to the reader. The list becomes much longer when we take pains to include some which are not so obvious to the domestic observer: changes in the size of the pupils, changes in the distribution of the blood, the discharge of sweat and other secretions, ete. Swallowing is essentially a reflex not to be executed unlesis there is at least a little moisture to be removed from the mouth.

As to the reactions which the child acquires with advancing development, we find no satisfacory standard which will enable 11 s to say of one that it is a reflex and of another that it should be otherwise named. The tendency is to restrict the term "reflex" to those responses to external stimuli which are common to all normal individuals, while those which are peculiar to certain ones we call habits or mamerisms. But the claim may be strongly defended that a labit is a personal reflex-an instance of a reaction to surrounding conditions given more or less of an inevitable character by the acquired structure of the subject's nervous system. Nail-biting may be regarded as an unfortunate reflex manifestation in which the maltreated finger-tips are sending up to the central axis the impulses which dictate further attacks upon them.

When we pass from habits to aceomplishments we must still recognize a degree of connection between extermal stimnli and the performance. The act of copying a worel or a sketeh may transend the reflex as commonly understood, but would serem to include its distinctive features. The ropy set is a souree of visual stimulation and the movements of the pen held in the skilled hamd are determined by its appearance. Even the answering of at question, it may be asserted, is an ace bronght to pass in consequence of the penetration of auditory impulses throngh the pathways of a brain prepared to react to 
them. But we shall follow the usual custom and restrict the term "reflex" to responses the capacity for which is inborn or universally acquired, and to acts which occur as surely when the attention is occupied with other matters as when they are themselves under scrutiny.

Our stock illustrations of reflexes are apt to be those in which brief and abrupt movements are witnessed. It is well to remind ourselves that adaptive changes of this kind may be gradual and sustained in character. One too easily overlooks the more continuous services of the nervous system. Physiologists apply the word "tonic" to such actions as are mild in degree, but maintained over long periods. Under normal conditions the skeletal muscles are incompletely relaxed; we say that the nervous system is subjecting them to a tonic stimulation. This subdued but definite activity of the mechanism is the result of the constant inflow of impulses from various sources; it has the reflex character. The slightly contracted state of the muscles is spoken of as a "reflex tonus." We speak often of an "arterial tonus," a sustained, moderate contraction of the small blood-vessels for which a particular portion of the nervous system is clearly responsible. We may not be warranted in saying that this tonic condition is equally with the other of a reflex sort, but its variations are so, and they constitute an interesting chapter in physiology - that which deals with the vasomotor reactions.

"Conditioned Reflexes."-Most reflexes seem highly purposeful in the sense that they are such as to contribute to the well-being of the animal. In certain cases the purposeful character cannot be recognized and the reflexes appear bizarre and illogical. Some light was cast on reactions of this eccentrie sort by experiments reported from a Russian laboratory a few years ago. The investigators found it possible to yolie a novel stimulus with one which was familiar, and eventually to confer on the novel stimulus much of the efficiency which at first belonged only to the familiar one. The following 
is a sinuple cxample: A dog secretes saliva when shown food which he likes. The reaction is what is sometimes (alled a psycho-reflex. The trial was made many times, and on each occasion a whistle was blown while the food was displaverl. At length the blowing of the whistle without the exhibition of the food sufficed to cause salivation.

The acyuirel capacity of the nervous system to excite the salivary glands in response to a special auditory stimulus was called by the first observer a "conclitioned reflex." Such eases afford a striking proof of the plasticity of the adjustor mechanism. Yet it may also be said that they afford evidence of its rigidity. In support of this last statement a curious fact is to be mentioned: it was found that when a dog hat hecome so sensitized that he would produce saliva when the whistle was blown, his system remained quite unresponsive to notes a very little sharp or flat as compared with the pitch employed in the course of training. It is reported further that if a chorel of three notes was used instead of a single one the sensitized animal would secrete saliva on the production of either of the simple constituent tones, but more for two sounded together, and most for the complete chorel.

Have we not here something directly related to the mysterious rapport of hypnotism? It seems strange that a human subject can become indifferent to all voices save one and yielel abject obedience to that controlling voice. But it may be conceived that this is only an claborate development of the ronditioned reflex. When the hypmotic state was induced the nervous system became attumed to the particular pitch ancl timbere of the speaker's tones. It is said that these are well enough reproclueed by the phomograph to make it posibibe to substitute the instrument for the hypnotist.

Probably we are all possessed of many conditionod reflexes. The reactions may be hard to detect amol still hareler to trace to their sources in past experieneer. Never- 
theless, frank and intelligent people can often furnish illustrations. The most frequent are probably connected with the large intestine and the bladder. Certain conditions which have no logical bearing upon the functions of these organs will regularly arouse them to inconvenient activity. A friend of the writer cannot mislay an article and begin to search for it without having an immediate awakening of the colon to energetic movement. On some occasion in the past there was probably a coincidence of the two circumstances and a cross-tie between two mechanisms has remained. Such a tie has undoubtedly an anatomic existence, though we do not expect to have it pointed out postmortem in the mazes of the brain. Outbreaks of perspiration in certain circumstances may be explained in similar ways.

Summary.-The salient facts regarding reflex action may now be concisely stated. Reflexes are adaptive reactions brought about by the influence of stimuli acting upon the receptors of the nervous system. For their execution five conditions must be fulfilled: (1) The endorgans, or receptors, must be ready to translate the energy applied from without into nerve-impulses. There must be pathways open for the conduction of these impulses to the gray matter of the central axis. (3) The central gray matter must have such an organization and such a degree of irritability that the arrival of the afferent impulses shall determine the departure of efferent impulses along definite paths. The fitness of the reflex to the emergency, as commonly observed, is explained by the physiologic linkage of certain afferent with certain efferent channels in the cord and brain. (4) There must be lines of effective communication between the central stations and the end-organs of the efferent system, namely, muscles and glands. (5) These organs must be capable of modifying their activity upon the arrival of the outflowing impulses. The change induced may be in the direction of increased activity or the reverse-excitation or inhibition. 
These statements serve to characterize reflexes in a positive fashion. On the negative side we should emphasize their essential independence of mental life. IV note the oecurrence of many reflexes, but our consciousness is a matter of olservation and not of initiation. The abrupt reflexes are "quicker than thought," while those which are gradual in their development are usually (a) able of passing through all their stages without our attending to them. When the will is enlisted at all-if we may trust our own impressions-it is about as often to restrain as to advance the process which we find taking place. Nothing is harder for the average student than to aceept the view that these acts witness only to structure and not to present intelligence. If the scientific assertion is unwelome, it may still be claimed that past intelligenee is registered in the structure which works so smoothly. Holmes said that "habit is action in the present from motives of the past"; the conception might be broudened to rover the fichl of the reflexes. But it will be found mexpectedly diffieult to defend even this thesis.

Voluntary Reactions. - If a man presses an electric key as soon as posibible after hearing a sound, fecling a contact, or secing a spatr, he is said to execente a voluntary reaction, and the time which intervenes between the stimulus and the response is called the reaction-time. It is gencrally not less than 0.12 second nor more than 0.2 second. The values for different avenues of stimulation are somewhat characteristic; for instance, the response to sound is more prompt than that to sight. The process differs from an ordinary reflex in requiring attention to insure the movement. The path of the nerve-impulses is a lone one, lying partly in the rerchrum and probably including many symapses.

When the howere cecticl receives an electric shock of sufficiont strength there is a wink which is quite involuntary. This is a reflex and it is acomplished within 0.0 ) serend of the stimulus. With a somewhat weaker shork 
it is often found that the delay is three times as long. Such a case is a voluntary reaction: there is a sensation, a purpose to wink, and then the movement. This common laboratory experiment brings the two forms of response into clear contrast. Consciousness is quite incidental to a reflex, and, if it is involved at all, it is subsequent to the act and not connected with the chain of events leading up to it. 


\section{CHAPTER V}

\section{THE GENERAL ANATOMY OF THE NERVOUS SYSTEM}

IT has been possible to proceed to this point with only the most general statement of the spatial arrangement of the parts which are united to form the nervous system. A certain amount of detail must now be supplied. It will be helpful to make some comparisons between what is to he seen in the simpler vertebrates and what is found in man. No description of the invertebrate organization will be undertaken; it is most interesting but peculiarly difficult to bring into line with the higher type.

Let us attend to the outlines of the nervous nechanism as exemplified in the frog, an animal which has been chosen for very many of the carchinal researches upon this systen. Here, as always, we recognize an axial or central portion and the nerves extending from it to all parts of the body. The axial portion is said to consist of the brain and the spinal corel. The brain is locked in the cavity of the skull; the cord extends through a canal made by the successive arches of the vertehrae, the individual bones of the spinat columm. Those nerves which take their rise from the brain are called cramial, the reference being to the cramium, which is the portion of the skull bomeling the brain. The nerves originating from the eorel are callect spinal. The remnial nerves issue from the skull through openings which are alled foramina. The spinal nerves find their way through notehes between adjacent vertebrae, intervertebral foramina, as they are called. The number of both the cranial and the spinal nerves is smatler in the frog than in many of the higher forms, inclucling man. 
The spinal nerves emerge in pairs which are symmetrically developed. A single member, right or left, in one of these pairs is found to be united with the cord by two roots. These are best referred to as dorsal and ventral, the former being nearer the skin of the back and the latter at a greater depth. The relations referred to are best understood when presented in a diagram (Fig. 10).
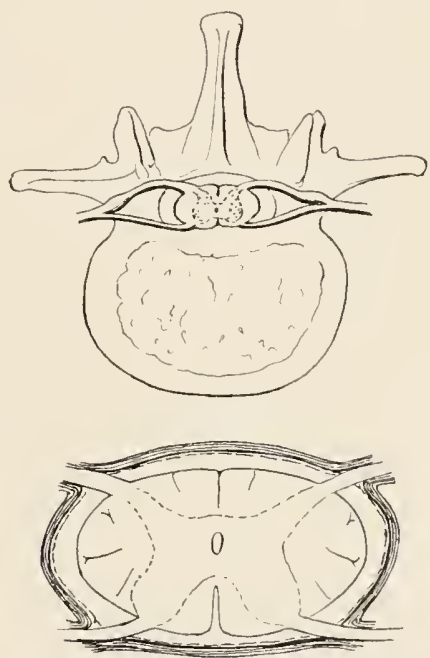

Fig. 10.- The upper figure shows the spinal cord within the arch of a vertebra. A pair of spinal nerves is shown, each nerve having a dorsal and a ventral root.

In the lower figure the heavy enclosure is the dura mater, the dotted line just within is in the position of the arachnoid, and then comes the space filled by the cerebrospinal fluid. The outline of the cord itself corresponds with the pia mater.

The same figure will call attention to the protective structures in the vicinity. Of these, the most striking is the bony arch. Within this is a dense membrane, the dura mater. A much thinner membrane is applied to the immediate surface of the cord and is scarcely to be separated from it; this is the pia mater. Between the two membranes there 


\section{THE NERVOLS SISTEM AND ITS CONSERVATION}

is an appreciable space containing a clear, limpid liquid, the cerebrospinal fuid. Strictly speaking, a third membrane, the arachnoid, intervenes between the dura and the fluid, which is, therefore, said to occupy the subarachnoid space. The membranes with the fluid retained by them are collectively spoken of as the meninges.

The regular fashion in which the spinal nerves part into dorsal and ventral roots might well suggest a difference in function corresponding to the anatomic separation. It has, in fact, been known for about a hundred years that the dorsal roots are almost wholly composed of afferent fibers and the ventral roots even more dominantly of those which are efferent. The statement of this contrast in function between the roots of the two sets is known as Bell's law. The cranial nerves do not part in this orderly way into dorsal and rentral divisions where they join the substance of the brain; moreover, they are extremely unequal in size. Some are found to be composed of afferent fibers, some of efferent, and some of both together. It will be evident that each spinal nerve, if tested beyond the point of blending of its two roots, may be expected to show both characters. Most nerves are mixed in the sense that they contain fibers of both kinds. In the sum of all the nerves it is said that the afferent filoers are distinctly more numerous than the efferent. In the spinal nerves the difference is molerate; in the cranial, the preponderance of afferent filer's is overwhelming.

$A$ crosis-section of the spinal cord brings to view several features which may be described later, but at the moment only one of these will be mentioned. This is the minute central canal, a reminder that the central nervous system is to be regardod as tubular in its fumblumental organization, though the walls of the primitive tube have encroached upon its avity until the remaining spase is very small compared with the masses of white and gray matter surrounding it. The slencler rentral canal of the cord leads forward to a murh more conspicuous series of chambers in the brain. We can now outline the anatomy 
of this superior portion of the system as it is seen in the frog.

Following the spinal cord to the most anterior vertebra we find that it is here continuous with the tapering hind
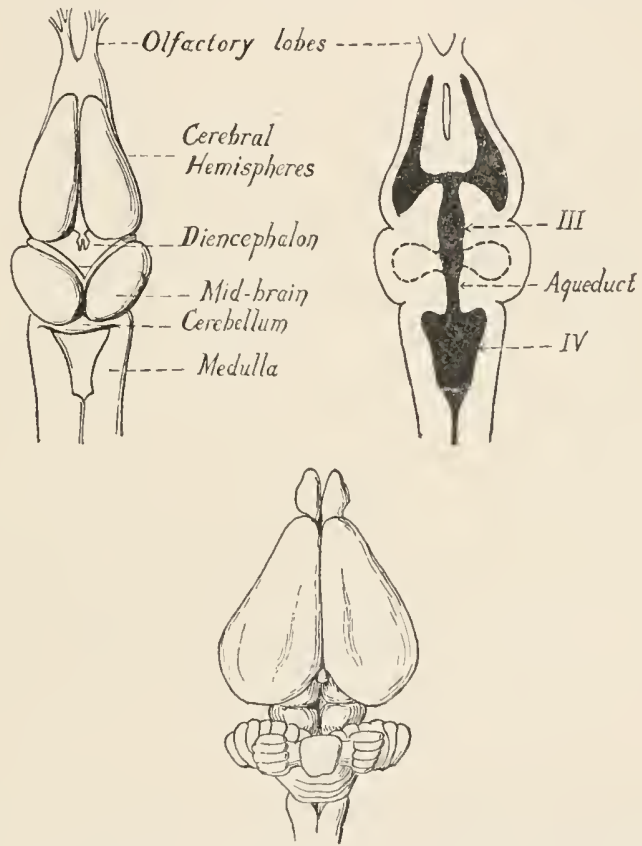

Fig. 11.-Above, the frog's brain is shown in its dorsal aspect and, within a similar outline, its cavities. The two lateral ventricles are not numbered. The cavities extending into the optic lobes are not made black because they are not characteristic of higher forms.

Below is the brain of the rabbit (dorsal view), to show how the midbrain is nearly concealed by the large cerebrum and cerebellum. (The scale of this drawing is much smaller than that used for the frog.)

end of the brain, the medulla, or bulb. The line of demarcation between brain and cord is assumed to lie between the back edge of the skull and the first vertebra; there is no sudden change in the appearance of the nervous axis 
itself at this place. If the overlying bone is removed the several divisions of the brain will appear somewhat as in Fig. 11. The medulla widens from its hinder to its forward limit and the eye is caught by a deep triangukr hollow, opening in its dorsal surface. The apex of the triangle is pointed back toward the cord. This hollow is one of the chambers of the brain, the fourth ventricle. Unlike all the other parts of the series of cavities, this one breaks the surface; the others are completely submerged and to be seen only after dissection. A thin roof which partially covers the fourth ventricle in life is almost invariably stripped from it in exposing the brain. The central canal of the cord opens out into the fourth ventriele at its pointed posterior extremity.

Forward of the mednlla are found the two large, ovoid bodies which, with the corresponding ventral structures, are conveniently covered by the term midbrain. A channel extends from the fourth ventricle through this region to the cavities still farther forward; it is pieturesquely named the aqueduct of Sylvius. We shall find the midbrain to be relatively much less prominent in the higher forms than in the frog. An alternative name for this region, applying more accurately to the dorsal eminenees, is the optic lobes.

In front of the midhrain we find in the case of the frog that by far the larger part of what remains is the cerebrum or the cerebral hemispheres. We yet distinguish, howerer, a limited portion of the brain between these paired structures and directly before the midbrain as the diencephalon. In the diencephalon the aquednet of Sylvius expands into a space which is quite narrow when measured from right to left, but more extensive dorsoventrally. This is the thirel ventricle. Eareh of the rerebral hemispheres has within it a cavity which is called a lateral ventricle. The total comnt of four ventricles is arrived at by reckoning these two bateral chambers, the third in the diencephalon, and the fourth in the medulla. The lateral ventricles communicate with the third by small passages. 
At the extreme anterior end each of the hemispheres is prolonged into a brush-like development of nerve-fibers which comes into relation with the nasal lining on the same side. These extensions are usuatly termed the olfactory nerves and are counted as the first in the cranial series. No other nerves come into direct connection with the cerebrum; even the optic nerves, which are so much more important in determining the reactions of the more intelligent animals, join the parts just behind the hemispheres and affect them only after the impulses have been relayed or forwarded. The optic nerves are second in the series as we count from before backward. Other cranial nerves emerge at short intervals behind the optic. It will be better not to enumerate them now, but to speak of them with direct reference to the human brain a little later.

All the divisions which have been described as having places in the organization of the brain of the frog can be recognized in the brains of the higher vertebrates. Their proportionate development we shall find to vary widely from what has been pictured. There is one region only hinted at in the brain of the frog which comes to be a large feature in many cases. This is the cerebellum. Its position in the frog is indicated by a slight dorsal growth at the anterior margin of the fourth ventricle.

We shall now find it helpful to compare with the brain of the frog that of the rabbit, which will show a state of things intermediate between what has been described above and the human condition which must be outlined presently. If we ignore differences of absolute scale we shall see at a glance that the cerebral hemispheres in the rabbit are more massive than in the frog. We shall see also that the cerebellum has become a part of the brain only less conspicuous than the hemispheres themselves. We can still discover between the cerebellum and the cerebrum the surface of the midbrain, but this section which was so prominent in the frog has become much less so. It is evident that a moderate additional increase in the bulk of the cerebrum and cerebellum would bring 
these two in contact and conceal the midbrain from view. Ineidentaly it may be noted that in the rabbit the dorsal aspect of the midbrain is seored by a cross-fissure, so that instead of the two lobes found in the frog there is a fourfold arrangement. On this aceount the region in question is known as the corpora quadrigemina.

A change in our point of view from dorsal to lateral ${ }^{1}$ will make it easier to grasp the result of the progresivere development of the cerebrum and the cerebellum. The figure will show how the midbrain is covered in the process and will suggest at the same time how the cerebrum rolls forward over the olfactory nerves, and how the eerebellum, extending backward, overhangs more and more the "avity of the fourth ventricle. In cats and dogs a stage is reached at which no glimpse of the midbrain can be had without forcibly separating the overlying parts.

T'o understand the ordering of the various divisions in the brain of man it is first of all necessary to appreciate this preponderance of the (crebrum and the cerelothum over the remaining portions. But there is another condition which enters in to complieate the interpretation. This is a bending of the axis upon which the brain may be conceived to be built up. In the frog a line drawn from the nose through the brain and back to the end of the spiual cord will be nearly straight. In the rabbit it is still true that the organization can be referred to an axis which is substantially straight. It is very plain that the attempt to project a corresponding line from the hmman nose throngh the brain and down the full length of the cord will yicld a curve suggestive of a fish-hook (Fig. 12).

This bending of the axis is dereloped in connection with the carriage of the hearl which is appropriate to the crect position. 'The lower animals generally travel along the line of their spinal eolmms. Man moves in a line perpendicular to his spine; that is to say, he wallis and gazes horizontally while his vertehral axis is kept vertioul. The nervous system must be aceommodated to this state ${ }^{1}$ Figure 12, upper drawing. 
of things. The bend in its axis is well indicated by an outline of the eavities in the human brain and cord. The aqueduct of Sylvius is inclined ventrally from the line of the central canal of the cord, and the lateral ventricles in the cerebral hemispheres are extended approximately at right angles to this canal. The olfactory

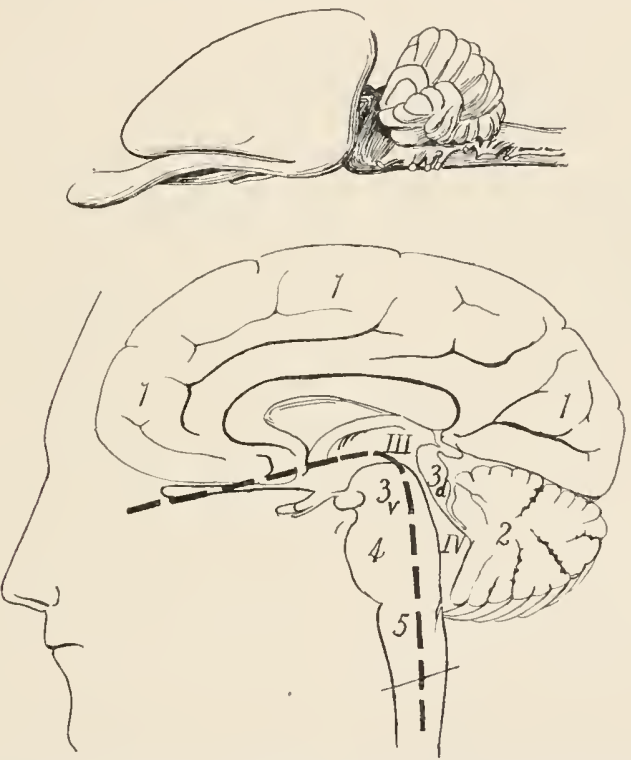

Fig. 12.-Above is the rabbit's brain from the left; below, the human brain in vertical fore-and-aft section, also viewed from the left. The bent axis is introduced in the lower figure.

1, Cerebrum; 2, cerebellum; 3 , midbrain; $3 d$, corpora quadrigemina; $3 \mathrm{v}$, crura cerebri; 4 , pons; 5 , medulla; 111 , third ventricle, which is flanked by the diencephalon; $I \mathrm{I}$, fourth ventricle.

outgrowths are also found to be in a plane perpendicular to the course of the cord.

If, now, we make allowance for the two conditions indicated-the overwhelming growth of the cerebrum and cerebellum and the rather sharp crook in the axis-we shall find it easy to see that, after all, the sequence of the 
divisions in man is the same as in the frog. It is true in both cases that the medulla is the prolongation of the cord within the skull. In both, the fourth ventricle practically breaks through the "loof" or dorsal surface of the medulla, but in man it is overhung by the cerebellum. In both types the aqueduet of sylvius leads through the region known as the midhrain and widens into a third ventricle reckoned as the eavity of the diencephalon.

In the brains of the ligher animals there is a ventral feature hardly indieated in the frog, but developed, generally speaking, in proportion to the prominence of the cerebellum. This is the pons (pons varolii), a structure which presents the appearance of an outgrowth from the cerebelhum clasping the medulla near its anterior border. Of course, this does not correctly describe the actual connections of the region referred to, though it is true that it contains many transverse fibers which pass into the cerebellum. It is to be noted that the cerebellum is distinctly dorsal in position to the main axis of the central nervous system. It may thus be said not to lie upon the direct course of the ascending and descending impulses which enter and leave the cranial cavity. So it is possible, for experimental purposes, to remove the cerebellum and leave this (hief highway still open for service.

The removal of the cerebelhum, with the object of observing the defieiencies which follow and so drawing inferences in regard to its previous activity, is permissible. But the plysiologist eamot excise the midbrain or the medulla for any such purpose, sinee he would lose not only the influenes of the part withdrawn, but would rheck the passage of impulses to and from regions anterior to the seat of operation. The destruction of the medulla would leave no line of communieation between the erebral hemisplieres and the trunk.

A few words may now be said about the distribution of gray and white matter in the central nervous system. In the cord the gray matter is internal and appears in a cross-section in a characteristic form often called an 
$\mathrm{H}$-figure. So far as the cord consists of white matter, it can be regarded without serious error as a huge nerve conveying impulses to and from the brain. Its gray matter serves to mediate simple reflexes. Yet it must also be remembered that the gray matter may bear a part in the transmission of impulses from one level to another. The gray matter of the cord shows two expansions in the course of its length, one between the shoulders and one close to the lower end. It will readily be inferred that these expansions provide for the massing of cells related respectively to the upper and lower extremities.

In the medulla, as in the cord, the gray matter is practically all internal. The $\mathrm{H}$-figure, however, ceases to be distinguishable, and instead there are more or less isolated clusters of nerve-cells which in several conspicuous cases are in connection with cranial nerves. A large proportion of the substance of the medulla, including about all of its superficial portion, is made up of fibers. For the most part these run longitudinally, but at certain places, as revealed in sections, there are many which sweep from left to right, and the reverse, crossing the midline.

In the restricted region which we have termed the midbrain we find that the corpora quadrigemina (Fig. $12,3 d)$, the four eminences which rise upon its dorsal aspect, are largely gray matter. Within, the alternation of the two types is somewhat intricate, but ventrally this part of the brain consists of fibers. The ventral white matter of the midbrain (Fig. 12, 3v) is seen just forward of the pons for a short distance, and it is referred to under the name of the crura cerebri. This is translated "the legs of the cerebrum," and the fact which doubtless suggested the odd name is that we have here a paired pedestal into which the larger proportion of the fibers coming from and going to the cerebrum are compressed. If a crude comparison may be admitted, we may liken the cerebrum to a great bouquet whose stems are gathered into the crura. 


\section{THE NERVOLS SISTEM AND ITS CONSERVATION}

The corebrum itself and the cerebellum present a contrast to the other portions of the brain when studied with regard to the distrilution of gray and white matter. In them there is a surface layer of gray sulstance, while the interior-and by far the larger part of the whole massis made up, in the main, of multitudinows fibers. The surface laver is called the cortex, the prinitive meaning of the word being the bark of a tree. Certain sulmerged portions of gray matter are found in the midst of the internal white matter in both the cerebrum and the cerebellum.

The human cerelorum consists of two hemispheres, between which there is a very deep longitudinal fissure. The separation of the two halves is so marked that one thinks of the wahut kernel with its comparatively slender isthmus. The comparison is faulty, however, in that the cerebral hemispheres have more than one bond of union. Their principal tie is to be found at the bottom of the longitudinal fissure, and when cut it appears in section as a white arch. It is the corpus callosum, a structure to which the plysiologists of the seventeenth century ascribed much importance. Several minor connections are obscrved lower down, all adjacent to the third ventricle.

In all the higher animals the surface of the cerebrum is much scored by fissures. These are called sulci, and the convex ridges between them are spoken of as gyri or convolutions. Such a type of organization evidently provides for a much more extensive area of cortex lhan would exist otherwise. Since cortical development stands in some relation to the intelligence and general rank of the animal in the scale of being, one is disposed to look for an especially markel wrinkling in the case of nath. The human hrim is, inderel, much more fissured than that of the ralshit, but it is not much more so than that of the cow. The attempt to make a great deal of this feature yickls lout little comfort (Fig. 1:3).

Regions of the surface of the cerebrum are ustually denoted hy employing the names of those cranial bones 
which orerlie them. Thus we speak of the frontal, the parietal, the temporal, and the occipital regions or lobes. The principle would entitle us to refer also to the sphenoidal and ethmoidal areas, but these terms are seldom heard. The word "lobe," often used with reference to these organs, is, perhaps, somewhat misleading. It suggests a degree of isolation more marked than that which actually obtains. The temporal portion deserves this designation more clearly than do the others, since it is

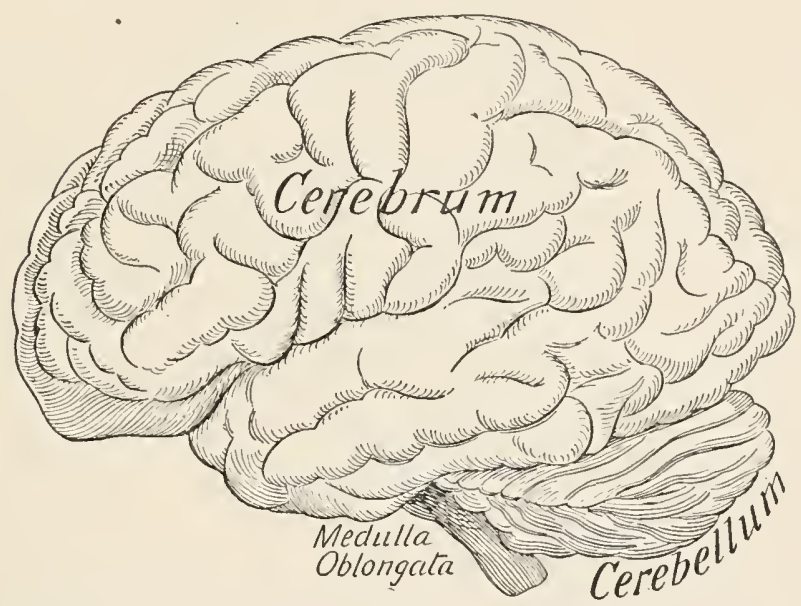

Fig. 13.-The human brain, from the left (Morrow).

quite distinct-set off by a cleft of exceptional depth, the fissure of Sylvius. On first glancing at a figure of the cerebrum one recognizes which direction is anterior by the presence of the temporal lobe, pointing downward and forward (Fig. 13).

The Cranial Nerves (Fig. 14),- Twelve pairs of nerves are united with the human brain. It has already been stated that only one of these, the pair mediating the sense of smell, is joined directly to the cerebrum. These bundles of fibers entering the under surface of the hemispheres 


\section{T2 THE NERYOLS SYSTHM ANI) ITS CONSERVATIUN}

(onstitute the shortest and most direct of all the paths which convey afferent impulses to the central stations. This fact is dwelt upon entertainingly in "The Autocrat

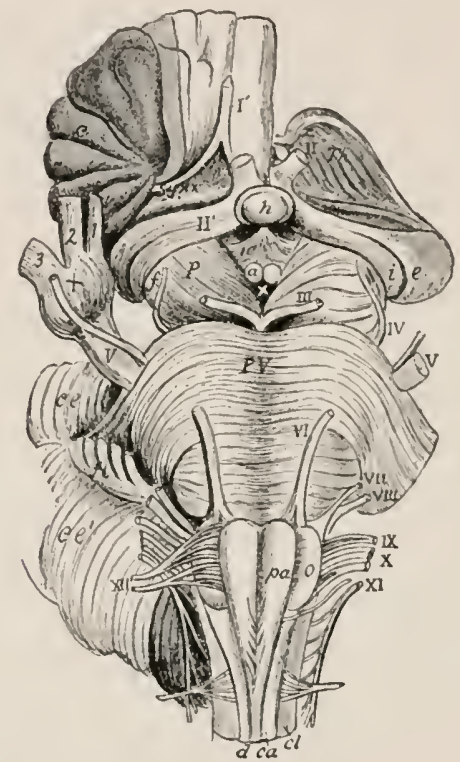

Fig. 14.-View, from below, of the eonnection of the prineipal nerves with the brain: $I^{\prime}$, The right olfactory traet; $I I$, the left optic nerve; $I I^{\prime}$, the right optic tract (the left traet is seen passing back into $i$ and $e$, the internal and external corpora genieulata); $I I I$, the left oculomotor nerve; $/ T$, the trochlear; $I$, 1 , the large roots of the trifacial nerves; ++ , the lesser roots (the + of the right sile is pliteed on the (iasterian ginnghion); 1 , the ophthalmie; 2 , the superior maxillary; and 3, the inferior maxillary divisions; $I T$, the

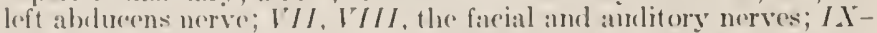

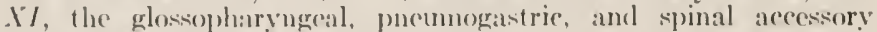
nerves; $. T /$, the right hypoglos:al nerve; ${ }^{1}$, the left suboceipital or first cervical nerve (D) Nancrede).

of the Breakfast Table." Considerably farther back we find the conspicuous optic nerves, the serend cranial pair, reaching the base of the brain and appearing to cross

'Rivaricle Edition, p. 75. 
as they meet. The feature thus produced is like an English $\mathrm{X}$ or the Greek letter Chi, whence it takes its name of the optic chiasma. Close behind the chiasma a short stalk depends from the brain and is connected with the pituitary body, an unpaired organ which is lodged in a hollow of the sphenoid bone.

The cranial nerves are of very unequal size and functional importance. A large one is the fifth (trigeminal), which enters the pons and thus serves as a convenient reminder that four pairs of the nerves are anterior and seven posterior to this structure. In this trunk are conveyed a great majority of the afferent fibers from the face, the front of the eye, the linings of the nose and mouth, and the teeth. It is responsible for a large share of human suffering. But efferent fibers are present also, and the chief muscles employed in mastication are governed through their agency. The seventh cranial nerve, springing from the medulla just behind the pons, governs the small muscles which are responsible for facial expression. The eighth nerve, entering the central axis very near the seventh, is the auditory, interesting not only as the pathway on which our hearing depends, but also for the part which it plays in the maintenance of equilibrium.

The tenth nerve is one to which reference must often be made. It is called the vagus or pmeumogastric. Its striking peculiarity lies in the fact that it is not distributed so largely to structures belonging to the head and neck as to the organs of the trunk both above and below the diaphragm. Hence its fibers are, as a rule, much longer than those of other cranial nerves. They reach muscular and glandular elements in all parts of the digestive system, while certain ones end in the heart and are of particular interest because of the rôle which they fulfil in the regulation of its beating. Still others come into relation to the larynx. Many of the vagus fibers are afferent and bring impulses from the tissue of the lungs, from the heart, and from other localities.

As to the less conspicuous nerves of the cranial series, 


\section{THE NERYOUS SYSTEM AND ITS CONSERYATION}

it is to be noted that three pairs (the third, fourth, and sixth in the enumeration) are eoncerned in the causation of movements of the eyes and in bringing about the adjustments for varying ilhumination and for vision at different distances. The six slencher muscles which serve to turn each eycball in whatever direction we desire are probably provided more liberally with motor nerve-fibers than any other muscles in the bocky. Our command orer them is correspondingly perfect; we do not fall short or overshoot the mark in looking from one object to another. If there is another instance of such precision in control of muscles it is the case of those which act upon the cartilages of the larynx in the trained singer.

lieference: Lickley, "The Nervous System," Longmans, Green it Co., London, 1912. 


\section{CHAPTER VI}

\section{THE AFFERENT PART OF THE NERVOUS SYSTEM}

TuE great majority of the fibers which bear impulses toward the central stations have their receptive endings near the surface of the body. A minority come from localities deeply submerged and, therefore, subject to stimulation as the result of internal rather than external conditions. The function of all afferent fibers is to coöperate in the production of reflex responses; a certain proportion of them, in addition, carry to the gray matter the impulses which determine sensation. With the shifting of our attention we are continually consigning to the class of reflex producers fibers which but must now furnished us with the data of consciousness. Our interest in sensation is so immediate and overwhehming that we tend to underestimate the unobtrusive work of those afferent elements which at any given moment are guiding subconscious processes.

Nerve-fibers of the Skin.-The human skin has been computed to have an area of about 1.7 square meters. It is thus as large as a rug 3 feet wide and 5 feet long. Afferent fibers in enormous numbers lead from small subdivisions of this large expanse and no point upon it is far removed from nerve-terminals. Sherrington has attractively compared the skin with its nerves to the surface of a pond where many aquatic plants are growing. Their branching filaments are distinet from one another, but often overlapped or entwined. When a stone is thrown into the pond it stirs most decisively the growth on which it directly falls, but other leaves and stems will share somewhat in the disturbance. Perhaps in some respects the skin is even more like a marsh in which the foot sinks, 
crushing the grases on which it is set and at the same time pressing down an area much larger than that which it actmally covers. It is precisely in this way that a pencil point pressed into the skin stimulates powerfully the nervetwigs just beneath the selected spot, but extends its effeet to others within a ecrtain radins.

The nerve-fibers of the skin take their rise in part from fine ramifieations among its deeper cells. Others lead away from special terminal organs of one kind and another. These microscopic end-organs (tactile corpuscles, (ate.) have been minutely studied and will be found deseribed in detail in works on histology. It is needless here to diseuss the relation of the sereral types of nerve encling to the several forms of stimulation to which each may respond. In the light of what has been said already (Chapter III) we shall assume that only one result ean follow the stimulation of a given fiber, whatever the means employed. If we are right in taking this position, we must conclucle that the variety of sensations which (an be elieited through the skin is made possible by a rorresponding number of afferent pathways.

We derive from the skin at least four kinds of sensation-pressure, warmth, colcl, and pain. As we have accepted, provisionally at least, the "Müllerian prineiple," we must believe that a fiber which is once found to give the sensation of pressure when it is stimulated ean never give any other sonsation. For the impulses, howrver they may be started on their way, are of an unvarying nature and take always the same direction. On their arrival within the eonfines of the central nervous system they must produce over and over the same set of effects. The only qualifying statement which should be made is that strome stimuli of any kind may, very probably, initiato impulses which shall penetrate farther than those originated hy less intense applications. So, according to one theory, pain may be produced hy a sufficiently strong excitation of any afferent nerve, itsoceurrenee being the sign of an extension of the hrain procesis beyond the 
usual field. But the more generally accepted view is that pain is a sensation for which a particular nervous mechanism is requisite and that the nerves concerned can give rise only to painful sensory phenomena.

Experimental study supports the a priori deductions in regard to the multiple character of the receptor equipment of the skin. If one applies to the arm a heated rod of glass, one's first impression is that sensations of pressure and temperature-perhaps of pain also-are produced by stimulation of a single spot. But if the trial is made more carefully, employing a slender instrument for the test and avoiding deformation of the skin, one brings to light what is called the "punctiform" distribution of sensibility. By this expression is meant the existence of particular areas of very small size from which particular sensations can be aroused, while others cannot.

It is possible to mark off a chosen region on any part of the surface of the body and to determine within its boundaries the points which respond appropriately to four forms of stimulation by the four kinds of sensation enumerated above. Four sets of points can then be indicated in color, and if the cutaneous map is preserved for a time the points are found to be permanent. They must be situated just over the endings of four distinct though more or less commingled sets of nerve-fibers. It is now easy to see how more than one kind of sensation may seem to be produced when the skin is touched. If the object which makes the contact is rather blunt, it is certain to affect one or more pressure-points, while it will either give or take heat to such an extent as to stimulate neighboring organs which are sensitive to temperature changes. The skin is like a mosaic so finely subdivided that a close examination is necessary to resolve it into its constituent parts.

We must expect that stimulation of a selected ending in the skin by unusual means will give no sensation but the one proper to that fiber. It is, in fact, rather difficult to excite a pressure-point by forms of stimulation other than 
pressure, but it is not impossible to do so, and the sensory result is reported to be still a sensation of pressure. A better example of perverse excitation is observerl when a spot previously found to be affected by cold is touched with a rod which is quite hot. The spot is found to respond with the only sensation which can possibly result from its stimulation, namely, that of cold. So when any area large enough to include both warm and cold spots is brought into contact with something hot, the sensation has a mixed character and may be discovered to contain recosnizable elements of wirmth and cold. Indeed, the tingle which we call "cold" may be so prominent that for a moment we think that the object has a low instead of a high temperature.

All the afferent fibers from the skin are gathered into the many small nerves which are found in all parts of the body, and these in their turn unite with others until the total number of the trunks is small and their average size considerable. In these larger nerves, as has been said before, efferent as well as afferent fibers are present. If we exclude for the moment the afferent nerves of the head, we shall find the remaining fibers of this description parting from their efferent fellows when the cord is closely approached and forming the dorsal roots as they pass in between the vertebra. Upon these roots there are observed to be enlargements, the forsal root ganglia, and microseopic study shows that these contain the perikarya connected with the fibers passing through, As staterl in Chapter III, these are of an oval outline, are situated on side branches from their respective fibers, and they are not provided with the ordinary short, branehing dendrites.

Before the division into dorsal and ventral roots is reached the afferent fibers from the surface of the body will have been joined by a smaller but still immense number from deeper regions. Fome attention must shortly be given to fibers of this class. It is evilent that the stimuli to which they are subject must be chicfly internal rather 
than external. Yet they are not altogether so. Strong pressures acting from without produce effects not limited to the skin, but extending to the underlying muscles and to other tissues. Muscles, tendons, and joints return to the central nervous system a host of impulses, the results of which are effective chicfly in producing adlaptive reflexes, but also to some extent in consciousness.

The afferent fibers, whatever their origin, enter the spinal cord well around toward its dorsal fissure, and then, as a rule, each divides into an ascending and a descending branch. The descending branches are said not to run far before they terminate among the cell-bodies of the spinal gray matter, doubtless by synapses, through which reflexes may be brought about. The ascending branches may run unbroken to the medulla or they may end in the gray matter of the cord. At intervals along their course the branches of both orders have short lateral extensions by which they establish intercourse with other neurons. The arrangement has already been sketched in connection with the discussion of reflexes (see page 50 ).

If incoming impulses are to call forth the more elaborate reflexes, and especially, we believe, if they are to give rise to sensations, they must reach the cerebrum. The pathway thither is imperfectly known and not of the first importance in a work like the present. It has just been said that some afferent fibers actually reach the medulla; those which have come from the feet and have this anterior reach are the longest of all neurons. There is reason to think that much of the conduction to the brain is accomplished through shorter neurons in a tandem arrangement rather than over these long, uninterrupted channels. When the merlulla is attained in either way, its own cells are supposed to take up the task of transmission. These are responsible for the forwarding of impulses to the important intermediate stations which flank the third ventricle and are known as the optic thalami. From these occurs the radiation to the cortex itself.

Sensations are apparently the psychic accompani- 
ments of certain processes in the cerebral yray matter. We must assume that the streams of energy flashing from point to point in the cortex are very numerous, and we cannot say why some are attended with corresponding phenomena in our consciousness while others are not. The problem of attention is suggested at once, and this belongs to the psychologist. For the physiologist it is a persistent mystery how the physical mechanism ean be so multifarious and the subjective experience so unified.

The afferent fibers which have thus far been discussed are those originating below the head. These exert directing influences upon the eontral mechanism which we are not likely to orerestimate, but their contribution to the current of sensation is much less vivid and interesting than that furnished by way of the cranial nerves. If there is a partial exception to be conceded, it is in the case of the fingers, with their wonlerful sensory equipment. Otherwise it neers no argument to prove the superior prominence of the eye and the ear in guiding intelligent concluct. To be without taste or smell woukl be a minor privation, but deafness and blindness are grave calamities, and when the two are conjoined we regard the victim with a pitying awe, which may be displaced by reverent admiration when we witness such trimmphant emergences as those of Laura Bridgman and Helen Keller.

Something has been said previonsly of the afferent service of the cranial nerves. It will be recalled that in these nerves there is no clear assorting of sensory fibers to form a series of dorsal roots. In two or three cases there are ganglia in which are gathered the perikarya which maintain the passing fibers. The largest of these ganglia and the one most frequently referred to is the Gasiserian ganglion on the trmek of the great fifth (trigeminal) nerve.

Vision.-The immense importance of the optic impulses in determining the content of the human mind and the conduct of hmman life is faithfully indicated in the large size of the optic nerves. Nearly half a million fibers are 
bound up in one of these, most massive of all purely afferent trunks. It has been stated elsewhere that the immediate connections made by the optic fibers are with stations in the midbrain or thereabouts. From these subordinate centers reflexes are doubtless caused, while, at the same time, impulses mount to the cortex where the processes induced become the physical basis of conscious vision.

Hearing.--The number of fibers concerned in carrying the impulses on which the sense of hearing depends is small compared with that of the optic conductors. It has been estimated that perhaps 14,000 fibers on each side are provided to subserve this function. The soundwaves which have come pulsing through the air to the external ear communicate their motion to a succession of structures in the winding cavities of the temporal bone, and ultimately to cells which can transmute this mechanical energy to the form of nerve-impulses. The resulting currents are led to gray matter within the medulla, forwarded thence to the midbrain, and finally, by a third relay, to the cerebral cortex.

The auditory nerve has a second part which is not supposed to have to do with hearing. This division, the vestibular nerve, brings to the brain impulses which have been started by displacements of fluids or of solid particles in the comparatively large portion of the internal ear which is looked upon as an organ of equilibration. There is reason to believe that when one sways-or, more radically, when one stumbles-such mechanical disturbances are brought about and impulses sent to the proper centers to dictate the compensating movements which are so promptly observed. The service of the ear in maintaining the balance is one which we seldom think of, and it is carried on for the most part with only slight involvement of sensation. But excessive stimulation of the internal ear probably has a share in developing the disagreeable feeling we call vertigo.

Taste and smell are two kinds of sensation which are often blended in our experience, but the nervous paths 
concerned are widely separated, as they rum from the receptors to the central apparatus. The olfactory fibers, as we have seen before, plunge into the muder surface of the cerebrum itself. The fibers on which taste depends are probably seattered in the trunks of two or three nerves, and their arrangement is thought to be subject to a good deal of individual variation, but it is certain that their place of entrance into the substance of the brain is far back of that for the impulses from the organ of sinell.

Sensations.- We are now in a position to make some general statements based on the outlines of the afferent system which have been given. It is evident that channels to the number of millions exist by which the central nervous system may be approached from without. 'The impulses moving along these pathways may lave been started by changes in mechanical relations at the nerveendings (pressure, tension, vibration). In certain cases they may be the result of temperature changes, either elevations or depresions. In other instances, including the action of the organs of taste, smell, and vision, the immediate source of the impulses must be deseribed as a rhemical change. However they may originate, the biologic function of all these inflowing currents is to determine adaptive reactions of the reflex type.

But as human beings we find the sensations which are associated with the arrival of certain of these inpulses of the greatest interest. Either intensity or novelty of stimulation will be likely to insure an echo in consciousness. We are usually quite ignorant of the state of most of our internal organs; this does not mean that no impulses are ascending from them to the brain, but rather that these impulses have a monotonous claracter. Foster is responsible for the assertion that we should instantly miss the sensory contribution of the viseera if it should (ease. To put the proposition somewhat cruclely, we may say that we have no sensations from the alimentary canal, but we should, in all probability, realize a difference if it 
were suddenly, though painlessty, removed. The background of consciousness would be altered; visceral sensation might be likened to the mountain range on the horizon, the constant presence of which would not distract attention from the domestic action in the foreground, though its disappearance woukd be something uncanny and appalling.

Sensations are commonly divided into two groupsthe general and the special. Cieneral sensations are those which are referred to the varying conditions of the body itself; special, to causes external to ourselves. Normal visual sensation is clearly of the special class. This is true also of hearing, smell, and taste. (It should hardly be necessary to say that matter in the nasal or mouth cavity is not truly within the body, but only in contact with a portion of its surface.) Sensations from the skin, as pressure, warmth, cold, and cutaneous pain, are conveniently regarded as special, on the theory that something is acting from without to give rise to them. Yet it may be noted that we very readily change our subjective attitude toward some of these experiences. We may say that we are warm or that the room is warm, shifting the reference in the most facile way between the external world and the body itself.

Cieneral sensations are, for the most part, disagreeable, a fact which one is inclinerl to connect with their common relation to conditions which call for correction. If hunger and thirst were pleasant to experience they would not impel us to take measures for their banishment. Of course, this is true of pain in general, though the remedy may not be so obvious. So largely do the general sensations belong to maladjustments that it has been suggested that the measure of health is to be found in the extent to which they are crowded out by the special. A man who is extremely ill may have little margin for attending to what he sees and hears; bodily discomfort may almost completely monopolize his attention. A man who is exceptionally well has little occasion to dwell on sensations 
of the general class. A simple diagram may serve to give vividness to this contrast (Fig. 15).

The transition from a condition in which special sensations fill the field of the attention to one in which they have become decidedly a minor matter may be quite precipitate.

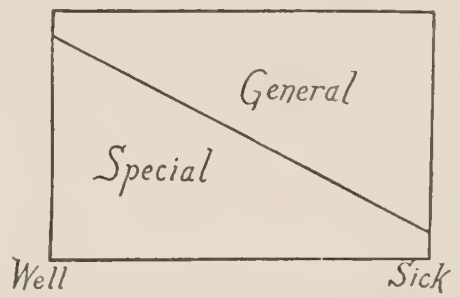

Fig. 15.-The encroachment of the general sensations upon the special in transition from health to sickness.

Consider, for example, the royager upon the deck of a steamer. At one moment we ser him engrossed by the beatuty of the sea and sky, the freshness of the breeze against his face, and the tingle of the pure air in his nostrils. After a very bricf interval he may he found utterly absorbed by one horrible generul sensation. 


\section{CHAPTER VII}

\section{THE NEUROMUSCULAR MECHANISM}

The most conspicuous manifestations of the activity of the nervous system are the contractions of the skeletal muscles. Locomotion, balancing, movements of the arms and hands, changes of facial expression, speech-all these are examples. So also is breathing, a rhythmic process which we are apt to regard as similar in its nature to the beating of the heart, but which is fundamentally different, inasmuch as every breath is the sign of an outflow of nerve-impulses from the central gray matter, while the heart beats as a result of its own intimate properties.

Each skeletal muscle has a supply of efferent fibers. It has also afferent connections which are of much importance, though usually overlooked. A large muscle, like the biceps in the upper arm, can be recognized to consist of numerous parallel bundles set apart by connective tissue. These bundles, in their turn, ean be resolved into more slender prismatic subdivisions, and the finest visible "grain" is perhaps the indication of the fibers which are the working units of the mechanism. A typical muscle-fiber is of hair-like proportions, being an inch or two in length and, on an average, about $\frac{1}{50} \overline{0}$ inch in diameter. Each of these fibers may be regarded as a muscle in miniature and has its own nervous connection.

It must not be inferred that the number of motor fibers in the nerves is equal to the number of muscle-fibers supplied. A single nerve-fiber, as it approaches its termination within the muscle, branches rather freely and is thus linked to a considerable number of muscle-fibers. It may govern as many as one hundred or the number may be much smaller. Muscles which are under the most 
precise voluntary control have an exceptionally liberal apportionment of motor nerve-fibers. Such is the case with the little muscles which rotate the eyeball, executing movements over which we have the most complete command. Doubtless the small muscles which act upon the vocal corch have, as already noted, a relatively large number of nerve-fibers by which their eninently skilled action is determined.

Each motor fiber proceeds from a perikaryon which may be in the lower sections of the brain if the destination is a muscle of the head, but which will be in the spinal gray natter if the muscle is in the trunk or limbs (see page 33 .

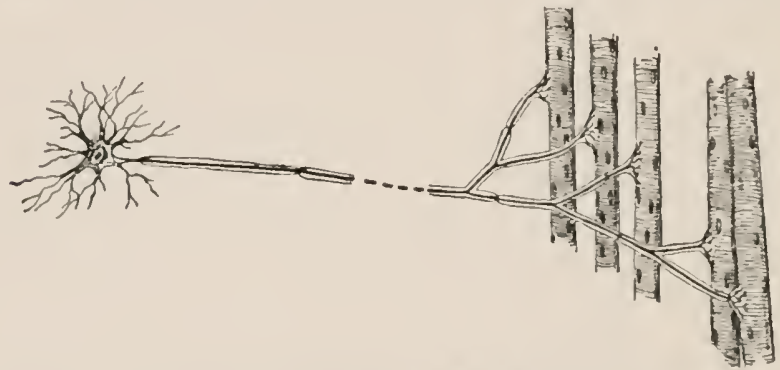

Fig. 16.-A "neuromuscular unit" as defined in the text. The motor perikaryon is united through its branched fiber and endplates with five muscle-fibers. The typic number would be much larger.

Every perikaryon so situated is evidently in a position to bring into action a moderate number of muscle-fibers if it is itself stimulated. A center for a muscle, to be worthy of the name, should consist of many perikarya so enchained as to act simultaneously upon the contractile mits of the muscle, leaving none of them unstimulated. A fact to be borne in mind is that the fibers of skeletal muscle cannot eommunicate the contractile process from one to another. They are insulated units and their coörlination nust be secured, if at all, by the manner in which the motor perikaryal of the gray matterare assemblerl. 
The muscle-fiber has been said to be the working unit of a muscle. A motor perikaryon, with its long axon extending to the muscle, branching at last and joining a cluster of muscle-fibers, may be looked upon as the neuromuscular unit (Fig. 16). In this combination there is a set of structures not yet described. The reference is to the intermediate elements between the nerve-fibers at their terminations and the protoplasm of the muscle. These mediating structures are called motor end-plates, and they have characters which differentiate them both from nerve and muscle. They must be transmitters of the excitatory process from the nerve-fibers to the musclefibers, and the interest felt in them springs from the fact that they conduct with very variable facility under changing conditions.

The simplest conceivable reflex finding expression through skeletal muscle would be realized in case a single afferent fiber were stimulated and its influence concentrated upon the dendrites of a single motor neuron. The resulting flutter of a few muscle-fibers buried among thousands of their fellows in a muscular mass could hardly be discerned. The most restricted reflex which we can observe doubtless involves a fairly large number of motor neurons with their dependent muscle-fibers. Moreover, it is supposed that adjustor or association neurons almost always intervene in the directing of the impulses.

In the present chapter it is intended to advance from the discussion of the simple reflex, already familiar in principle, to instances of motor performance which are commonly held to lie outside this class. One thinks immediately of the so-called "voluntary" movements. - It has previously been stated that there is no clear demareation between the two varieties. The more carefully one analyzes the conditions surrounding each, the less distinction there seems to be. A reflex movement is one occurring promptly and, as a rule, inevitably in response to a change of extemal conditions. A voluntary movement is also an adjustment depending upon 
external conditions, though some of the factors determining it may lie far in the past. It is, of course, an act of which one is conscious and which one desires to see taking place. It is more profitable to attempt to mravel the physical mechanism than to enter the metaphysical discussion which is suggested.

Movements of the muscles which are closely associated with our consciousness and, as it seems to us, directed by it are brought to pass hy neurons having their perikarya in the cortex of the cerebrum. The fibers belonging to

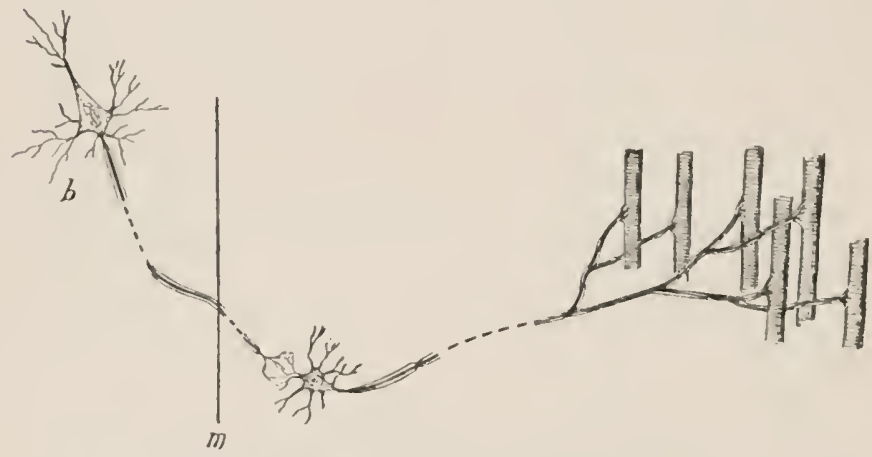

Fig. 17.-Here a "neuromuscular unit" like that in Fig. 16 is shown under the sway of a cortical motor cell (b). The "projection fiber" from this ecll crosses the midplane of the body as suggested by the line $m$. In reality, a typie eortical cell probably influences a number of eells of the lewer order.

such neurons never pursue an unbroken course to the muscles which they can call into aretion, but run down to form syluapeses with nerve-clements of the type already mentioned, which are cither neatr the place of origin of those cranial nerves which contain motor fibers or clse in the spinal gray matter. The fibers which transmit impulses from the cortex to the neurons directly presiding over the museles belong to the class alled projection fibers. An oxlet peruliarity of these is that, as they deserend, they generally aross the midplane of the nervous system 
and finally enter into relations with the motor apparatus on the opposite sicle of the body (Fig. 17).

The typic relation of skeletal muscles to the nervous system having been indicated, three subjects now suggest themselves for discussion in some detail. These are the gradation of responses, coördination, and neuromuscular fatigue.

Gradation of Responses.-It is a familiar but none the less a wonderful thing that we so successfully adapt our muscular efforts to the purposes which they are designed to serve. If one raises a book from the table one does not fling it upward with useless excess of energy, nor does one waste much time in preliminary contractions which do not suffice to move it. Unless one is deceived in his estimate of the weight to be handled, there is evidence of the most admirable economy in the execution of the movenent. Judgment may sometimes be found at fault, as when a bottle of mercury resists so surprisingly the attempt to lift it or, in the opposite fashion, when an empty box is picked up by one who has been handling a series of boxes which were heavy.

How this grading of contractions to their uses is brought about is not entirely clear. In all probability, a vigorous voluntary effort means a cerebral process which is comparatively widespread and intense in degree. A small movement, or the sustaining of a trifling weight, may mean a less intense or a more localized process, or it may mean both. If intensity is what counts, we may assume that whether a contraction made by a given muscle is great or small, the number of projection fibers employed to bring it to pass is the same. On the other hand, it is interesting to consider the second possibility, that is, that a contraction will be large if the number of neuromuscular units coöperating to produce it is large, and reduced in proportion to the reduction of the number of these units engaged. Keith Lucas, ${ }^{1}$ of Cambridge, England, is the physiologist to whom we owe the second ${ }^{1}$ Journal of Physiology, 1905, xxxiii, 125; 1909, xxxviii, 113. 
conception. Though it seens at first to be rather chifficult to entertain, we shall find that a strong case "an be made for it.

If every muscle-fiber is comparable with a repeating firearm in which new ammmnition is rapidly placed in position to be clischarged, it is hard to see how a stimulus strong enough to have any effect can do less than discharge all the encrgy which can possibly be released at the moment. If a blast is to be fired, it is immaterial whether a small or a large spark is used for the purpose. This is precisely the case with the heart. The form of muscular tissue composing the walls of this organ is said to obey the "all-or-none law," by which we mean that none but full-sized contractions can be obtained from it.

It is the conception of Lucas that the isolated fiber of skeletal muscle would be found to conform to the all-ornone prineiple if we could make experinents upon it. The real difference between such fibers and those of the heart, he supposes, lies in the insulated character of the former and the protoplasmic union of the latter. A process of contraction once started in the leart will ustally sweep over all the bundles which make up its sulsstance. In skeletal muscle such a process is clefinitcly limited to the units arotually reached by nerve-impulses, and a maximal response cannot be secured unless the stimulation can be made to affect every filer through its cncl-plate. A stimulation of only a certain proportion of the units will result in a movement-or a tension at the tendon bess than the maximum. Berause the number of units is large the number of posibible gradations between the last and the greatest will he correspondingly latre.

The idea set forth hy Lueas an he expressed in other work. It makes what we rall a muscle-assmming mity of action for all the fibers which can act upon a rommon temelon-a musculature, that is, a system eapable of more or less localized action at somr times and of a mutual reinforcenent anomg all its parts when all its powers are called in platy. When we venture to speisk of at muscle 
as though it were necessarily integral in its nature, we may be taking an unwarranted liberty." The objection to this view, that a muscle containing some active and some idle elements should give evidence of the fact by its general appearance, is not a weighty one. A muscle which is maintained in a prolonged contraction probably presents an intricate picture of alternating activity among its fibers. If we could distinguish what is going on we might see hundreds of these shortening, while corresponding numbers might be relaxing. The net result of rhythmic action on the part of vast numbers of units, providing that they keep "out of step," may well be to give a gross impression of constant shortening. This is precisely the explanation offered by Lingle ${ }^{2}$ for the continuous or "tonic" contraction observed in the alimentary canal.

If we adopt the description of the inuscular mechanism given above, we can accept Lucas' theories entirely, and shall assume that a small movement is one to produce which only a small percentage of the available fibers are put into simultaneous contraction, while a large one is the external sign of the more general participation of the fibers. The experimenter sometimes sees indications of localized responses in skeletal muscle, and more attention to this matter is greatly to be desired. It is certain that if there is any failure of the nerve-cells to act when a muscle contraction is being sustamed, there will be unemployed fibers in the muscle. We readily grant that the power developed by physical training is partly due to increased ability to make groups of muscles act together, and it does not seem unlikely that there is such a thing as an intramuscular coördination which has to be secured.

Many interesting considerations follow the admission that muscles may act fractionally. It becomes quite possible that a part of the resources represented may not be within reach of our usual deliberate control. Such inac-

${ }^{1}$ Gertrude F. Barbour and the author in American Physical Education Review, February, 1912.

${ }^{2}$ American Journal of Physiology, 1910, xxxvi, 361. 
cessible units may be thrown into action in a reflex fashion or when the cerebral processes are of an exceptional character, as in strong emotion, hypnosis, delirimm, and the like. These stites are often ocasions for the most astonishing display of strength. This is the more surprising because the subjects are not necessarily athletic or even of average muscular development. Surely in the case of a man wasted by fever we have no right to assume a superior condition of the muscles themselves. If such a man surldenly becomes violent and masters attendants whom he could not handle when in his normal condition, it is most natural to infer that his peculiarity consists in a more complete power to command his limited muscular resources than is realized at other times.

Other possible explanations may, nevertheless, suggest themselves. The eapacity of muscles to respond to the stimulation proceeding from the eentral nervous system depends in part upon local chemical conditions and upon the amount of the blood-pressure. When we shall discuss the physiologic features of emotion we shall emphasize the value to the muscles of the internal secretion known as adrenalin. This is poured out by the adrenal hodies in times of excitement and has a marked effect in the direction of reinforcing contraction and postponing fatigue. To adrenalin we may ascribe a share in conferring upon the individual what we recognize as the "strength of desperation." Such a chemical adjustment may oc'ur in delirium or under hypnosis.

In the last-named condition it is a rommon demonstration to extend the body of the subject from one chan to another and to seat another perion upon him midway between the points of support. The muscles which surcessfully meet this severe test mily be untrained and insignificant in appeanance. Is their mexperetod rigidity diec to chemical alterations in their make'-up or to a stimnlation of their fibers which is much more inclusive than can orehnarily be secured? May not both classes of factors be present at once? 
We need not refer to unusual or pathologic examples to confirm the impression that the degree of command exerted by the nervous system varies very widely indeed. The most energetic responses are probably those produced when a number of afferent channels are simultaneously used to promote movements which could be reflexly evoked in connection with either one of these paths. Camis $^{1}$ has shown that in the lower animals it is possible to secure more powerful reflex contractions by stimulating two sensory nerves at once than can be caused to occur by the most intense excitation of either of these paths by itself. Some would interpret this result to mean thạt the same perikarya are more strongly stimulated when the approach is made through the larger number of afferent fibers; others would infer that a larger number of motor neurons are made accessible to the influence of the stimulation. Possibilities like these will receive additional discussion when we reach the subject of fatigue and its postponement.

Coordination.-This word has already been said to be so comprehensive that it can be made to express the main function of the entire nervous system. It must now be viewed with especial reference to the execution of muscular movements. We seldom call into voluntary action a single muscle quite unaffected by any other. The use of solitary muscles in pure reflexes is equally rare. In the vast majority of cases, though we may be able to select one muscle as the chief performer, we have to recognize the auxiliary part played by its fellows in carrying out even what seems a simple movement. It is theoretically possible to bend the elbow by contracting a single muscle, the biceps humeri, but in executing the act in the habitual manner we find that the other muscles of the arm are not passive, but are changing their tension in such a way as to give steadiness, precision, and economy of force to the whole proceeding. Certain ones directly reinforce the essential movement, others assist indirectly by making ${ }^{1}$ Journal of Physiology, 1909, xxxix, 228. 
more stable the parts of the slieleton which must be held as a fixed anchorage with relation to the parts in motion.

Particular attention must be directed to the inhibitory phenomena which are known to accompany most movements. Sherrington, of Liverpool, holds the foremost place among those whose researches have served to reveal the importance of this matter. When a musche is selected at random and its mechanical relations are observed, we can usually find one or more other muscles which ean be recognized as adapted to pull against it. We say that these muscles are the antagonists of the first. So in the case of the biceps humeri, already mentioned as applying its foree to raise the forearm and to bend the elbow, we see that the triceps, on the back of the upper arm, must have the opposite effect. Technically speaking, the biceps is a flexor and the triceps an extensor.

In other parts of the body we find muscles which are less clearly arranged to act as antagonists, but the principle is, notwithstanding, a general one. Certain muscles raise, while others depress, the ribs. The analysis of such effects becomes more difficult when we consider examples like the bending and straightening of the back in which many nuscles participate. The diaphragm offers a curious illustration; when its center is drawn downward by the contraction of its marginal portions the viscera are crowded aside and inust be accommodated by the stretehing of the muscular abdominal walls. Hence, the abdominal muscles are collectively antagonists of the diaphragm, but the transmission of pressure is through the contents of the cavity. Sometimes opposing muscles are of very unequal strength. It is plain that those which raise the lower jaw and set the teeth are incomparably more powerful than those which make the counternovement, and there is little oceasion for a strong mechanism in the second case.

Often we contract antagonistic muscles simultaneously and with balanced force. 'This is done when the object is to secure firmness in any part-to resist the tendency to 
move rather than to cause a movement. When a limb which was previously held firm by such means is suddenly bent, it can be shown that two changes have occurred. Not only have the flexors shortened, but their opponents, the extensors, have been inhibited. They do not actually push, but they cease, in a perfectly definite way, to resist the movement which is to be brought about. Sherrington showed this in the most convincing manner by an experiment in which the rotation of the eyeball was under observation. He first determined conditions under which he could unfailingly secure the turning of the eye in a certain direction, we will say, toward the nose. The responsibility would seem to lie with the internal rectus muscle. By cutting the nerve of this muscle he paralyzed it. Then, repeating the stimulation which had caused the reaction before, he still saw the eyeball swinging in the old direction, though not so far as before.

What happened, that the eye should continue to turn as though drawn by a muscle now disconnected from the nervous system? The movement could be explained only upon the supposition that the antagonistic muscle did not fully relax until the action of its governing neurons was suspended at a moment when those normally presiding over its opponent were stimulated. A diagram will be helpful. In the leg of an animal the same type of inhibition has been demonstrated. If a reflex extension has been secured so frequently as to be predictable and a flexor muscle is then detached from the joint, but left in connection with its nerve, this muscle will be found to lengthen whenever the reflex is executed. It is the "law of reciprocal innervation" that when the centers excite a set of muscles the antagonists are inhibited. By inhibition in this case is meant the cessation of a mild continuous stimulation which is normally brought to bear upon all muscles excepting at such times (Fig. 18).

It will now be evident that a coördinated movement requires the excitation of some muscles, each in an appropriate degree, and the abolition of the habitual residue 
of contraction (tonus) in other muscles, which must yicld readily that they may not hinder the movement. In all but the simplest instances another element comes in, that of sequence or sucersion in the responses of indivichal muscles. Most movements oecur in stages and many have an alternating charaeter. When this is true we must suppose that each step establishes conditions of pressure or teusion in the noving parts of such a nature as to excite certain receptors, and that the next shift in the musculature follows as a reflex. In the higher animals and in man only a little of this coördinating power resides

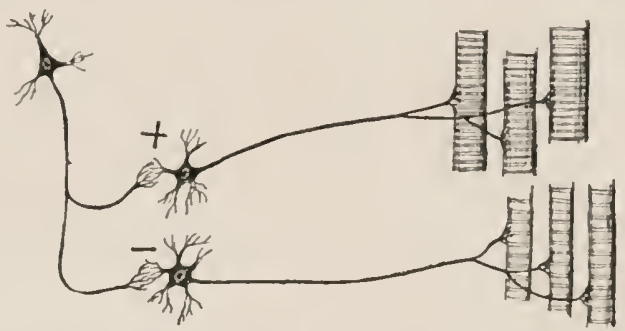

Fig. 18. - The principle of reciprocal innervation. The eortical neuron is representecl as exeiting the upper of the two subordinate neurons, causing the contraction of one group of unusele-fibers, while it inhibits the second neuron, allowing the associated muselefibers to relax. The + sign suggests stimulation; the - sign, inhibition. Doubtless the actual arrangement is less simple than this.

in the spinal cord. Most of it is represented in the brain. At this place it is comvenient to speak briefly of the physiology of the cerebellum.

The Cerebellum.- It will be recalled that this division of the brain is a dorsal outglowth of the nerve-axis. It is comnected by a rich supply of fibers with the mechlla melinel, the ventral region known as the pons, and, less direstly, with the ecrehrum. Its prominemese in different spereses of animals is most unequal. It is large in the fosls. greatly reduced in the frog, very large again in the hird, and fairly large hut overshadowed hy the cerehom in most mammals. A moment's reflection will show that the 
size of the cerebellum can scarcely be correlated with the intelligence of these types; further consideration inclines one to the belief that it is in some sense linked with elaborate and active neuromuscular mechanisms.

A fish gives little indication of intelligence, but it has a most multifarious muscular system corresponding with its intricately developed skeleton. The bird has much more intelligence, but is distinguished most clearly by its powers of flight. A prominent cerebellum seems always to imply capacity for locomotion and balancing. This general contention is borne out by the results of experiments in which this part of the brain has been partially or wholly removed. When a physiologist wishes to determine the service of a particular structure in the nervous system he cuts it away, if this is possible, and keeps the animal alive to observe the resulting deficiency. This procedure is justified only when two conditions are fufilled: first, no pathways between other stations than that under observation must be interrupted; second, the effects recorded must be those due to the actual lack of the part which has been sacrificed, and not to the irritation set up at the seat of the operation.

The pioneer experiments upon the cerebellum were made in France about one hundred years ago. The investigator found that a pigeon recently deprived of this part of the brain gave a distressing picture of incoördination. The bird could not fly nor even keep its feet. Its struggles were painful to witness, and the more so because there seemed to be no lessening of the normal sensitiveness and capacity for terror. In its staggering and fluttering about there was no apparent loss of the power to contract individual muscles, but the most obvious loss of the ability to secure the needful coöperation of the groups on whose action equilibrium in rest or motion depends. The doctrine based on such observations was to the effect that the cerebellum is in charge of the general musculature so far as this is used for equilibration and perhaps for other habitual types of performance. 
The work of more recent sturlents has shown that the control formerly credited to the erebellum was too absolute and exdusive. Our belief is still that this part of the brain is much concerned with subermscious muscular adjustments requiring extensive coördination, but we no longer regard it as the sole seat of such regulation. It has been found that animals recover in great part from the profound effects of the removal of the rerebellum, and it is natural to conclute that the immediate results which are so striking are due largely to irritation at the place operated upon and not so definitely to the loss of its functioning. 'The recovery is never complete. A $\log$ without a cerebellum may walk and swim again, but not with the full vigor and steadiness of the normal animal. Some element of reinforement or eompensation is permanently lacking.

As regards the human nervous system, it is usually held that the cerebellum is dereloped by practice and that it comes to contain much of the synaptic machinery for maintaining the balance at rest and in motion. It has often been supposed to assume command of complex movements which were at first guided at all stages by the cerebrum. Thus, it has been imagined that a child learning to walk, whose attention is plainly concentrated up)on the taking of each step, is dictating its uncertain movements from the cerebral cortex, but that the higher medianism is in time relieved of the detail and set free for new activities, the cerchelum taking its place, at least to a considerable extent.

If this is a correct conception, it may be inferred that later arepuirements of the individual, such as swimming or skating, maty likewise aall for coretural direction until they herome rasy and unconscious, when their governmont may be corebellar. Aceording to this view, the corobellum is intimately related to all aceomplishments which wo ran spoak of as "second nature." But this is more certainly true of these which invelve a large share of the muscles than of localized actions. The use of a 
pen probably remains essentially a cerebral act, though one may trace a copy with a minimum of conscious attention. Disease of the cerebellum interferes chiefly with movements which eall for the poising and timely control of the main mass of the body rather than with skill of hand.

Students are slow to realize the vast importance of afferent impulses in the execution of coordinated movements. When one sees a victim of spinal disease whose disorderly and badly regulated motions make him a painful spectacle, it is natural to infer that there is inability to command the muscles. Yet if it is a case of typic locomotor ataxia the chief trouble is with the ascending paths. The afflicted man suffers from the want of a guiding sense. He cannot readily perceive the extent of the movements which he is executing, nor the resistances encountered. He is likely to do much better when he has the use of his eyes than he can in the dark. All people are assisted by the eyes in the maintenance of equilibrium, but these receptors become still more important when there is a failure of the impulses from the motor apparatus itself.

Breathing.-An important subdivision of the general neuromuscular system is that which stands in control of breathing. The muscles used are such as we ean employ singly or in groups for various purposes. We can also modify our breathing if we choose, but only within limits. It is supposed to be impossible to commit suicide by holding the breath. It is increasingly difficult to continue forcing the breathing beyond one's inclination. Since we cannot long underbreathe, nor yet overbreathe, it is natural to assume that there is some positively acting, involuntary mechanism normally dictating the rate and depth of the breathing movements. We have evidence of very long standing that this mechanism indeed exists and that its chief center is in the medulla.

Breathing is not dependent upon the cerebral cortex. Complete division of the nervous axis at the level of the 
pons does not stop the respiration. If the injury is extended backward into the medulla, breathing is suspended permanently when certain cell-chusters are destroyed or when they are cut off from commmication with the spinal rord. The French workers who first demonstrated the absolute dependence of lifo upon the integrity of this very limited region called it the "vital knot." It is generally referred to as the respiratory center. It is so related to the remainder of the nervous system that it is involved in almost every reflex act of any magnitude. Its ordinary action scems to be determined by the condition of the blood which is sent to it. If the dissolved carbon dioxid is increased, the center is excited to cause deeper and quicker breathing. If the same gas is reduced to an unusually low concentration in the blood, the stimulation of the center is suspended and there is a pause in the breathing (apnea). 


\section{CHAPTER VIII}

\section{THE NEUROMUSCULAR SYSTEM: NEUROMUS- CULAR FATIGUE}

Nothing is more familiar than the fact of experience that muscles used long and severely respond less and less readily to our requisitions upon them. This progressive flagging of efficiency, together with the subjective sense of difficulty in commanding the muscles employed, we speak of as fatigue. When we add the adjective "neuromuscular" we open the way to a discussion of the respective share of muscular and nervous elements in the development of this condition. In the laboratory we can devise experiments such that fatigue of muscle is studied quite by itself; in the living body muscles are used only when their controlling nervous mechanisms are in action.

Fatigue, whether in muscular fibers or in neurons, may conceivably result from either of two causes. It will be inevitable if the store of energy-producing substance runs low. This is a type of fatigue which approaches exhaustion as a limit. The second possibility is that byproducts or end-products of the chemical process which is going on may so accumulate as to become a hindrance to the continuance of that process. This is probably the ordinary happening: muscles which refuse to work are not destitute of all fuel, but are, figuratively speaking, clogged by ashes and half-burned chinkers which remain as relics of the combustion which has recently taken place.

So far as muscular tissue is concerned, we know something of the products which are capable of depressing its activity. Three compounds are usually mentioned as bearing a part-carbon dioxid, lactic acid, and acid 
potassium phosphate. These are all acielie in nature, and it is supposed that any other aciol, introduced experimentally, will have a similar effect. Undefined fatigue substances probably exist in addition to the ones named, and they may not all have an acid character. A most important fact to be noted with regard to these metabolic products is this: the same compounds which in high concentration can poison the muscle to the point of apparent paralysis, act as stimulants when they are present in small amounts. In this we find one explanation of the favorable effect of moderate preliminary exereise upon muscular apacity. A muscle is not so efficient when it is first aroused to activity after a period of rest as it is when it las been used for a time.'

The phenomenon refered to-the gain in power which comes with a brief series of contractions-is spoken of as the "stail-case effect," or of ten, using a Gorman equivalent, as the Treppe. "The proof that it is due in part at least, to the so-called fatigue substances we owe to Lee of Columbia. Other factors undoubtedly enter in; when one is "warming up" one profits by the adaptation of the cir(ulatory system to the new requirements and, perhaps, also) by changes in the activity of the organs of internal secretion. But when all allowance has been male for such sources of reinforcement, we must still attribute much to the favorable influence of the products of activity exerted before their accumulation has become exeessive.

We are now in position to consider the probable seat of fatigue in the neuromuseular apparatus. Recalling the unit of this mechanism as previously defined, we find that the possibilities are more numerous than would at first be supposed. The musele-fiber may be fatigued. The junction of nerve and muscle, the motor end-plate, is another structure which is subject to imparment by its own use. This is, indeed, a relatively weal link in the chain. Fatigue of the nerve-fiber may be discegarded; the encluring nature of the white matter has alrealy been IF. s. Lee, Pop). sici. Nonthly, february, 1910. 
commented upon (see page 39). But fatigue of the motor perikaryon is to be reckoned with, and so is fatigue at the synapses through which its discharges are determined. It is not wise to make dogmatic assertions as to the precise order in which failure of these unlike structures is to be anticipated when they are kept steadily at work.

If a proper balance between destructive and recuperative processes can be struck, a neuromuscular mechanism need not exhibit fatigue in spite of what scems like continuous use. This is the case with the diaphragm, which bears its part in the taking of every breath, but seems not to show any weakening of response or loss of irritability until it shares the general decline of old age. As the diaphragm is not automatic, but contracts only in response to stimulation traceable to the brain, we must suppose that in the nervous as well as in the muscular portions of this combination restoration normally keeps pace with decomposition, and that the waste-products are not suffered to gather at the seat of action. (The diaphragm is chosen rather than the heart to excmplify this balance because the beating of the heart is not dictated from without.)

If we leave out of further account the muscles used in breathing and their presiding neurons, we shall be ready to agree that in general our neuromuscular equipment is subject to daily if not more frequent fatigue, and calls for rest that it may be renewed. The renewal must inchude the washing away or perfect neutralization of the fatigue substances and the introduction of fresh fuel supplics. To make our discussion concrete, let us fix our attention upon an imaginary pedestrian who is found toward the end of the day covering the last mile of a long tramp. In what respects is his system altered from its state at setting out in the morning?

His leg muscles have done the heaviest work. They have produced in the course of the walk a great quantity of carbon dioxid. This has, presumably, been removed quite 
promptly and fully through the lungs. But the other aced products may now be present to an extent which suffices to render the muscles lesis responsive to central command. The same or similar eompounds may have affected the motor encl-plates in such a way as to make difficult the transmission of effects from nerve to muscle. If a blockade is established at this point, muscular response may fail at a time when there is yet plenty of potential working capacity in the muscles themselves. It is generally held that this is just what oceurs: the encl-plates become impervious to stimuli, while other parts of the apparatus are still in fair working orker.

One is tempted to draw a comparison between the endplate and a sufety-fuse, such as is used in connection with an electric fixture. The fuse is intended to be destroyed under conditions which might otherwise threaten damage to more valuable portions of the system. It is readily renewed. So we may think of the end-plate as something easily impaired by use, but also easy to repair. It is better that wear and tear should fall upon this strueture rather than upon the more highly organized protoplasm of nerve-cells or muscle-fibers. We may now assign as one condition associated with our walker's painful progress the increasing difficulty of end-plate transmission.

Another condition is operative at the same time. This is the persistent return from the musculature itself, the joints, and the soles of the feet of afferent impulses inhibitory to continued walking. In part these impulses give rise to sensations of lameness and weariness. In part they may impere action without having their sign manifest in consciousness. Fatigue, so far as it is due to impulses of this class, may be regarded as disinclination rather than incapacity. If we are ingenuous wo must admit that much of our fatigue has to be classified under this head. Such a sourec of deterrent impulses as a blistered foot las a double offect upon the sufferer. Besides making lim foel disposed to stop), it eauses him to adopt an unmatural gait in the endearor to "faror" the injured 
member, and this means that comparatively untrained muscles are called upon. Enclurance is thus inevitably lessened.

We have now recognized two probable elements in the familiar state of the tired man. These are end-plate fatigue and inhibitory impulses mounting to the centers. Additional factors are undoubtedly concerned. Among these we may inchude some measure of true muscular fatigue, dependent on the local chemical changes in the contractile material and perhaps on changes in the composition of the blood and lymph. We must bear in mind that fatigue substances of this class may be distributed far and wide by the circulation and depress the functional activity of muscles which have not themselves been much used. An unfavorable effect spreadiag to glands and to the nervecenters is easily possible. Our pedestrian may be feeling the results of such a diffuse poisoning as he plods along.

Deterioration of the motor perikarya in the cord and perhaps in the brain may be one source of the observed waning of power. Reference has been made some time since to the demonstration of visible changes in these bodies which Hodge and others have succeeded in making conclusive. A new picture of the central element in general fatigue we owe to the school of Sherrington, and particularly to one recently associated with him, Alexander Forbes.' This new emphasis is placed upon the synapses through which stimulation of the motor perikarya must be accomplished. Each typic perikaryon has a number of these possible approaches. When it takes part in a simple reflex it is not excited through the same synapse as though the stimulation were conveyed to it from the brain.

Now, there is reason to believe that synapses, like endplates, are links of limited endurance in the neuromuscular chain. If, however, a synapse becomes fatigued and incapable of efficient conduction, there is the possibility, not present in the case of the end-plate, of substituting a ${ }^{1}$ American Journal of Physiology, 1912, xxxi, 102. 
new route for the application of stimuli. We have very satisfactory evidence that some of these synapses do fatigue, and that an appatrent renewal of motor command is secured when new walys of stimulation, involving different sensory paths, are devised. Let us suppose that our woary traveler sudelonly hears martial music. If it is his nature to be moved by the strains we may expect that, for a time, his pace will he quickened and all extemal signs of fatigue diminished.

How shall we interpret the marked effeet of the musie? There may be more than one opinion as to this, but we

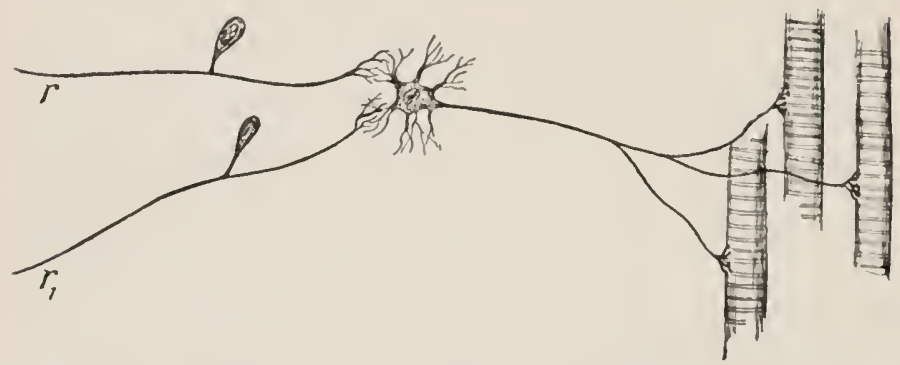

Fig. 19. - The principle of fatigue in reflex action-Forbes' eonecption. When the reflex obtained through $r$ fails, the action ean be renewed by shifting stimulation to $r$. The motor parts are the same in both eases, hener the fatigue is in a route of approach to the center. One must, in imagrination, multiply all the elements illustrated.

may indicate a possible explanation along the lines of Forbes' experiments. First, we must briefly describe his methods. Ho has studied the fatigue of the reflex merchanism in cats. A nerve contaning afferent fibers is ehosen and its central end is stimulated. Cortain muscles respond, and one of these is selected for cilleful observation, When the stimulation is applied repeaterly the contratetions of the musele are progresiseng resured until at length none atu be sereurel. Fattigue all some point in the atppartus is to be inforred, hut where"? The answer is fortheoming when at shift of the electrockes is made to 
another afferent nerve. Such a shift is followed by renewed activity on the part of the muscle to which attention is directed (Fig. 19).

In this case the motor elements used in the earlier and in the later part of the trial are presumably the same. It is the afferent neurons which are different. Fatigue of nerve-fibers is negligible, and the conclusion must be that failure to conduct has occurred at the place where the impulses of peripheral origin must exert their effect upon the motor neurons. This is the same as saying that we have here an instance of synaptic fatigue. Much potential capacity for action may still reside in the efferent equipment, but a new line of approach must be adopted to demonstrate it. Forbes has used animals in which only the cord and not the brain has been intact, thus simplifying his conditions as far as he could. It secms legitimate to extend the same principle to muscular performances in which the brain is concerned. This we shall now undertake to do.

The neurons, which have their perikarya in the cortex of the cerebrum and send their dependent projection fibers down the spinal axis, are not self-stimulated. They are thrown into action, like the neurons of lower rank, by impulses affecting them through synapses. Now we may fairly suppose that the efficiency of these cerebral motor neurons is greatest when they are stimulated from all sides, so to speak, rather than in a one-sided fashion. Here we have a key to the invigorating influence of rhythmic music upon the walker and perhaps to many other phenomena of the same class.

The tired man to whom we have so often referred has been kept in motion through the day by a variety of external stimuli. Some of these have had a very direct effect upon the lower centers, as in the ease of the impulses returning from the soles of the feet at every contact with the ground. These, together with others from the joints, the tightening tendons, and probably from the muscles themselves, have been ever prompting the 
taking of an acklitional step to be adkled to the lengthening series. Tisual impulses, varied with the changing scenery, have been giving rise to cerebual curents which have favored the holding of the muscles to their long task. But now a time has come when the impulses returning from the locomotor organs are deterent rather than encouraging. Inhibition at the lower centers is overrilden with increasing difficulty by the action of the higher complexes.

In the brain itself the visual currents may cease to be favorable. 'There is no longer the desire to see beyond the

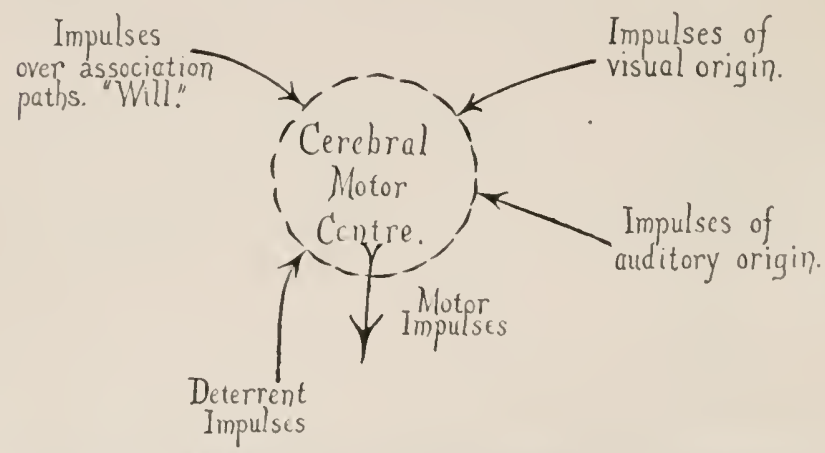

Fig. 20.-To suggest, though incompletely, the concentration of certain streams of impulses upon the motor cortex in one tired by prolonged exertion. To bring in play a fresh path of approach is to secure some renewal of activity. "To abate the deterrent impulses hats a like effect.

next turn of the road or to gain the next ridge. What is neerled to rouse the flagrging cortical centers is stimulattion over afferent paths that have not yet been brought into use. One of these is the auditory nerve. The rat has had but little to do with reinforeing the walker's efforts up to this time. Hence the musir wakes to ready response a part of the nervous system which has been but little fatigued hy any action strietly its own, although the overflow of fatigue substances formed elsewhere may have injured it to some extent. The cortical motor neurons are reached over paths nearly inactive until now 
and by means of synapses which have not been fatigued. The new application would be vain if there were not still muscular resources available and possibilities of synaptic transmission from the projection fibers of the cerebrum to the motor neurons of the cord (Fig. 20).

What shall we say of the soldier who is roused from what seemed to be utter fatigue by the close pursuit of the enemy and the whistle of bullets? Is this a simple case of setting up brain currents which arrive at the motor centers by fresh routes and unimpaired synapses? It may be so in part, but whenever a strong emotional reaction is entailed there are likely to be chemical reinforcements of muscular capability. This is a matter which may well be left for discussion in another connection. The general principle has been stated in the last chapter (see page 92), where the augmented production of adrenalin in times of excitement was mentioned.

The remarkable postponement of fatigue in the case of those who like to dance is worthy of some comment. Consider the country girl, whose daily tasks are heavy enough to leave her quite tired at nightfall and ready for an early bedtime. On the exceptional evening when there is to be a party the usual day's work may have been faithfully done, but there may be no signs of the accustomed weariness. Instead, she goes to the dance and for hours pursues a form of vigorous exercise in which the muscles used are, in the main, the same which were called upon in the domestic round. Perhaps the emotional state is intense enough to warrant the belief that internal secretions are modified to support the muscular activity. Whether this is so or not, we can see that the conditions favor an extensive and symmetric stimulation of the cortical areas.

When the girl in question was engaged in sweeping a room she was held to her clull duty by certain internal stimuli of an obscure but evidently monotonous character. 'The "sense of duty" as realized in consciousness is attended by the transmission of impulses to the motor 
apparatus, but the number of these impulses is far less than it might be if various external conditions favoring reinforcement coukl be ackled. At the dance the reinforeing factors are present in the nost efficient combination. There is the music, there are the lights and the shifting play of colors as the figures move, there are contacts, ancl all the while a richness in the psychic experience totally foreign to the drudgery at home. This psychic richness doubtless corresponds with the physiologie fact of multiplied brain-currents.

The difference between play and work, between doing what we keenly enjoy and what we feel we ought to do for some remote result, may be said to be the difference between a motor performance in which many pathways are traversed by the impulses which unite to stimulate the neuromuscular mechanism and one in which the number of these paths is small and not much subject to variation. Titchener once surprised an audience by the declaration that "all work is a waste of time"; this he elucidated as meaning that the zest which we associate with play is the basis of better aceomplishments than can be attained when only the feeling of obligation is operative. The boy who becomes very tired of chopping wood can use the same muscles in a game, and his parents may twit him with the fact. But while it is true that he is using the same muscles and the same spinal neurons, perhaps the same projection fibers from the cerebrum, he is not using the same afferent chanmels nor the same cortical approaches to the motor centers. The achult cannot honestly lay claim to immunity from fatigue of this sort.

Elements in Training.-A great deal that has been said in this and the preceling chapter nay conveniently be reviewed moler this head. In what respects does an untrainel netromuscular system differ from one which has been developed by use". We shall find as many possibilities in this comnection as we have in our attempt to analyze fatigue. ${ }^{\prime}$ c shall have to pay attention to the muscles, the culdplates, and the eentral organization. 
One fact is impressed upon the mind of the man in the street: that muscles grow with use. We shall not be inclined to make this the foremost consideration, but it is well worth emphasizing. This is not the place to enter upon any discussion of the causes underlying this wellknown growth. It may be due in part to improved circulation and in part to chemical conditions arising when contractions take place. It may be said to be a principle of rather wide application in biology that a destructive process, during vigorous life, will be followed not only by a process of repair, but by overcompensation. This is held to be true of antitoxin production and acquired immunity to disease. It is simply illustrated in callous formation: when friction destroys the surface layers of the skin they are not merely replaced, but their number is increased. The increase in the mass of a muscle consequent on its regular use is also a reaction from a decomposition process, for every contraction is executed at the cost of some substance disintegrated. But the growth of the muscle is not wholly analogous to the formation of a callus, because in the first case it is believed that we have no multiplication of fibers, but only an increase in volume on the part of those present.

One may make proper allowance for the greater size of trained, as compared with untrained, muscles, and he will be convinced that the gain in power is out of all proportion to the gain in bulk. Betterment of quality must certainly be admitted. The service of exercise to a man may be rather to give him full command of the tissue which he has than to put more at his disposal. Superior quality in muscle may mean an actual chemical change by which the fuel is made more available or stored in larger quantity, or the chief improvement may be in the efficiency of the circulation. Much will depend upon this, for the supply of oxygen to the muscle protoplasm is an imperative requirement.

In the third place, it is conceivable that facility of end-plate transmission is one of the gains. Difficulty in 
securing responses because of conditions existing at the junction of nerve and muscle may be one of the characteristies of the untrained, as it is of the fatigued, state. The increased enclurance denonstrated by those who have put themselves upon sparing diets (Fletcher, Chittenden, et al.) is most easily explained on the theory that the end-plates were previously subject to a chronic impairment owing to the presence of avoidable metabolic products. Such a situation would be equivalent to continuous fatigue and would limit at all times the working eapacity of the muscles. Exercise may be assumed to bring about a more favorable condition at this important locality in the neuromuscular complex.

Still another result of training may be more extensive and effective imnervation. We shall make much of this if we aceept the Lucas doetrine of the fractional response of muscles. Aceording to this view, the muscle which has not been nuch used contains elements which are not aceessible to stimulation under any orlinary state of affairs. With regular use the number of these idle fibers may very likely be steadily reduced and a corresponding increase of force and endurance realized. The defect overeome may be at the encl-plates or it may be in the central nervous system. If it was originally at the endplates, we may picture the perikarya which preside over the untrained muscle as being all active, but unable to (all portions of it into contraction. If it was central, we are to conceive of idle perikarya among those which are at work, each uncmployed neurom having a cluster of dependent muscle-fibers which remain at rest.

So far we lave spoken of peripheral improvements, silve that in the last instanes we have introduced the idea of a possible. ecentral factor. Wo have reognized the advantages aceruing (1) from the actual growth of the muscles, (2) from improved contractile substance, (3) from more reliable end-plates, and (4) from better "team work" among the neurons governing single muscles. Now, hy a simple extension of the last-named factor, we 
may include the gain through coördination. 'This is what we mean by acquiring skill. In all but the most elementary movements the best combinations of contractions on the part of different muscles have to be secured by practice. The physiologie change which makes the gain possible must consist in the establishment of new ties between the various groups of neurons at all levels in the central nervous system.

Better coördination means better economy of force. When one is riding a bicycle in the early days of the experience much strength is wasted. The foot which is coming up resists the foot which is going down. This is a type of an interference which is widespread where many muscles are set to work in an unwonted form of exercise. When the "knack" is attained, much less internal work is done for a given external result. This has been proved by measurements of the respiratory exchange in persons who were performing certain tasks (climbing hills, for instance), with and without adequate training. It is altogether probable that in reaching the full measure of economy, precision, and endurance the coopperation of the cerebellum is secured. 


\section{CHAPTER IX}

\section{THE AUTONOMIC NERVOUS SYSTEM}

THE term which is used as the title of this chapter is employed to cover that part of the efferent system which does not control the skeletal muscles. The negative description seems awkward, but is nevertheless accurate and fmal. It is equivalent to the statement that the autonomic system regulates the action of the heart, the glands, and all structures in which there is contractile tissue of the kind known as plain, smooth, or visceral musde. This varicty of tissue occurs in the alimentary canal, the gall-bladker, the urinary bladder and the ureters, in the reproductive organs, in the blood-ressels and lymphatics, and in the bronchial tubes. It is atso represented, though sparsety, in the skin. It forms the aceommodation or focusing muscle of the eye and its presence in the iris makes possible the familiar changes in the size of the pupil.

The term "autonomic" is akin to the political word "autonomy," and implies "self-regulating." A contrast between this division of the nervons system and that which governs the skeletal muscles is suggested. It is a common practice to call the skeletal muscles "voluntary," and to regard the heart and all the organs equipped with plain muscle as "involuntary." The distinction is as apt to mistead as to be hedpful and it will not be insisted upon here. Of course, it is true that we often have a foreknowledge of the movements of our skeletal muscles which we do not have in any such degree with respect to the other motor elements in the body nor as regards the behavior of the glands. But we must note that much of the activity of the so-called roluntary musches proceeds with little conscious attention on our part (breathing, balancing), 
while we shall find that there are many correspondences between the states of consciousness and the reactions brought about through the autonomic system.

It will not be profitable to say much about the anatomy of this division of the nervous system. The details are exceptionally difficult. One point, however, must not be omitted: so far as we know, each path from the cord or the brain to any outlying locality reached by autonomic influences is a tandem arrangement of two orders of neurons (see page 33). The neurons of the first order-

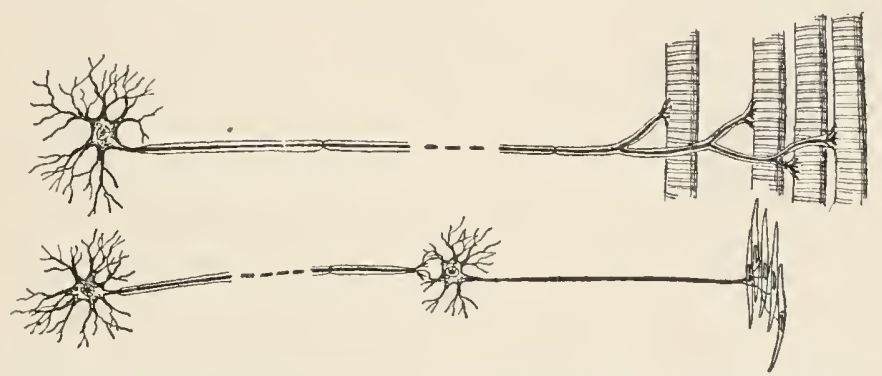

Fig. 21.-To contrast the path to the skeletal muccles, already familiar, in which one neuron extends from the central nervous system to the contractile structures with the autonomic path in which two orders of neurons are employed to span the same interval. Cells of visceral muscle are represented at the end of the postganglionic fiber. In the interest of simplicity the preganglionic-neuron is made to influence only one of the lower order. It would really affect several.

preganglionic, as they are called-have their perikarya within the brain or the cord and extend outside to a greater or less distance. They end by forming synaptic connections with neurons of the second order-postganglionic-and these complete the transmission to the secreting or contractile tissues to be affected. The synapses between neurons of the first and those of the second order are usually to be found in ganglia, detached collections of gray matter variously situated. Two chains of these ganghia are seen in the back of the body cavity, one on either side of the spinal column. Preganglionic 
fibers reach them from the neighboring spinal nerves, and their postunghionic fibers cither rejoin the spinal nerves to be distributed with their peripheral hranches or pass directly to endings in the visecra. These two chains with theil connertions are known under the curious old name of the "sympathetic system." The word used never had its psychologic meaning.

"Autonomic" is a more inchusive term than "sympathetic." The sympathetic system is that part of the autonomic receiving preganglionic fibers from the thoracic and lumbar portions of the spinal cord. There are autonomic pathways begimning in the brain which are not reckoned in the sympathetic system, and there are others at the lower end of the spinal axis which lie outside its anatomic limits. We shall not often have occasion to refer to the sympathetic system apart from the larger comples of which it is a fraction. Canglia belonging to the autonomic system, hut lying outside the two sympathetic chains, are found in very many localities; for example, behind the eye, in the walls of the heart, and clustered about the arteries which supply the digestive organs. They are not to be confused with the ganglia commected with afferent paths, which are found, for the most part, close to the point of entrance of such paths into the eentral nervous system.

We may now pass to a condensed statement of the operations of the autonomic system mpon varions departments of the physiologic mechanism. We may well speak first of its control of the cirenlation. This is exereised partly through the ardiac and partly thromgh the vasomotor nerves. The heart is a muscular pmunt, and on the fore and frepuency of its beat depends the volme of blood sent thromgh the arteries to all regions of the borly. Its beating is fumclimentally antomatie, but subject to extensive regulation through the nervereenters. Antonomic piths to the heart-monsele an he traned from two somess. Of these, the most conspictums and the carliest to be studied is represented hy aertain fibers in the large 
nerve known as the vagus, the tenth in the cranial series (see page 73 ).

When the vagus nerves of a dog are both cut, it is commonly observed that the rate of the heart is considerably increased. This is taken to mean that a restraining or inhibitory influence was previously exerted through these nerves upon the heart's activity. This impression is confirmed when the peripheral end of one of the cut vagi is subjected to electric stimulation. The heart may be made to stand still for some seconds and the circulation is stopped. This would kill the dog in a short time if it coukl be continued, but it camnot; the heart is said to "escape," that is, to resume its beating in spite of continued stimulation of the vagus. Still, the rate and force of the beat can be kept below the original standard for an indefinite time. The natural conclusion with reference to the share borne by the vagi in the government of the heart is that they contain fibers through which its activity is generally held in check and a reserve for emergencies guaranteed. The organ may be assumed to expend its power unprofitably when these fibers have been eut.

The heart receives some nerve-fibers in addition to those which reach it by way of the vagi. These others come from the sympathetic ganglia near its own level in the thorax. They are not easily picked up for stimulation in the living animal, but when the experiment is successful they are found to have an effect just opposite to that which has been deseribed. They furnish paths through which impulses can be sent to quicken and make more forcible the beating of the heart. The branches coming to the heart from the sympathetic ganglia are caller the cardiac accelerators. Simultaneous stimulation of the vagus and an accelerator path brings out the fact that the two sets of fibers are true antagonists; the influence of the one can be neutralized through the other.

This is a type of nervous organization which we find again and again in the body. Antagonistic nerves are almost as obvious as antagonistic muscles. Being pro- 


\section{THE NERYOUS SYSTEM AND ITS CONSERVATION}

vided with such a double supply, the heart may be made to beat faster through the spurring which it receives from its accelerators, or a similar quickening of its rate may represent merely a lessening of the habitual vagus inhilbition. A slowing heart may be exhibiting the results of cessation of the accelerator prodding, or the case may be one of intensified inhibition. On the whole, it is held that the ragus mechanism is the more important of the two.

Vasomotor Control.-A prominent department of the autonomic system is that devoted to the regulation of local blood-flow by bringing about changes in the diameter of the small arteries and veins. The blood-vessels of microseopic size are relatively rich in muscular elements. The majority of these contractile cells are plaeed with their long axes at right angles to the eourse of the blood, and the natural result of their contraction is to diminish the bore of the ressels and to rechure the flow through them. As the situation is now pictured, it is supposed that the larger arteries and veins shrink and swell as the pressure of the blood within falls or rises, but that the very slender vessels of both classes contract and relax by virtue of the living tissue contained in their walls and in response to impulses sent from the central nervous system. Nervefibers conveying inpulses to the muscular coats of the small blood-vessels are called vasomotor fibers. Like those which end in the heart, they are of two clasises.

The first kind of vasomotor fibers to be observed at work were those which we now call the vasoconstrictors. By this term we lesignate fibers by means of which a narrowing of the vessels can be secured. They have connections such that when they are stimulated the contracetile elements in the walls of the arteries or veins to which they extend are shortened. The "tome" of the vessects in question is said to be increased. A diminished bloodflow through the parts reacherl by the arteries or drained by the veins is to be expected. Vasoconstriction is the ustat effect when the peripheral portion of a nerve chosen 
at random is subjected to stimulation. When such a nerve is cut the vessels in the field of its distribution are generally found to dilate; this is taken to show that a tonic influence was being exerted through the vasoconstrictor fibers and that this has ceased with the interruption of their continuity.

We speak of a vasoconstrictor center in the medulla. There is evidence that impulses are normally flowing at all times from a certain region within this section of the brain to hold the small blood-vessels in most parts of the body in a state of contraction beyond that which is natural to them. Three orders of neurons must be required to accomplish the purpose: first, those which descend from the medulla to end by synapses against preganglionic neurons in the cord; second, these same preganglionic neurons, whose axons run to detached ganglia in the sympathetic chains or elsewhere; and third, postganglionic fibers extending from the ganglia to the blood-vessels. Destruction of the well-defined vasoconstrictor center in the medulla results in a universal slackening of the essential vascular tone in the entire body.

The second variety of vasomotor fibers is not so often seen in action. They are the vasodilators, fibers which, when stimulated, cause the enlargement of the vessels and so of the blood-stream in the parts to which they lead. This action is an inhibition. It was first demonstrated in the case of a small nerve known as the chorda tympani, which makes a connection with one of the salivary glands. Cutting the chorda tympani has little effect on the circulation in the gland, but when the nerve is stimulated the gland becomes flushed and swollen. At the same time the outflow through the veins is obviously increased; it is said that the blood coming away no longer shows the darkened color usual to venous blood, but is as bright as the arterial. The experiment has shown that in this nerve at least there are fibers through which an increase of the volume of the local circulation can be brought about.

There are other, though not many, examples of vaso- 
dilator action on the part of particular nerves. There is suffieient reason for the belief that in many mixed nerves visodilator filer's really accompany the vasoconstrictors, but that the working of the first chass is masked in our ordinary labolatory trials by the greater efferet of their antagonists. When wo stimulate a nerve we ale obliged to impress the stimuli upon ath the fibers in it; in the living bock there is no such necessity. Under conditions specially devised it is possible to obtain results which lead to the view that vasodilators are widely distributed and lear a eonsiderable part in the regulation of the circulation. Their existence in connection with skeletal museles, glands, the skin of the face, and the tissues of the genitals is well rerognized.

We are, therefore, to think of the nerrous system ats having two loutes by which it an influence the beat of the heart and two by which it an mochify the cleceree of contraction of the blood-ressels. There is the possibility of inhibition of the heart through the vagi and the possibility of inhibiting the tone of hlood-resiels thromgh the dilators. The heart can be driven to greater contratetile aretivity by neans of its aceclerators and the hlood-ressels can be contracted in a greater degree by the vasoconstrictors. The correspondene is helpful, eren though we have to do in the one ase with rhythmic, anch in the other with sustainel, action. But it is only fair to achl that in the ease of the heart the inhibitory mechanism appears to be more important than its antagonist, while the vasoconstrictors seem to have a more consporemous influenee than do the vasedilators in secoring the proper elistribution of the blood. In shert, the heart is most of the time inhibited to some extent, while the blexel-vessols are most of the time clefinitely antracterl. Their andition is sureh that they may be contracted more, or more relaxed, as a result of variations in the aretivity of the vasoconstrietor ("onter.

The ehief value of the nerrous equipment of the leart must lie in making it posible to speed up the circulation 
when there is a call for more oxygen and for the rapid removal of wastes from the tissues. Muscular activity is the occasion when this need is most urgent and when the response of the heart is most striking. In a more moderate degree the heart is required to maintain a more active circulation after the taking of a full meal. The combined effect of vigorous exercise and a recent dinner probably constitutes a maximal demand upon the rescrve power of the heart.

Tasomotor adaptations serve to satisfy local, as contrasted with general, needs. Activity in any limited portion of tissue, as in a gland or in a small group of muscles, can be supported without making an appeal to the heart. It is only necessary that the blood-vessels leading to the active region shall be clilated so as to conduct thither a somewhat larger share than usual of the total stream. This circumscribed increase in bloodsupply will mean a certain subtraction from the flow in other directions, but if a single small gland is to be compared with all the rest of the body we must admit that the loss shared by so many organs may easily be imperceptible in any one of them. When a relatively large mass of tissue has its vessels dilated, there is often a compensatory construction somewhere clse. The foremost illustration of this principle is found in the reciprocal relation between the surface of the body and the deeper parts. We observe that heat applied to the skin increases the flow of blood through the heated area; reason and experience both show that when such an increase occurs the internal vessels must be less dilated than they were before.

Some space may well be devoted to a discussion of the effects of external temperature on the distribution of the blood. When we have evidence of increased blood-content in any part we say that a congestion exists. When the skin is flushed as a result of being warmed, it may be said to be congested, though the word is so often used of abnormal conclitions that we may prefer the mikler term 
"hyperemie." Congestions are of two types, active and passive. In botl there is a local excess of blood, but in the active form it is blood swiftly flowing through widely opened vessels, while in the passive sort it is blood arrested or (lammed up, a state which naturally suggests a venous obstruction.

The congestion produced in the skin by heat is active in character. 1 glance at the swollen veins convinces one that they are carrying a great volume of blood out of the flusher rearion. The reaction is a serviceable one; it tends to rid the body of heat, both by increasing radiation and conduction from the skin and by sustaining the activity of the sweat-glands, which at such a time secrete much water to be evaporated. If the external temperature is so high that the body is cooler than its surromdings, the raliation and conduction transfers may be reversed, but it remains important to have an abundant circulation in support of the secretion of sweat. There is at present some dould as to how far the inclease of blood-flow which heat produes in the skin is a reflex and how far a direct effect of the high temperature.

When the skin is moderately cooleci, it becomes pale, the obvions sign of diminished blood-flow. This prevents a wasteful loss of heat to the exterior and so conserves the bodily resourees. But ereryone knows that more pronouncert cooling will shortly incluee a redelening. How does the rednesin produced hy cold differ from that produced by leat? Investigation of this question is easily conclueterl. If one hand is put into very cold water and the other into water as hot as can be borne, hoth hands will be red. but certain differenees will le (puickly apparent. It has been said that the veins in the heated hand are swollen; in the chilled hamel they are small and dark. This fatet, taken in comnection with the tendency of the cold skin to berome bluish, shows that the eongestion produced by cold is of a passive nature. Much blood is in the area, but it is making only slow progress through it. The condition is best anounted for on the theory that a marked 
contraction has occurred in the microscopic veins, holding back the blood in the capillaries, which accordingly swell even though the arteries leading to them may be below their average size at the time. (It is the amount of blood in the capillaries which determines the color of the surface.)

The capacity of the vasomotor system to make appropriate responses to changes of external temperature is far from equal in different subjects. What we call "vital resistance"-the power to withstand exposure without ill effects-must depend largely upon the extent of this capacity. It is probable that the variable feature is not so much in the execution of the primary reaction to weather changes, as in the reliability of the secondary adjustment, the promptness and vigor of the rebound to normal vasomotor conditions after a disturbance. The person who quickly develops a "glow" after a cold bath is a living demonstration of such a vasomotor resilience, and we know that such a person is not likely to take cold or to be otherwise upset after being caught in a shower or obliged to sit in a chilly place. Still we must not fail to reckon with other factors than the vasomotor when we compare susceptibilities; there are ahways chemical as well as mechanical differences between two human bodies, and the bacteriologist refers to peculiarities of chemical endowment when he speaks of the superior resistance of this or that man to infecting agents. It is well for us to keep both considerations in sight. If two men fall through the ice and both escape unfortunate consequences, it is entirely conceivable that the immunity in one case may be due to vasomotor reactions which guard against the persistence of conditions which invite infection, and in the other to specific properties of the blood.

Something should be said of the vasomotor adjustment for changes in position. This is a matter often ignored by the writers of physiologic text-books, but it does not require much reflection to convince one that it is of high importance. The inevitable influence of gravity on the blood is to add to the pressure in all vessels below the 
heart and to subtract from the pressure in those albove the level of that organ. The actual pressure of the blood in any ressel is the resultant of a certain quantity referable to the energy of the heart-beat plus or minms a quantity due to the clevation of the locality as compared with that of the heart. If the borly were always ereet, the situation might be met, one may suppose, by the development of thicker and less vielding walls in the resiols of the lower extrenities, lut, in reality, there has to be provision for changes from the horizontal to the upright position, and even for bringing the head to occupy the lowest place.

When a man rises from his bed he does not normally feel any distinct faintness or dizziness as he would if there were a serious impaiment of hlood-supply to his brain. Yet the tendency for the blood to forsake the higher ares of the cireulation and to distend the lower ones must be a very positive force. It is manifest when there is actual faintness, the individual being comparatively comfortable while lying fown, though he may be utterly unable to sit up. Ire have to conclucle that in health the shifting of the blood is prevented with singular efficiency by the establishment of a higher rasomotor tone in the vessels on which the adderl pressure falls. This is one of the first functions to fail when disturbing conditions arise; it is the lack of this reaction which "confines one to his bed" when sick. Compensation for the hearl-down position probably nevel comes to be perfect. We see even in arrobats of long experience the intense fheshing of the fares when the head is hanging down, as in swinging by the feet from a trapeze.

Ife have sern that the vasomotor system makes important and widespread changes in the distribution of the hlowel under the influence of rhanges of the external temperature, and that it exercises its powers to guard against injurious morlifications in distribution when the posture is shifted. We have also stated the general principle that this system dilates (or permits the relaxation of) vessels at any center of musual activity. It would be easy to 
extend this discussion by inchurling other instances of vasomotor accommodation. A most interesting and suggestive case is the reaction which accompanies sleep. This and the reciprocal case of the reaction that comes with fixation of attention may be left to be dealt with in another chapter.

Other Autonomic Functions.-Besides regulating the beat of the heart and the local blood-supply, the autonomic fibers convey impulses to contractile structures not related to the circulatory system. The government of the alimentary canal is carried on by means of such paths. Here, as with the heart, there is a resident automatic power in the walls of the tube, and what the nervous system does is to modify the intrinsic tendeney to tonic, rhythmic, and progressive (peristaltic) action. A long time ago, in the present treatment, it was said that inhibitory rather than excitatory influences are the rule in this department of nervous control. It will be convenient to discuss the extent of autonomic government of the digestive tract when we come to the abnormalities observed in the neurasthenic. Autonomic impulses to the bladder and reproductive organs are apt to be excitatory, though here again the double possibility of reinforement and inhibition remains.

A division of the autonomic system which is of minor significance, but interesting because it is curious, is the pilomotor part. Under this head we include the fibers which go to the scattering development of plain muscle found in the skin. The contractile elements so placed are attached to hairs which may be rudimentary and scarcely noticeable. When the muscle-cells contract under nervous influence, either erection of the hairs or the risings of the skin known as "goose-flesh" may be caused. Occasions on which the hair "stands on end" are apparently rare in human experience, but they are common enough in the life of the cat. This animal has an excelient pilomotor system.

Of more importance is glandular control. The auto- 
nomic system includes nerve-paths of the stanclard type (preganglionic and postganglionic fibers) to many organs of secretion. 'This is conspicuously the case with the sweat-glands. It is true, too, of the tear-glands, the salivary glands, and those in the lining of the stomach. It is certainly true of the adrenal boclies and probably of the pancreas. 'There is less eertainty regarding a direct nervous control of the intestinal glands, the liver, and the kidneys. When glands are artive it is to be expected that vasomotor support will be given to them through the wide dilation of their blood-ressels. But the kind of nervous control of which we are now speaking is believed to be exerted upon the epithelial rells forming and chischarging the product. 'Typic secretory artivity may be promoted in two ways by the autonomic system: by this direct stimulation of the working eclls of the gland and, indirectly, by the enlisting of the vasomotors to secure a freer circulation. In some glands-for example, the kichey-it is the volume of the blood-flow on which the performance of the gland chicfly depends. When this is the case it becomes difficult to decicle whether grovermment of the other orker, that is, by true secretory fibers, surely exists. 


\section{CHAPTER X}

\section{THE CEREBRUM}

A sTUDY of comparative anatomy shows that, on the whole, there is a gradation in the development of the cerebrum which corresponds fairly well with the degree of intelligence and the variety of reaction which different animals exhibit. In the brain of man this division reaches its most conspicuous rank. For at least a hundred years the correlation of intelligence with the cerebral evolution and especially with the extent of the cortex has been universally accepted. It is said that only two animals have cerebral hemispheres more massive than those of man. These are the elephant and the whale; in both, the great size of the body removes the brain from any comparison with that of man. In fact, the brain of the whale is relatively small.

Starling says that in proportion as the cerebrum becomes prominent, the possibility of predicting what response will follow the giving of a certain stimulus diminishes. The animal is less and less machine-like. This is closely connected with the fact that two animals of the same species can show individual traits to an extent which is determined by the importance assumed by the cerebrum in the reactions of that species. One rabbit does not differ in very many respects from another; two cats are quite unlike and may be said to have character or personality. In Chapter III the point was made that the higher type of nervous system is that in which individual as well as racial acquisitions are stored. We may now add that such storage is the particular-though perhaps not the exclusive-work of the cerebrum.

If two persons could exchange their spinal cords, both being in good health, it does not appear that the 
exchange would be attended by any remarkiable gain or loss to either. The slight and limited spinal reflexes would not be likely to be at all strange or unfamiliar to the new possessors of the transferred e(puipment. If each could now take for his own the medulla of his fellow, he might notice a certain strangeness in his reactions. Vasomotor idiosynerasies might be realized. The heart might alter its average rate. Exporience might reveal changes in the capacity of the digestive system under new central government. Now, if the cerebollum were also to be earried over from $A$ to $B$ and the corresponding part removed from $B$ and given to $A$, the results would probably be much more positive. Peculiaritics of gait, aceomplishments or shortcomings in the line of equilibration, skill in daneing or swimming-any of these might go with one rerebellum to the new owner.

The paragraph above suggests what is undoubtedly true of man, that some arequisitions are registered in the cerebellum if not lower down in the nervous system. But when all allowane has been made for this we feel sure that the man who had surrendered his spinal cord, his medulla, and his ecrebellum to another, receiving alien structures in their stead, would still be essentially himself. One almost slurinks from contemplating the imagrinary exchange of one cerelorum for another. To do this must he in a most literal sense to "give one's solf away." So far as we can see, the stock of memories and associations which A regarded as exclusively his would begin to determine the belavior of the organism still woming the outwarl appearance of $B$.

This falmonse presentation merely enforees the contention of Loeb that the corebrum is the ehief organ of assonciative memory. Animals in which it is not much rleveloped have little apacity to loum anything hy experienee. In proportion ats it becomes dominant in the nervous system, memory becomes the basis of action

1 "Comparative Physiology of the Brain" (in Science Series), New York, 1900. 
and individuality becomes inevitable. Memory is used in two senses. Speaking subjectively, we use it to mean conscious recollection. We can use it in a purely objective way to mean no more than the modification of reactions resulting from individual contacts with the environment. When we say that "the burnt child dreads the fire" we usually mean that the child recalls with distress an unfortunate oceurrence in its past. But the condition can be indicated in quite another way. We may say that the nervous system of the child has been so altered by a past impression upon it that it will cause the child to draw back from the fire. A type of action is implied which is essentially reflex.

The boy, like the moth, may be attracted by the flame until the negative reaction has been established; the difference between the two nervous systems compared lies to a great extent in the capacity of the higher one to be modified by use, the lower one persisting in its hereditary response regardless of consequences. The burnt moth probably does not "dread the fire" in either the psychologic or the physiologic sense. The contrast set forth is that between a system without any part closely corresponding to a cerebrum and one in which this department is dominant.

The general conception outlined is justified by the results of experiments in which animals of various kinds are deprived of their cerebral hemispheres and kept alive for observation. The consequences of the loss are grave just in proportion to the part played by individual experience in the government of the organism. Most fishes survive the operation with no clear sign of deficiency. When this is not strictly true it is because the particular fish studied has been one which was regulated in its movements by the impulses derived from the organ of smell. It must not be forgotten that this sense organ and no other is detached from the remainder of the nervous system when the cerebrum is destroyed. It is said that sharks, which have been made "decerebrate," as the term 
goes, are very sluggish. But this does not mean that they were greatly dependent upon the organization of the cerebrum; they "an be just as seriously affected if their olfactory receptors are destroyed, the cerebrum remaining intact.

A frog is regarched as a higher animal than a fish. A (lecerebrate frog, however, departs so slightly from a normal one as to force us to conclude that here, as in the fish, the cerebrum has no important influence on the behavior of the animal under the ordinary conditions of life. It is commonly stated, however, that there are real points of difference between normal and (lecerebrate frogs. The latter are entirely able to swim and hop, but they will not save themselves from death in a pan of water when it is slowly warmed. ${ }^{1}$

The classic instance of the profound effects following the removal of the cerebrum from an animal of high grate was afforded by the experiments of Flourens, in France, early in the nimeteenth rentury. He subjected pigeons to the operation, which is rather a simple one to perform upon the bird. The descriptions which he gave have been modified by modem students to make allowance for the well-marked recovery of pigeons from the immediate shock of the procedure. In this case, as in that of the cerebellum, it is only the listing consequences of the loss that we have a right to emphasize. Observers have not been wholly agreed concerning the nature of the deficiency in all its details, but it seems safe to say that a pigeon without a cerebrum gives no further sign of memory or focling.

To see such a pigeon is an instructive experience, and especially when the spectator takes aceount of his own emotional reaction. He is likely to anticipate that he

${ }^{1}$ Burnott (Anorican Journal of Physiologr, 1912, xxx, S()) has observerl that deeerebrate frogs alefinitely lack the power shown by the intact animals to become "used to" certain pathwas. A trace of adaptation on the part of individuals to their surromurlings serems, thorefore, to be represented in the ecrebral equipment of these animals. 
will feel pity for the mutilated animal. Instead, he cannot watch it long without finding it amusing. He becomes convinced that it is not a sensitive and suffering creature, but an elaborate mechanical toy. It adjusts itself to external conditions with great success so far as the immediate exigency is concerned, but with no anticipation of the future nor reminiscence of the past. In default of stimulation it is relatively inert. It is customary to say that it does nothing spontaneously. The word, however, is a vague one and may well be avoided. An action is called "spontaneous" when we cannot tell how it was caused. Some actions of the decerebrate bird may be placed in this class.

A pigeon withcut a cerebrum can be kept alive for weeks, but only by constant care. It will not find food or water for itself, though they may be placed in its cage. In flying and walking it passes around obstacles, but all the evidence goes to show that there is no appreciation of the objects in its path. Another pigeon exists for it simply as a mass of matter, with no more power to stimulate than a block of wood. The former mate or the young bird appealing for food-these are treated merely as things with which a collision is to be avoided. It is clear that the eyes serve well to regulate locomotion with reference to the surroundings, but they are deprived of the power to cause any reaction based upon the individual experience of the bird.

Detailed accounts of the behavior of the decerebrate pigoen may be found in larger works and they are full of interest. The main points to be insisted on are (1) that the muscular capabilities of the bird remain little impaired in the absence of the cerebrum, and (2) that these muscular activities no longer signify that memories connected with the past life of the pigeon are aroused. It is probably fair to claim that the word "memory" in this statement can be used either in its subjective or objective sense. Moreover, it is not only the previous accumulation which is destroyed, but also the possibility of ac- 
quiring new impressions which ean furnish grounds of conduct.

The removal of the cerebrum from a mammil without causing the immediate death of the animal might well seem an incredible feat of surgery. Nevertheless, it has succeeded in a number of cases. The most celebrated of these has been the one which is referred to as Goltz's (log. By three earefully conducted operations the entire mass of the cerebral hemispheres and, unintentionally, somewhat more of the brain was broken up and washed away. The dog was kept alive and narrowly observed for a year and a half after the final operation. It was then killed and the autopsy showed the thoroughness of the destruction. Its health and strength had been declining for some time before it was sacrificed.

The decerebrate $\log$ affordech a general confirmation of the inferences drawn from the pigeon. It was idlotic, but not erippled in any department of its mechanical activities. A noteworthy fact was that it was restless rather than sluggish. Its aimless rovings supporterl the opinion quite widely held that an important function of the cerebrum is to inhibit the action of the lower brain eenters. Sometimes the dog appeared to sleep, but, if we are right in our interpretation, its waking was not to consciousness, but only to sommambulism. It showed no fear or affection. It would snap at the hand of a tormentor, but only under the direct stimulus of provocation; it would not harbor a grudge against him.

Concerning the human being, of course we slo not have evidence from cheliberate experiment, but we have the fatets in a valst number of chincal catses. A sturprising and instructive one has been reported quite recently. Elinger and Fischer have deseribed the condition of a defective child that died of tuberculosis when nearly four yoars old. It hatb made no appreciable progress in accuming new reactions from the dity of its birth. It usuatly laty in apparent stere, seomed to be blind, and could not be said 1 Archiv f. d. ges. Physiologice, 1913, clii, 535. 
to show any token of consciousness. The postmortem examination showed entire lack of the cerebral hemispheres.

When we compare this shocking instance with the case of the $\operatorname{dog}$ or the pigeon, we are led to believe that the human cerebrum is of such overwhehning dominance that many functions which in the lower animals can be subserved by other parts of the brain have been largely transferred to it. In man it is probable that the subordinate centers for the eyes are incapable of any extensive or useful reaction when their cerebral connections are severed. It is not likely that the power to balance and to walk could be preserved in man as in the dog through the agency of the midbrain, cerebelhm, and medulla without the cerebrum. To be sure, the decerebrate child had never learned to walk, and it might be urged that the cerebrum might be essential for the attentive act of learning and not for exercising the power when acquired. But we have many other cases in which the ability to walk was lost when only a limited part of the cerebrum had suffered injury.

In apes, which approach the human type of organization, the loss of a restricted region from the cerebrum is said to lead to absolute blindness so far as can be determined. The power to avoid obstacles, so striking in the dog and the pigeon, entirely disappears. In all probability, a decerebrate human being would be deaf, despite the fact that the auditory nerve would retain its connection with the medulla and so with the remainder of the nervous system. Pigeons without the cerebrum respond to certain sounds by sluggish movements.

Granting, as we must, that the cerebrum is essential to intelligence and to all action based upon inclividual experience, we are at once led to inquire whether it is all alike or whether particular parts have particular functions. In other words, is there cerebral localization of a definite character? This question was asked by Flourens long ago, and he attempted to answer it on the basis of 
further experiments on pigeons. He came to believe that one part is like another and that the result of an injury is determined by its extent and not by its position. Speaking somewhat crudely, it mily be said that this view made the working of the brain romparable with that of the liver: all its parts were supposed, to be working in the sames way amel all its functions would suffor-quantitatively rather than qualitatively-from a circumscribed injury.

From the time of Flourens to the present scientific opinion has shifted back and forth in a curious mamner. In his own career he found limself called upon to defend his clatims against a school of ingenious persons who upledel the doctrine of a very precise localization of cerebral properties. This teadhing was presently known as phrenologer and attracted much notice. In the hegimning the phrenologists were sincere in purpose and more or less scientific in method. Their sucessors departed widely from the early traditions of the school, and are now found in the purlieus of our cities along with palnists and ('airvoyants. The general conception was begimning to be discredited when Hohnes ${ }^{2}$ wrote of it so incisively. Regarding the claim that it is possible to toll what is within the skull by measuring its slight convexities ancl depressions, he woll said that this was like laying one's finger on the iron wall of a safe and saying: "Lnoler this spot lies a ten-chollar bill."

Francis Joseph Gall, the Austrian founder of phrenology, secms to have had little interest in the brain as related to the bocly, but much in its assumed arrelation with mental endowments and deforets. He and his disciples made careful meaturements of the contours of the head in all types of men, from the most gifterl to the most deferetive and clepraved. A prominenee upon the surface of the

The article "Ihrenology" in the Encyclopedi: Britannie:a c:an bre rocommenderl.

"The I'rofessor at the Breakfast Table," Riverside Edition, $19 ;-20)(1$. 
skull was supposed to indicate an extra cerebral development beneath, and if a special merit or failing coexisted in the individual the notable feature of the brain was held to be responsible for it. This summary statement is scarcely just to the pioneers in phrenology, for they did not commit themselves until they had a great mass of data. They published large books, conducted periodicals, and even had museums in which the comparative study of human skulls was carried on.

A cursory glance at their later writings shows how disingenuous they became. They showed an unrivaled skill in getting around difficulties. A certain protuberance was held to indicate a certain propensity, but its occasional absence from a subject in whom that propensity was well marked did not cause them any trouble. In such a case they said that the subdivision of the brain under discussion had been worn down by excessive activity. This would seem to require a plasticity of the cranial bones beyond that commonty observed. When external measurements were made upon the forehead it was somewhat hard to allow for the variable extent of the frontal sinuses, cavities which occur in that bone, but they did not fret themselves about that.

Phrenology lost the respect of conscientious men of science before the middle of the century. The prevalent feehing was one of skepticism regarding all claims for localization of function in the cerebrum. When, after an interval, new ideas concerning the connection of particular properties with particular regions began to be advanced, it was in a totally different spirit from that of the old teachings. The new localization was of the control of bodily functions and only guardedly extended to the problems of the mental life. The return to the belief that the cerebrum is not all ahke may be said to date from 1870. It made headway rapidly for about twentyfive years and has been followed by another reaction, so that present-day writing on the subject is cautious and conservative. 
The performances of the cerebral cortex have been likened to those of an orchestra. The comparison would have been acceptable either to an old-fashioned phrenologrist or to a believer in the diffuse distribution of brain activity. A series of solos by different instruments would symbolize the phrenologic conception; a harmonious production of music by many or all the players would represent the of her interpretation. Local injury, alcoreling to the first view, would be the silencing of a solo instrument and would ("anse intervals of stillness in the symphony. If the second view were found to be correct, the local damage would not result in absolute interruption of the music, but only in lessening its volume and richness.

It is difficult to say exactly what is meant by "cercebral localization." In all probability, the term does not mean the sime to different people who use it. It would seem that to some it has meant that chefinite regions of the cortex are in receipt of certain impresions, and cam, at a later time, give rise to impulses determined by these stored impressions. Descartes must have hat some such an idea as this when he likened the retention of memories to the imprint of a seal upon wax. Quite another view is possible, and, incleed, it is the preferred one at the present time. This is the conception that a given funcetion appeats to be commected with a given area simply because so many of the paths necessiry to that function lie within the pateh of eortex in question.

To appreciate the modern interperetation of the working of the ererebrum it is necessary to keep always before one the reflex principle. Wo reatlily apply this principte to the spinal rorel. Inpulses flow in and, in ronseguence, others are sent out. It is not difficult to extend this to the mechllit, the midbrain, and the ecrebethm; the chice difference between the responses from these parts and from the corch lies in the greater length of the pathways pursued by the inpulses, the greater number of synapses "rosied, and the increased capacity for variation. When 
we consider the cerebrum we are too apt to assume that conditions there differ radically from those at lower stations. We cannot ignore the relation of the cerebral structures to our consciousness, but we shall escape much confusion if we hold fast so far as we may to the reflex arc as the fundamental fact in the organization.

Impulses enter the cerebral cortex from the afferent division of the nervous system as they enter other parts of the gray matter. Only here the direction which may be given to these impulses is far less certain than in the lower central complexes. The net of pathways has that individual character which has been emphasized, and because of this no two cerebral cortices can react in just the same manner. The great number of simultaneous processes going on in the cerebrum results in apparent collisions and interferenees which make it still harder to predict the effect produced by a stimulus - be it sight, sound, or other external influence. Finally, a most important fact about cerebral reaction is the indefinitely long time that may elapse between the stimulus and the expressed result. A condition which operated on the cortex at a certain time may seem to have been wholly ineffective, but it may modify the reaction to another stimulus much later. A bit of information which was read with indifference and apparently forgotten may shape one's course of conduct in a future emergency.

It is held by some, among others by Morton Prince, that nothing is ever forgotten. Difficulties and limitations in the way of recollecting must be admitted, but it remains probable that every impression made upon the cortical organization is a permanent one. Every stimulus modifies the cortical structure in some degree, and it is forever unlike what it would have been if that stimulus had never been applied to the receptors. The psychologic corollary is that we are likely to recall under particular conditions anything that we have ever heard, read, or witnessed. The difficulty is to control the "conditions" referred to. The images from the distant past, often of very trivial 
objects and situations, which arise in our dreams faror the belief of l'rince.

We must now attempt to connect the view that the cortical reactions are essentially reflexes, though of ten dekayed and modified by many factors, with modern doctrines of localization. A bricf discussion of the "motor" areas" will be in order. It was discovered in $1570 \mathrm{by}$ Cieman investigators that electric stimulation appliced to the cerebral cortex of the dog at certain, definite places

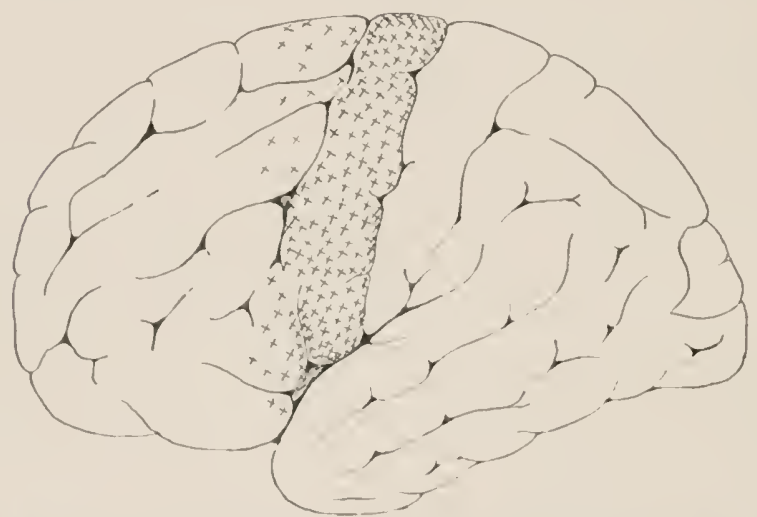

Fig. 22,-The human cerelorum is sketched from the left side. The crosers are sprinkled on the area from which the muscles of the right half of the body appear to be governed. This area extends out of sight over the toj of the brain and dips into the fissure between the two hemispheres.

(alls into play the muscles of the body in a manner which can be predicted. The museles thrown into entraction are for the most part on the opposite side of the borly. In the ape motor aleas exist in the same sense: excitation

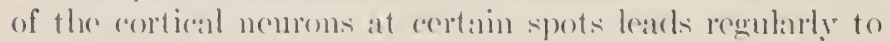

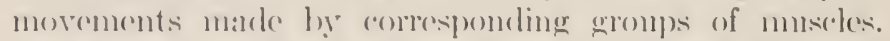
It is known that the same representation of the muscular system in mosilu form ran be domonstraterl on the surfate of the rerehmm in mam (Fig. 22). These areas are evi- 
dently unlike each other and unlike the neighboring areas from which electric stimulation elicits no visible reaction. They are believed to contain the perikarya, from which motor projection fibers extend downward to make synaptic connections with neurons which directly innervate the muscles.

But in our discussion of fatigue we have insisteck that the perikarya at the origin of any set of projection fibers camnot be regarded as the ultimate source of the impulses which traverse these fibers. By losing sight of this fact many writers have probably made too much of the cerebral motol areas. 'They have been spoken of as though they were creative in function or as though they were certainly the precise spots where the metaphysical force impinged upon the material mechanism. Loeb protested against such naïve views and presented the alternative with great chearness in his "Comparative Physiology of the Brain."

Activity in the motor areas doubtless precedes most of our muscular activity. But what takes place in the motor areas is the result of currents arriving within their boundaries from other parts of the brain. So the reresponsibility is shifted to these other regions, and from these again to others. The true fountain-head is not found in the cerebrum at all, but in the receptors of the afferent system or in the energies of the external workd. When this is said we merely reiterate the statement that the type of nervous action is the reflex, and that we cannot make an exception of those processes which are directed through the cercbrum. "Through" rather than "by" is the preposition, and the distinction is of the greatest importance.

The central exchange of the telephone system is an impressive example of intricate mechanism, but it is, after all, an intermediate point, and its function is to give direction rather than to originate communications. More damage can be done to the whole system by destroying the cxchange than by attacking any other single feature, 
but it is evident that cutting all the wires at various places would have the same crippling effect. This is a fair analogy to help one to understand the present conription of the corticil centers. They are not believed to originate impulses, excepting as impulses come to them; their peculiarity is found in the faet that in them a vast number of neural ares of correlated function are brought so close together as to be readily subjected either to stimulation or to damage.

This may be maintained as well for other areas of the brain as for the motor regions. For example, cortain portions of the cortex at the back of the cerebrum, partieularly where the surface of aach hemisphere is infoleded and lies against the surface of its fellow, are held to be visual eenters. It is reported that injury to these fields impairs the usefulness of the cyes and, if suffieiently extensive, causes complete loss of sight. These are regions which visual impulses entor after having been rolayed by the milbrain struetures, and they are regions from which impulses are nomally sent away to other parts of the brain so that other actions mat be modified ats a result of the inflow from the eyes. 'To destroy such areas (on both sides) is to (lestroy useful rision, hut it is really a system of pathways which has becn interrupted and not a repository of visual impressions.

If we reduce all the activities of the cerebrum to claborated reflexes ind, its such, demand for them external (allsition, inmediate or past, what becomes of freedom of the will? This is a troublesome and unweleome question which different thinkers have answered in different fashiom. It may be thought to lie outside the proper splere of the plysiologist, but it confronts him when he becomes a trateher of hygiene. It haunts every min of serencere as it has hamed theologians and philosophers of all ages. Many have been brought to the essential position of Jonathan Edwards, which was, in hrief, the view that we are free to do what we will, but not to will what we shall do. Candid scientists often admit 
with Münsterberg ${ }^{1}$ that one must alternate between two views without seeking to reconcile them; as an investigator one must look for material causes, but for the sake of moral power and conviction one must hold fast the belief in free agency, which has always commended itself to the men who have done most for the world.

Another assertion of Münsterberg may be quoted at this point. Many writers constantly refer to the "subconscious mind" in their discussions of brain activity. Is it not better, asks the psychologist, to reserve the word "mind" for that which is conscious? Physiologists will certainly agree to this; most of the action of the nervous system is subconscious, but nothing would seem to be gained by calling such action mental.

1 "Psychotherapy," Moffat, Yard \& Co., New York, 1909, chap. iii. 


\section{CHAPTER XI}

\section{THE CEREBRUM AND HUMAN DEVELOPMENT}

The motor areas of the eerebral cortex were first demonstrated by experiments upon the dog, and later shown to exist in the brain of the ape. In the cerebrum of man they are known to occupy a sinilar position and to have the same properties. This is to say, that when points within them are electrically excited, movements result, and chiefly on the part of muscles on the opposite side of the borly. The subelivisions of the general motor' area are permanent in the sense that the same group of muscles always responds when al selected spot is stimulated. The areas are better dereloped in man than in the ape, and better in the ape than in the dog or the cat. This is in harmony with the fate that muscular movements in the lower animals are largely gorerned by means of reflex ares that do not ascend into the cerebrum. It follows naturally that injury to the motor regions in man results in irreparable interference with muscular morements, though we have seen that in the dog the entire cerelorum may be destroyed and the power of locomotion remain.

It may secm strange that the existence of motor arean should have been proved for the human brain. The facts are as follows: In certain types of epilepsy it was noted long ano that each attack is ushered in by an invarialule initial movement. The closing of one fist or the drawing of the lips toward one side may give a reliable warning of the approathing eonvulsion. When it became known that definite motor areas ocesur in the hrain of the ape, the surgeons conjertured that homologous areas might be assumed to have their place in the brain of man, and 
that such eases of epilepsy as those referred to might be due to mechanical sources of irritation acting at the subcenter for that part which was first moved at each seizure. In the course of time operations for the relief of epilepsy were undertaken. Acting on the theory that the brain of man is similar in its large features to that of the ape, the surgeons plotted in advance the presumptive position of the motor areas in general, and of that one in particular which was thought to be subject to abnormal stimulation. In very many cases the spot of cortex which they proceeded to expose was found to be under obvious pressure or otherwise affected by pathologic conditions. A measure of relief from the epileptic symptoms followed such operations, though complete cures were not usual.

When the surface of the human brain has been laid bare for these operations it has been possible to apply weak electric stimuli to its convolutions, and the movements made by the skeletal muscles of the subject have justified the behief that the organization here is, indeed, closely similar to that in the ape. Microscopic study supports this view. A conspicuous system of projection fibers can be traced from the supposed motor regions inward through the internal white matter of the cerebrum and thence down the brain-stem. In the medulla the great majority of these fibers cross the midline and pass down the cord on the side opposite to that of their origin. They form synapses with motor cells of the cord and so command the muscles.

The impression prevails that a portion of the cortex just posterior to the motor areas has as a distinctive property the reception of afferent impulses from various parts of the body. It must be remembered that incoming impulses from without the central nervous system never find an uninterrupted path to this level; the original neurons do not pass above the medulla, if, as a matter of fact, they extend so far. It is by synaptic relays that transmission to the cerebral cortex is secured. If we adopt the usual conception of the cortical centers, these areas of reception 
are significant chiefly as they forward impulses to other places. As Loeb has said, this is a dymamic rather than a static form of localization. As this is true of the sensory impulses from the body at latege, so it is probably true for the more highly developed semse organs, such as the eye and the rar.

In the brain of man, as in that of the monkey, the visual impulses-or, rather, the impulses of visual origin-are projected to the hinder part of the cortex and, rhiefly, to the area catled the cuncus. This is a distinctly marked triangle set off by fistures upon the surface of the occipital lobe which confronts the corresponding area of the opposite side. As the relation between the eerebrum and the skeletal muscles is so latrgely a crosied or contralateral one, the inforence might casily be drawn that the impulses from the right eve would be found to arrive in the cortex of the left sirle, but in the human organism this is not so. The relationship is less simple. Approximately half of cach eye has efficient comnections with the cerebral cortex on the same sicke. An able teacher has likened the situation to that of a driver with a pair of horses. His right hand holds the reins which eonnect with the right side of both the bits; his left hand is joined through the reins with the Irft side of both. Carrying this comparison over to the visual apparatus, it reads like this: the right occipital rortex is functionally related with the right halves of both the retine; the left rortex, with the left lualves.

The general statement just made recpuires a qualification in view of a very interesting fact. There is in the renter of each retina a restrioted region, the fovea, which has superior vistal possibilities. (When we speak of fixing the eye on an object we mean fixing the imatge of the objert upon the foreat.) This part of the retina is believed to have at double representation on the cortex-both eyes projecting impulses to both sides of the brain. Thus, no injury confined to one side of the brain can be expereted to destroy the use of rither fovea. It cam blot out nearly, but not quite, half of the field of vision. 'The 
"central vision," which is of the foremost importance, is bound to survive, thanks to the reduplicated projection in the cortex.

The auditory path leads first to the medulla and thence, by repeated relays, to the cerebrum. The best marked projection of the impulses from the organ of hearing is
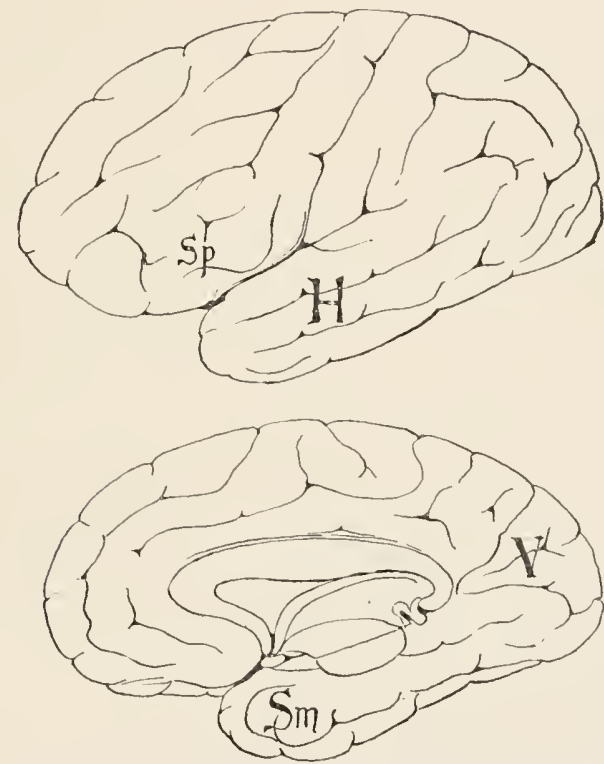

Fig. 23.-The upper figure represents the left hemisphere from outside, that is, from the left. The lower figure shows the internal or mesial aspect of the right hemisphere, that is, the right hemisphere from the left side. Areas usually claimed to possess special relations are marked as follows: $H$, hearing; $V$, vision; $S m$, smell; $S p$, speech.

upon the cortex of the temporal lobe, and damage to this part has often caused deafness. The effect is to impair more considerably the reactions from the opposite ear, though some limitation is imposed upon the usefulness of the ear of the same side. An area for the reception of impulses of olfactory origin is said to be well set off. It 
is not far from the place of entrance of the olfactory fibers into the lower surface of the cerebral mass (Fig. 2:3).

While these several regions of the cerebral cortex have been mentioned with especial reference to man, little has been said so far that would not apply as well to the more lighly developed animals. It is a question of great moment whether there are to be liscovered in the brain clear and well-localized signs of human eminence. As to the answer to this question, there is, unlappily, at great deal of disagreement. Fifteen or twenty years ago the average writer woukl have felt warranted in more positive assertions than it is usual to make at the present time. But in spite of conservative tendencies there are some teachings which retain weight for most physiologists. The first and most sweeping of these is that the developments in brain organization which correspond with intellectual advance are one sided rather than symuetric.

Early metaphysicians, like Descartes, were troubled by the dual form of the brain. So long as they emphasized its connertion with mind instrat of body, such a double character seemed unreasonable. As soon as men begam to view the brain in its relations with the paired muscles and sense organs of the body, its division into right and left halves appeared justified. But the desire to find in it some basis for a unity closer than that of two equal and coöperating halves was hound to rise again. Most investigators think that it has been fulfilled in the probable facet that one of the hemispheres is dominant and the other subordinate, so far as truly intelligent activities are concernerl.

Most people are right handed. This means that the motor area on the left side of the brain has a superior organization. Byy this we now understand at superior

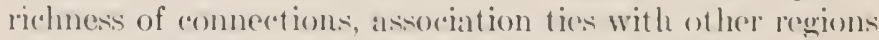
of the hemisphere. The majority of physiologists will probably $\mathrm{gos}$ so far as to siy that the machinery of intelligenes lies more in the left than in the right half of the cerebrum in right-handed individuals. It is supposed that 
in the left handed the balance is reversed: the right hemisphere is the dominant one. The most interesting claims made in support of such views have reference to the representation of language in the human brain.

The brain of an illiterate man is organized in such a way that oral expression of thought is possible and that the speech of others is comprehended. The educated man has, in addition, an equipment that makes possible the expression of thought in writing and its appreciation through reading. The answering of a question is an act of the reflex type, but one which requires for its execution the fullest development of brain paths. The manner of its accomplishment must depend upon innumerable past events. The destruction of certain connections might be expected to render it impossible to reply to the question. This is a state of things quite often realized. Brain disease is often signalized by disorders in the field of language. Such disorders are not sharply distinguished one from another, but the attempt is often made to classify them under several heads. In general, it may be said that the power to understand and to reproduce language is associated with connections made through the cortex of the left hemisphere excepting in left-handed subjects.

Long ago it was noted that in cases where there had been loss of intelligent speech during life a certain limited area in the left frontal region was often found abnormal on postmortem examination. This area became known as the speech center, and the interference with speech resulting from its impairment was named motor aphasia. The reputed center is probably a place within which many of the arcs which are necessary for vocal expression of ideas are brought close together. Motor aphasia is not an actual paralysis of the muscle groups required for speech. The use of the same parts for other purposes, such as swallowing, coughing, and even for voice production, when this is not strictly intelligent, may remain quite unimpaired.

The distinction between the intelligent and the merely 
mechanical employment of the vocal organs may be illustrated by one of the many curious stories told of persons with aphasia. A man who suffered from an injury to the region assumed to bear this important relation to language lost all command of speceh save that he still swore on occasions. This seriocomic state of affairs is not difficult to explain. Habitual profanity is scareely a gemuine form of speech; the fow works userl are repeated under the most varied ciremstances with no specific appropriatenesis. They come to be little more than animal outeries. As such they might be expected to survive the wreck of the organization which has for its duty the rendering of thought in correctly chosen words. Thoughtful cursing would be an appalling performance.

Motor aphasias may differ in degree throughout all grades from a mere linitation in vocabulary to absolute abolition of speech. The inclividual characteristies of the cases are often of strange interest. A number of them are cited in a fascinating way by Thomson in his delightful book, "Brain and Personality." We may refer to one shrewel deduction of this practitioner which seems highly suggestive. In a family of his acquaintance there were several children. One of them and only one showed a marked preference for using the left hamd in the first and second years. A rather severe struggle followed, the parents and attendants secking to make the child right handerl. Its initial tendency was at length overruled and it grew up like its hrothers and sisters. But in one resperet its history was contrasted with theirs: all the ot hers talkerl at an early age, while this child was distinctly backwarrl.

Thomson's explanation is an attractive one. He suggests that in the brain of the child who showed the disposition to use the left hand rather than the right the organization of the right hemisphere had begun to forge aldead of that of the left. If there hat been no interferencer from withont, the pathways employed in the use of lan-

1 Dodel, Mead d Co., New York, 1907. 
guage would have been opened in the right hemisphere also. When the left hemisphere was forced to provide the nervous government for the skilled hand the mechanisms related to language had likewise to be furnished by that side of the cerebrum. Time was lost when the original foundations in the right hemisphere were abandoned in favor of new ones which had to be constructed in the left.

When the command of spoken language suffers it is commonly observed that the subject shows some loss of general intelligence and of the power to read and write. But there have been many cases in which one or another of these specific accomplishments has been more or less completely abolished without much impairment of the remaining functions. So we read of the loss of the ability to write consequent on damage to a region just above the speech center as usually indicated. The writing center, if it has as definite an existence in space as has been claimed for it, is near the motor area for the trained hand and may be thought of as a special extension of that area.

Sometimes the power to read is lost, though the victim is not blind. The letters are seen clearly enough, buit do not rouse the associations which they had previously acquired. It is a set-back in education-a return to the condition of the child whose eyes are keen, but who has not learned to read. Since reading is a specially developed function of vision, it is not strange that a state like this has often attended injury to the hinder part of the cerebrum on the left side and outside the general visual region. Destructive processes near but not covering the supposed auditory area of the left temporal lobe have sometimes led to a condition described as "word deafness," sounds being distinctly heard, but words no longer serving to convey their old meanings. The experience is probably just that of listening to an unfamiliar foreign language.

The integral existence of four centers for language, that is, for vocal speech, writing, reading, and the translation of words spoken by others, is not so confidently maintained as it was a few years ago. If the true con- 
ception of a "center" is merely that it is a place where a large number of paths related in function lie close together in the cortex, we shall expect to find that none of the nsw's of language can be cut off by local brain injury without reducing to some extent the other powers. This has been saicl to be observed, at least as a rule.

The attempt has been made to ascertain whether the apparent smperiority of the left cortex can be demonstrited with the microscope. Methns, of Johns Hopkins, his recently reported that sections made from the supposed speech center in a luman brain and from the corresponding area on the opposite side have proved to he makerlly unlike. The cortical layer on the loft sicle was much thicker than that in the specimen nsed for comparison. The greater thickness seemed to denote a more 'xtensive development of dendritic proeesses in the part hele to have the special functions to fulfil. But these facts were not presented without a word of eaution. 'The same investigator compared sections of cortex from the brain of a highly olucated man and others from homologous localities in the brain of an ignorant Austrian peasant. The drawings made showed a decidedly more intricate organization in one ease than in the other, but, contrary to the expectation of every one, the more imposing appearance was that of the meducated brain!

No modem advocate of cerebral localization has approached the old phrenologie precision in denoting the functions of all recrions. Large portions remain without designation other than that of "association areas." "Through them, by fow or many relays, wo suppose that the connections are made which letermine the reactions which shatl oreur under all dircumstances. Histologists latve made the general statement that only the areats which are definitely dassed as motor or sensory haw projection fibers moliating between them and lower levels of the nervous system. Berond the boumblaries of the areats immerliately ancerned with the delivery or the reception of impulses traveling to or from the 
various parts of the body are extensive regions linked with them and with each other by paths composed of "association fibers." Hence the association areas seem to rank above the others in the cerebral organization, being one remove farther from the receptors and effectors in which the nervous system begins and ends.

Presumably it is the association areas which register most fully the details of the incliviclual history, and so come to be in some sense the protoplasmic record of experience and of character. But the representation is diffuse, and the attempt to attribute a specific share to this or that fraction of the whole has not been very successful. The most attractive description of the association areas and the possible distribution of their work is that of Flechsig. ${ }^{1}$ He has suggested that the association area which lies mainly in the parietal lobe is particularly engaged in correlating the impulses received in the primary sensory areas around it. The great frontal area which is more distinctly withdrawn from the sensory stations, but which arjoins the motor centers, may be supposed to transmit impulses to the cell groups controlling movement. The influence exerter through the frontal region is assumed to be largely of an inhibitory character.

If the views advanced by Flechsig were quite ccrrect, it should be possible to find confirmatory evidence in the nature of insanity when induced by local bram disease. Degeneration in the parietal region might be expected to cause dulness, apathy, and inaction because the power to appreciate the significance of things seen, heard, and felt woukd be impaired. On the other hand, clamage to the frontal convolutions might be expected to lead to erratic, ill-regulated conduct, perhaps to violence or depravity. The facts are not entirely in accord with the theory, but many individual cases are so, and it is possible that all can be explained under its broad provisions.

Clinical observations constantly impress upon us the ${ }^{1}$ Gehirn und Seele, Ieipzig, 1896. 
danger of being too dogmatic with regard to the local functions of the brain. We are reminded of this when we consider the extremely unequal results of various brain injuries. Sometines profound effects follow what seems quite limited destruction; sometimes extensive lesions leave no noticeable deficiency. Gumshot wounds of the brain are usually fatal, but they are not always so, and it is to be remembered that a bullet penetrating the brain substance works havoe with the structure far beyond its own path, displacing the tissue and producing pressure in distant places. There lave been extraordinary cases of immunity from serious consequences when the brain has sufferecl gross harm. Of those carefully recorded, none is more remarkable than that of Phineas (iage.'

The aceident which befell this man oreurred in the year 1848, when the Rutland Railroarl was under construction in southern Vermont. It happened near the village of Catrendish, where a rock eut was being made. Gage, who was one of the workmen, was tamping a charge of blasting-powder in a deep hole which had been drilled into the ledge. The explosive was ignited and the massive iron bar was torn from the hands of Gage and driven through his skull. It entered his left eheek and went out through the top of his hear, having pushed before it a cylindric body of gray and white matter from the left hemisphere. The rictim did not even lose consciousness. He survived for twenty years, and it is not known that he showed any abnormalities excepting blindness in the left eye. This was due to the elipping of the optic nerve on that sicte and not to any cerebral damage.

1 Gee the statrment of Gingr's physicitn, Willians, in the guide book of the Rutlant Railroal, "The Heart of the (ireen Nountains," 1 s97. 


\section{CHAPTER XII}

\section{THE CEREBRUM AND THE LIFE OF THE INDIVIDUAL}

In some of the tissues of the body there is a constant formation of new cells at every period of life. This is true of the skin, and is nowhere more evident than in the case of its outgrowths, the nails and the hair. In other tissues there is no addition to the original number of the cellular units. It has been stated in another connection (Chapter VIII) that no multiplication of the units occurs in the skeletal muscles, though there may be an increase in the diameter of the fibers. It is a most significant fact that in the nervous system the maximum number of the neurons appears to be attained very early, and hence any later change will mean a diminution. The great advances made from infancy onward to maturity are not based upon any corresponding multiplication of the neurons. They are accomplished in spite of a stationary or even decreasing number of these elements, and must be referred to the formation of new routes of communication among them.

It has been said that the limited powers of the nervous system in the newborn are indicative of the great individual development which awaits realization. This subject may now be pursued in some detail. The receptor system of the infant is probably complete. On the effector side the muscles, especially those of the legs, have yet to grow considerably to sustain a proper proportion to the total mass of the body, but they are fully provided with efferent fibers from the motor cells of the lower order in the cord and brain. The department of the nervous system which is farthest from its future condition is the intermediate 
portion, the adjustor or association medianism. The ties which will later determine the responses of the oreanism to all mamner of stimuli have mostly to be established; only a few are congenital.

The light which enters the ryes of the newborn baby probably produces the same retinal processes which it will always prochee. The optic patls lie ready to convey the resulting impulses to the brain. The lower enter: in the midbrain and thereabouts may be traversed by these impulses quite as they will be in adult life, and the simpler eyc reflexes, such as winking and rontraction of the pupil, can be evoked. But the radiation of the intpulses from the visual centers in the cerebral hemispheres is probably insignifieant. A few months later the chilu reaches in the right direction to grasp objects which are brought into the range of its vision. Physiologically speaking, this means that a serviceable bond of mion has been established between the receiving station for the visual impulses and the area from which the motor inpulses take their departure from the rerebrum. When the head is turned toward the souree of a sound it seems reasonable to conclude that a similar connection has been secured between the auditory and the motor regions.

These physiologic gains are undoubtedly aceompanied by mental advances of a patrallel sort. In a passage of great literary beauty George A. (iordon' has sketehed the attaimment of psychologic correlation between sensations mediated by different paths. He points out that for the baby a month old the mother is represented by a visual inage, a voice, and a comforting touch. The three sensations have nothing in eommon save the fact that they are wekeme to the infant conseiolsiness. A momentous step is taken when they are first enceresed to originate in the same cutity-a "benign power," as the anthor cited has expressed it. On the material side this revelation to the mind of the ehikl must be anditioned hy the opening

1"Itimate Conceptions of Faibh," Houghton, Mifflin \& (o., Boston, 1903, 102-101. 
of new association paths in the cerebrum. When, after an interval, the child finds a name for the mother we have evidence of an additional evolution of such bonds.

All of education, from infancy to the fulness of development, is of this same type. "Reaction to stimulation" is the term which covers almost all which the organism does, but the capacity to react is always qualified by the entire past history of the individual. Every incident in the course of life has left its impression. The formation of habits is the symbol of the channeling which is proceeding in the cortex. This fact has been alluded to in the chapter on Reflexes and it may now be enlarged upon. In infancy a very few repetitions of a reaction may make it a matter of regular recurrence or, in other words, a habit. This is partly due, we may suppose, to the plastic nature of the tissue involved and partly to the absence of paths of prior formation.

When the word "habit" is used, the connotation is likely to be a disagreeable one. But this ought not to be so, for it is the power to form habits which is the basis of human progress and efficiency. If it were not possible to acquire the ability to perform many acts as though they were reflexes, making no demand upon the attention, we should never advance far in our individual development. If the task of dressing one's self remained as laborious and continued to require the same thoughtful planning in later life as in the days of childhood, when it was first accomplished, one would lose just so much time and strength which is actually available for fresh lines of thinking. As each necessary act becomes, as we say, second nature, the mind is released for new conquests.

The late William James ${ }^{1}$ wrote most wisely of the advantages and the dangers incident to our habit-forming propensity. It was his suggestion that habits can be placed in three classes: those which are clearly the best possible, those which are plainly undesirable, and a great

1 "Psychology, Briefer Course," Henry Holt \& Co., New York, 1892, chapter on Habit. 
number which are neither to be particularly commended nor condemmed. The habits of the first class are evidently' to be cultivated and rherished, while those of the second class are to be abandoned. These statements are platitudes, but the teaching of James regarding the habits which are neither good nor bad is worthy of areful consideration. His contention is that such habits are to be arbitrarity changed from time to time; not that the new practices are any more hygienic or attractive than the old, but that by such deliberate changes one preserves the mastery of the situation and the adiptability of the nervous system to altered conditions which the future may bring.

It is easy to find opportunities to follow this suggestion. One maly find that a cortain phrase is being used repeatedly in conversation or in writing. An equivalent phrase may be substituted; this is combating the tendency to form a rigid habit. A certain melody may rum in the head; the act of cutting short its continuance and causing another air to take its place or, better still, silencing the subjective music for the time is attended with an agreeable sense of being in eommand of the cerebral activities. James has said in substance that one should note what one is inclined to do and then do something else. This practice might eonceivably be overdone, but the want of such initiative and the passive areeptance of all the minor habits as they make their appealance is the eommon defect.

It is not too much to claim that such self-discipline is a postponement of old age. We have said that the characteristic of the young nervous system is the ease with which paths may be opened in it. The nervous system in middle life has many woll-defined paths which are omployed with regularity in doing the daily work to which the subject has been trained. Changes become eonstantly more difficult and are macle more rehetantly. Foster has said that in old age the brain lookds a record of the past rather than a promise of what may be realized. Monotony of enviromment and ronsequent uniformity of reaction are factors which are calculated to bring on pre- 
maturely this rigidity, which must in any event arrive at last unless death anticipates it.

The hardening of the arteries in later years is an inportant and widely discussed feature of the senile decline. Portending the day when "the pitcher shall be broken at the fountain or the wheel broken at the cistern," it is a material type of the invisible change in the constitution of the central gray matter which gradually limits its capacity to respond to new exactions. Much as arteriosclerosis can be postponed by temperance in eating and drinking and by a wise ordering of all the activities of life, so the loss of plasticity in the cortical organization can be delayed by the same temperate conduct with the adcled element of a studied variety in its employment. It seems to be much more within our power to do this than to prevent the inevitable stiffening of the crystalline lens which abolishes the accommodation for near vision at about the same period for all persons with normal eyes.

It will be gathered from what has been said that if the young nervous system excels the older one in its capacity for variation in reaction, the older one surpasses the younger in its confinement of its energies to profitable channels. It is the more economic of the two. This is much like saying that it has the greater exercise of inhibition. In it, wasteful diversions of nerve-currents to call into play effectors which serve no useful purpose have become reduced to a minimum. When a child no longer cries when matters are not altogether to its liking and, instead, seeks compensations in each situation, it has suppressed or inhibited a lower type of reaction in favor of a higher one. The progress of education always continues to be marked by such substitutions.

This inhibition of primitive reactions by others based upon complex experiences is best illustrated by the human being, but is not wholly wanting in the most intelligent of the lower animals. The dog that endures abuse at the hands of children without turning upon its tormentors 
exhibits it impressively. We feel at once that we may acknowledge kinslip) with a creature in which we recognize the beginnings of virtue and nobility. Transkated into physiologic terms, the self-control on the part of the dog stands for the existence in its brain of countereurrents which stay the execution of the simpler reflexes.

As men and women we find ourselves called upon not only to restrain many of the elementary reactions, but also to employ inhibition with reference to trains of thought. The power of concentration and the power of detachment are nearly relatel. It might seem that they were diametrically opposed, but a little consideration shows that what we call "concentration" depencls on the banishment of irrelevint ideas, and one who ean do this will, as a rule, have the ability to banish the central as well as the competing thoughts at the proper time. Those who have carried the most crushing responsibilities for long periods and rendered the greatest services to mankind, have frequently been those in whom the power of detachment from their cares was most remarkable.

Iincoln furnishes an illustrious example. Those who were near him were puzzled and sometimes offended by the abandon with which he put asicle perplexing problems to enjoy humorous books or amusing plays. It was not so plain to them as it appears to us now that this relaxation was the physical and mental salvation of the heavy-laden president. Because he could dismiss the pressing questions when it was no longer profitable to dwell upon them, he could return with renewed strength and clarified judgment to his task a little later. Stedman silw the motive and wrote sympathetically of

"... one who, longer to endure,

Called mirth to calse his eraseless idole,

Yet kept his nobler purpose sure."

The same finc attaimment of mastery over the currents of the montal lifo has often given efficieney to those who, unlike Iincoln, have had no large endownent of physical 
stamina. This was doubtless the case with Darwin, who could not long pursue any single interest, but had to find something to contrast with it after a short period of attention. The quantity and the quality of the work which he produced in spite of this limitation convince us that he must have had in equal measure the power to apply himself in the most concentrated fashion and to relax with the same degree of success. The latter achievement is probably found to coexist with the ability to go quickly to sleep.

One who has cultivated the ability of turning resolutely from one line of thought to another will find abundant opportunity for the excreise of this power in effacing what is disagrecable in favor of what is pleasant. This may be true either of memories or of anticipations. The healthy mind-doubtless correlated with a healthy brain-is greatly aided by nature in banishing distressing recollections. Psychologists recognize that such an individual retains in his thought much more of detail and of vividness when the experience reviewed is pleasant than when it is the reverse. A normal person should be able to reproduce with but little diminution the feelings which attended joyous and uplifting moments, but he should find that pains and mortifications recalled from his past have atrophied to colorless abstractions. The opposite condition is particularly deplorable and may characterize the neurasthenic.

In the voluntary control of thoughts regarding the future we must recognize a matter of inestimable importance. They are happy who can systematically magnify the approaching good and disregard the impending ill, considering it only to the extent that prudence and unselfishness require. There are few examples more inspiring than those which we owe to women who approach terrifying surgical ordeals with their attention steadfastly fixed on other concerns. We do right to pay tribute to their self-forgetfulness, but it may fairly be added that their splendid discipline is the best thing possible for the conservation of their own resources in the crisis. 
Much is written of the injury to general health which is wrought by fear. The teaching is not so familiar that there are many people who need to limit the extent to which eertain entirely happy expectations oceupy their minds. Yet this may farly be elamed when dwelling on a distant happiness hecomes a cause of discontent. The homesick college student knows that to be forever reckoning the days that remain between the present and the tardily coming vacation brings more of depression than of stimulation. It is better to emphasize the agreeable eonditions which can generally be discovered close at hand.

Monotony in occupation and association must be held to threaten harm to the nervous system and so to the general health. We see the consequences in remote country districts, where each person secs but a few others, and where the round of duties to be performed is narrowly fixed from day to day and from year to year. Add to the wearing uniformity of circumstance the anxicty over the slender income and it does not secm strange that in such localities the proportion of mental derangement is high. In many a weather-beaten farmhouse there are taciturn, desponding, and bigoted people, cherishing bitter grudges against neighbors, and making no effort to maintain sociability in the family circle. Exery such man or woman is a witness to the tragic results of life without wholesome variety in contacts and interests.

A mind well stocked ought to be able to neutralize in a great measure the drawhacks of such surroundings, though it frequently appears that the man of ostensibly high education is quite dependent upon external soureses of diversion. Not many college gradnates rould spend a winter on a poverty-stricken farm without repining, but it may be asserted that the sucesse of an arademic training may be measmed by the eapacity of the possessor to find rontentment independently of novel stimuli. It is too much to ask that he shall prefor such isolation; formal education is naturally a preparation for further development in which the enviromment should bear its part. 
But if the exigency arises it should be possible for the trained mind to meet it with equanimity.

A store of happy memories and generous affections should be competent to provide a foil to the depressing influence of monotonous circumstances for a time at least. Few would care to be tested long. Books have been one of the chicf resources of those who have contended without degenerating against the tedium and pettiness of their lot. Memorized portions of the best literature may lave a share in saving intellect and character from deterioration. The silent or audible rehearsal of such passages may be more bencficial than a concert or a play. No one can estimate the steadying power that has been operative in the minds of our ancestors as they have pondered the words of the Bible, "the ever-open Thesaurus" of immortal truth immortally phrased.

As we think of the means of avoiding a dead level of the mental life and the value in it of reserve capacity for inhibition, the topic of the Sabbath suggests itself. It is easy to caricature and condemm the Sunday of the Puritans. Many of the restraints which it imposed may appear arbitrary and undesirable. But certain great blessings came from it to those who cordially acquiesced in its conventions, and even in a measure to those who conformed more grudgingly. It made a radical break with the routine of the other six days and it encouraged selfcontrol rather than self-indulgence. The "Continental Sunday," toward which we seem to be moving, has too little of inhibition. The jaded nervous system, by a property which may be called perverse, demands excitement, when the real need is rest. We shall find in this fact the key to much that we have to discuss in a later chapter.

The student who refuses to let his studies encroach upon his Sunday is not likely to regret his course. He will find a zest in his work when he resumes it on Monday which is the direct consequence of the intermission. The religious prohibition of our fathers may not be well founded, but the dictates of hygiene may be made to take its place. 
Those who demur against the proseription of religion may urge that the assigned English literature or history is intrinsically finer thim any matter likely to be substituted for it; on grounds of hygiene, howerer, a change is to be desired. fome experiments recently reported from the Harvarel Medical School support this daim in a very positive way.'

Daily trials were made upon a large number of students to determine their "sensory threshold," meaning in this case the least electric shock which they could fecl. The stimulation was through two fingers of the same hand. When all the results were averaged, it was found that a diminution of imitability was registered from day to day as the week passed, until on Saturday the threshold reached its highest level. That is to say, it took a stronger shock to attract attention on that day than on any other. On Monday the threshold was down again; this is the same as saying that the irritability was restored to the highest pitch. There must have been some cumulative fatigue from one day to the next which was not off-et by the night's rest.

The students in this gromp probably had very variable programs for Sunday. But it could be said of all of them that the oceupation on that day afforded a contrast with that which filled the rest of the week. Perhaps we maty find in facts like these the explanation of the miform seven-day cyele agreed upon by so many races and creeds. Experience may have shown that a longer period of routine leads to progressive impaiment of efficiency, while economic presisure has not permitted the interruptions to become more frequent. Surprise hats been expressed that the subjective juclenuent on Monday morning is apt to be that the eondition is one of munsual inertial rather tham of stuperior capaceity. It is rery likely true that the highest imitalility does not correspond with the best state of the nervous system for consecutive work. The subject maly be too easily distracted. Hence, it may

' Martin, Withington, and Putnam, American Journal of Physiology, 1914, dxiviv, 97 . 
very well be that the best working days will come later in the week. Still, the important fact remains that a balance must be maintained, and the seventh day, bringing change if not rest, is invaluable.

A word regarding the relation of attendance on church services to the health of the nervous system may not be out of place. If we hold to the principle that a contrast in thought and feeling is what we must seek to secure when we turn from our common, necessary interests to others which invite our attention, we shall find that much can be said in favor of the formal exercises of religion. To cease from our narrow calculations, our competitive endeavors, the struggle to please all types of associates, and to contemplate fixed and eternal realities is to alter as completely as possible the currents of mental life.

It may be said in this connection that the atmosphere of very many churches at the present time is far less favorable to this bitterly needed substitution than it was twenty-five years ago. When a church becomes a sociologic forum its power to restore the jaded individual is obviously lessened. We cannot wholly regret the heroic note in current preaching, the insistent call to social service and political reform, but this is a function which is shared with the press and the secular platform, while spiritual renewal is the preëminent office of the church of Christ. 


\section{CHAPTER XIII}

\section{EMOTION}

THE fact has been emphasized that a very large proportion of the action of the nervous system proceeds without clear tokens in consciousness. On the other hand, it may be urged that the general coloring of consciousness is symptomatic of much that is taking place in all departments of the neural mechanism and, indirectly, of many states of the outlying organs which we cannot attend to in an analytic fashion. Our intense feelings we speak of as emotions, and it is generally held that their development depends in a great measure upon conditions outside the cerebrum through which the fusion of effects is brought about.

The doctrine that stirring feelings never have an adequate foree in the mind until there is a characteristic inflow of afferent impulses from various sources to give them positiveness is known as the James-Lange theory. According to this view a person is not truly angry until his muscles have assumed a rertain tension, his heart action a certain thythm, and his blood-ressels a certain tonic regulation. He does not realize rage until his facial expression and his posture combine to denote it. His emotion is interpreted to himself by the same signs which make it known to others. If one who fecls angry (an inhibit the muscular manifectations and relax his features he will experience a sense of hudicrous inpotence and dissatisfartion, though he may be well a watre that the oreatsion for lis wrath retains its full valielity.

si) the experienes of grive in its fulness requires the sensations that arempany the nuserenlar state of one who has given way to sorrow and the tingle of shedeling tears. To 
know the meaning of fear, one must blanch and cower. These ideas are not readily accepted by the student who considers them for the first time; they have not proved convincing to all psychologists. But for our present purpose it does not much matter whether the bodily accompaniments of emotional states precede or follow the feeling. What concerns us is the plain fact that they attend it closely. They are, moreover, in proportion to its intensity, and it is important to realize that all emotion is exercise and often of a strenuous and far-reaching kind.

People who criticize athletic sports often argue somewhat in this wise: Here are 20,000 people idly viewing a contest in which 18 baseball players are taking part. The proportion of the idle to the active is more than 1000 to 1 . Such a statement does but scant justice to the facts. There is an unsuspected quantity of muscular activity among the spectators as they watch the game, and they often find that they have earned a wholesome fatigue when it is ended. As they bend forward or rise in their seats, perhaps giving vent to cheers or imprecations, as they flush and tremble, now holding the breath and now gasping or sighing in the stress of their feeling, we cannot question that both the skeletal muscles and the autonomic system are being strongly played upon. It is only when the game is very one sided or the looker-on is very blasé that the hours passed in the grandstand can be classed as idle.

A previous reference has been made to the fact that in times of marked excitement the adrenal bodies are aroused to unusual activity and discharge their powerful product, adrenalin, into the circulation at a more rapid rate than normal. The demonstration and the interpretation of this fact we owe to Camon. He was able to show by a delicate test that adrenalin makes its appearance in the blood of a cat when the animal has been agitated by the sight of a dog. Additional experiments by workers in the same laboratory have shown that adrenalin is capable of delaying the onset of muscular fatigue. This is accomplished partly, though not wholly, by its acting as an anti- 
dote to the fatigue substances at the end-plates. Under the same conditions which cause the discharge of adrenalin there is likely to be a notable rise in the sugar of the blood above the usual small pereentage.

The rise of the sugar may be sufficiently marked to cause some of it to pass into the urine. This feature of the emotional state has been noticel in human beings. Cannon found that such an escape of sugar oceurred in most of the members of the Harvard football squad at the time of the game with Yale in 1913. This was true of the substitutes who had merely expected to be called in as well as of the active players. Moreover, the same "emotional mlycosuria" was found to be eommon among the spectators. It is probably a rather frequent reaction; possibly the exeitement of being examined for life insurance may sometimes suffice to eause it and to mislead the physician who detects sugar in the urine. In all cases it is the glycogen or animal starch in the liver which has been transformed to furnish the sugar, and it is believed that the change is brought about by the influence of adrenalin in the blood.

Cammon has shown great insight in his explanation of these phenomena of emotion. The funclamental fact is that emotions are experienced by the lower animals and by primitive men at moments when vigorous action is to follow. Rage is the prelucle to conflict. Fear will be followed by flight. Sexual passion will eventuate in sexual aggression. Civilization complicates the order of reaction, and inhilition of the higher type represses these activities. The physical accompaniments of emotion are hetter suited to the ancestral than to the modem conclitions. The mobilization of sugar appears to anticipate a demand for fuel on the part of the sheletal muscles. The extra adrenalin at the same time promotes enduranee.

Very recently Camon and his co-workers have demonstrated another and a curious change in the blood after an enotional crisis. This is a distinct redurtion in the time needed for astgulation. The atoting of the blood is a 
defensive reaction tending to check hemorrhage and, in case of wounds, to increase the chance of survival. Cannon suggests that emotion is experienced when wounds are imminent, and so a purposive character can be discerned in this physical change as in the others.

If emotion is exercise, it may be asserted that a life poor in emotion is a life which lacks wholesome stirrings in both the neuromuscular and the autonomic reahms. It is probably true that people who have had a humdrum existence are apt to be wanting in endurance. The country cousin on a visit to the city is utterly wearied by days of sight-seeing and evenings of entertainment in spite of keen enjoyment of it all. It has of ten been observed that volunteers from the eity are more readily made into seasoned and hardy soldiers than are the more formidable looking farmers. A measure of training is inseparable from irregular hours, various associates, changes of boarding-place, and the more harmless dissipations of the city. The hurry, the noise, and the glare, the very things which are held to injure the nervous system, harden it and adapt it to endure new forms of stimulation if it is intrinsically strong enough to withstand them.

At the same time it is easy to see that excess in emotion is exhausting to all the physical resources. Most people know how profound is the weariness which succeeds a severe paroxysm of anger. It is not much less marked after sudden joy or a thrilling spectacle. There seems to be much that is common to all the major emotions, though they seem well differentiated in retrospect. Cannon thinks it probable that the adrenal body is similarly involved in all of them. The feeling of weakness that comes in their wake may be due in part to a subnormal production of adrenalin on the part of the exhausted cells.

Long ago James wrote in his always illuminating way of the use and abuse of the emotions. He made much of the idea that every emotion experienced should become a motive for conduct. If it cannot be so applied, its repeti- 
tion should, so far as possible, be avoidel. 'This teaching now appears to have much more biologic truth in its favor than it secmed to have when first published. If the oceasions in the lives of anmals when emotion is stirred are oecasions for decisive action, we must heed the moral and not too radically break with our inheritance. If the primitive expression is out of the question, we may still be ingenious elough to find a harmless or even a profitable substitute.

Specialists are now laying all possible stress on the comnection between nervous disorders and the suppressed or unsitisfied tendencies which are believed to work harm during long poriods of latency. The curbing of a wish, when this means not only the check but the annihilation of the desire, is a nolbe excreise of inlibition. The denial of expression simulaneously with the continued entertaimment of the wish is exeecelingly hurtful. The frequent experience of emotions which do not secure any motor outlet is also abnormal. Angor may not lead to fighting, nor even to seolding, but it may be turned into a motive for vigorous action. Some one has shrewdly suggested that the boy who is heartily vexed at heing set to chopping wood or weeding the garden will work all the more swiftly and conergetically for his irritation. If this is the actual result, and not an ill-natured dallying over the task, he will be much better off at the elose than if he had sullierl and idled until exeused. "Emotion" and "motion" are words nearly related, and the conditions for which they stand should be related ats rosely.

The emotion of sympathy is one which we readily recognize as peruliarly exhausting to bear when it eamnot be translated into acts. "Iset us love not in worl, neither in tongue, lut in leed and in truth" - there is hygiene as well as humanity behind the injunetion. Sympathy with suffering may in many cases sulject the one who feck it to a forture more keen than that which has oecasioned it. Such viearious pain is not to be avolded altogether, but it is groatly alleviated when ono fincls something to do for the sufferer. How the useless torment of viewing dis- 
tress is replaced in the physician by the endeavor to relieve is set forth in the exquisite story of "Rab and his Friends" - "pity, as an emotion, ending in itself or, at best, in tears and a long-drawn breath, lessens, while pity as a motive is quickened, and gains power and purpose."

It was with similar ideas that James taught that the pleasure of the drama or the symphony concert ought to find its application in the better performance of one's work or the readier expression of kindness toward one's associates. The same may be said of the exaltation felt in the presence of beautiful natural scenes. This seems like ethical preaching, but it is none the less sound hygiene. In fact, the present age far more than any that has gone before understands the closeness of the parallel. The teaching with regard to emotion is, after all, just that of pedagogies, that it is not profitable to receive without giving back. Reaction is the law of the nervous system from first to last.

We have attempted to make the point that all emotion is exercise, and that, accordingly, emotion in moderate and reasonable variety is a source of general development; in short, of training. It will be well to show how women, far more frequently than men, are likely to suffer from the want of such stimulation. They often work by themselves and lack the spur of companionship during a large part of the day. Their friendships are seldom as warm and comforting as those between men. Many do not find time for the daily paper, and, with all its faults, the press causes its readers to visualize and in imagination to enter into the course of stirring events. The husband, who profits by the diversion of his newspaper, the little journey to and from his place of business, a more or less social. occupation, and a lively lunch party at noon, should not forget how colorless by contrast has been the day of the wife at home. More deliberate effort is necessary in her case than in his to bring in the needed elements of enthusiasm and interest. It is peculiarly unfortunate that so many women are denied the full benefit of the Sabbath 
though being required on that day to evolve the most claborate dimer of the week. The natural consequence of such restriction in scope for the emotional life is at first losis of ambition and later of endurance also.

A plea may be entered here for singing. We Americans atre too self-conscious to enter readily into this wholesome pleasure. It would do us good to imitate the Ciemuns and nulie singing a common feature of our gatherings. Even singing by one's self may be beneficial. The advantages derived are partly those of a general neuromusenlar exereise and in part connected with the rery marked and agreable cmotional reaction. People who sing, though it may be quite badly, are apt to have at ractive personalities. A chamming old minister who set the lighest value upon romgregational singing once said that the Seripture was draftere to inchude the least gifted individuals in the injunction to "make a joyful moise muto the Lord."

Camnon has assembled many of the facts concerning emotion in a novel and suggestive form. ${ }^{1}$ After emmerating the antonomic manifestations, so largely his own discoveries, he points ont that the regional distribution of these in the topography of the nervous system is distinet and curious. The outflow of impulses accompanying the majol enotions is concentrated in the thoracico-humbar or so-called sympathetic division. This department contains the fibers which command the dilation of the pupil, the sereretion of sweat, the addition of adrenalin to the blood, the development of goose-flesh, aceeleration of the heart, reduction of blood-flow in the digestive tract, and the inhibition of its artivity. Wr have noted that these changes prepare an animal for exertion. Even those which seem to have a negative character-as the anemia produced in the alimentaly canal-may he indirectly helpful, since they reinfores the cirroulation in the skeletal museles.

Now, there ale antonomic patlis which start from the ramial recrion and which ane, therefore, anterior to the sympathetic. The responses to stimulation of these 1. Imerisan Jommal of P'sychology, 1914, xxv, 256. 
paths are not familiarly recognized in the display of emotion. They include slowing of the heart, contraction of the pupils, salivation, and increased activity of the alimentary canal. They seem characteristic of periods of tranquillity rather than of excitement. Again, posterior to the sympathetic, we have the sacral autonomic. In the fibers comprised in this division are those which promote micturition, defecation, and sexual reactions. While the bladder and the rectum may fall under the disturbing influence of emotions, their normal actions are executed in the absence of agitating conditions.

Cannon's grand generalization is, accordingly, to the effect that the thoracico-lumbar autonomic has an "emergency function," and that it is employed in crises of rage, fear, and pain to give the animal the utmost command of its resources. The activities of the other autonomic mechanisms have to be held in abeyance at such times, and are carried on only when there is no external cause of distraction. It is urged that the autonomic accompaniments of all the major emotions are too nearly identical to differentiate them, and that this fact restricts and weakens the James-Lange theory. No condensed statement can do justice to the article referred to, which should be consulted.

A manifestation of emotion which is of minor importance, but which has attracted popular attention because of its picturesque aspects, is found in certain clisturbances of the electric equilibrium of the body. ${ }^{1}$ It is probably fair to claim that all physiologic processes are attended by quick shiftings of potential. These changes have been extensively studied in nerves, in muscles (including the heart), and in glands. They are of small magnitude and must be registered by delicate instruments. If the two hands are plunged into cups of salt solution which are connected through a sufficiently sensitive galvanometer, there will be evidence of electric instability. The rhythm 1911.

${ }^{1}$ Wells and Forbes, Archives of Psychology, New York, March, 
of the heart-hat will be reproduced by oseillations of the inclicator. Voluntary muscle contractions will displace it.

Now, if a series of words is spoken in the presence of the man whose liands are in circnit with the galvanometer, it is likely that at least a small excursion will follow a ach word. But some words will have much more power than others to give direction to his thoughts and to arouse his foelings. The swing of the gatvanometer will fathfully demonstrate the degree of the emotional response. 'Thus, if names of girls are repeated, the subject of the inquisitorial experiment may react to each stimulus by an appreciable sign, but he will pay tribute to the name of his fiancée by a striking movement of the recorder. These electric disturbances are not surely localized, but they testify to the involvement of contractile or secreting structures-perhaps of both-in the phenomena of emotion. 


\section{CHAPTER XIV}

\section{SLEEP}

ABout one-third of an average human life is passed in the familiar and yet mysterious state which we call sleep. From one point of view this scems a large inroad upon the period in which our consciousness has its exercise: a subtraction of twenty-five years from the life of one who lives to be seventy-five. Yet we know that the efficiency and comfort of the individual demand the surrender of all this precious time. It has often been said that sleep is a more imperative nceessity than food, and the claim seems to be well founded.

The writer once asked a psychologist how he would define sleep, and received the answer, "Why, it is nothing at all." It has been simply described as inattention. Both these characterizations turn upon the idea that sleep is a suspension of consciousness and ignore its physiologic features. Our own judgment as to whether we have been asleep or not is evidently based upon the same conception. If this is the whole story, no animal can be said to sleep unless we grant that it is conscious at other times. We readily recognize that sleep is more clearly a part of the lives of the higher animals than of those below them in the scale, but it is hard to set limits to its occurrence. All mammals and birds are assumed to sleep; probably the reptiles do, but we do not feel so sure about the frog or the fish.

It might be more rational to reverse the order of inquiry and, instead of asking how far down in the scale there is skeep, we might ask, at what level, as we ascend the scale, lo we find animals awake? Is not all life, below a certain stratum, somnambulistic? An idea much like this has 
been expresised by Thomson. It is, briefly, as follows: sleep becomes necessary at the same stage in development where there is the earliest entertaimment of conscious purposes. Animals which are never actuated by such purposes will not owerdo. Their motabolism, their waste, and repair will go on in a fairly even mamner, each output of encrgy being followed by a prompt subsidence of activity to permit recuperation. But as soon as there is any germ of will, any interest in the pursuit of an object, the organism will be spurred on until the compensatory change has to be of a profound and long-continued kind, and, moreover, has to abolish the entertainment of the conscious purpose while it is in progress.

While we camnot help emphasizing the relation of sleep to conscionsness, and, therefore, on the physiologic side, to the cerebrum, we are obliged to concede that other parts of the nervous system are involved. This is plain from the fact that decerel)rate hircls and mammals still exhibit an alternation of $t w o$ (onditions which have the outward aspect of sleeping and waking. The periodic depression is not confined to the cortex, though a slight change in the chenical condition of the cerebral gray matter would seem to be sufficient to produce the purely psychice experience of going to sleep.

Whaterer may be the essential condition of sleepe, it is farored hy the cessation of external stimukation and postponcel by the action of such disturbances. It is probably for this reason that most animak are disposed to sleep at night. This will most surely be the case with those which recerve a larese shate of their guiding impressions through the aye. Nomal man falls in this olass. His eyes are his most important receptors, but beasuse of his command of artificial lighting he is not compelled to submit tamely to the suggestion that he go to sleep at sundown. Ho has developed a curious habit of being active far into the night ancl sleeping far into the day, at least in the spring and smmenere of the temperate zone. This tendency may suggest a whimsical ritation of the first law 
of mechanies: "A body in motion continues in notion, a body at rest continues at rest, unless acted on by an external force."

The purposes served by sleep are plain. It is a state in which the local and general losses of the tissues, which have not been fully met as they have taken place, can be offset. Bodily rest without sleep gives an opportunity for such repair in the skeletal muscles, but not necessarily in the receptor system, and certainly not in the cerebrum. Even the skeletal nuscles are probably better rested in sleep than they can be otherwise, for their relaxation is more complete. As to the autonomic mechanisms, it is harder to determine how far they are granted a remission of activity during sleep. We have to bear in mind the fact that many of the autonomic influences are inhibitory in character, and the interruption of such currents would lead to an actual increase of activity in the organs reached by the nerve-fibers. No case of this kind is certainly known, but the principle helps us to understand how there may be no interference with digestion while an animal is sleeping, as it is likely to after eating heavily.

Many theories have been advanced to account for the passage from the waking to the sleeping state. It will be helpful to consider what conditions other than sleep commonly suspend consciousness. Two suggest themselves, the one mechanical and the other chemical. One is interference with the circulation in the brain, and the second is anesthesia by drugs carried through the medium of the blood. Though we may call the first a mechanical cause of unconsciousness, it is, doubtless, a chemical one at bottom, for lack of blood-supply must lead to chemical alterations in the neurons. Fainting is an instance of this action. The other type of influence may be illustrated by ether or chloroform narcosis, as well as by the coma of diabetes, where the acidity of the blood is the source of trouble. Normal sleep has sometimes been thought of as a swooning and sometimes as an anesthesia. When the former cause 
is assumed, we have an anemia therory; the alternative is a theory of toxemia.

The nightly rxperience of falling asloep does not very distinctly suggest fainting. But when the drowsiness is umusualy compelling and unwelcome, as when one nods in chureh, the resemblance does not appear so remote. The rapidity of the passage from clear consciousness to the realm of dreans or to oblivion favors the belief that a mechanical factor has operated to determine it. The most natural assumption is that a vasomotor change has taken place. Howell has pointed out that such a change may be due to fatigue of the vasomotor center. During our waking hours this part of the autononic system is required to respond to frequent and varying demands. Some of its duties have been indieated in an earlice chapter.

If the center is really subject to fatigue, we may suppose that it eventually becomes difficult to stimulate it sufficiently to maintain the normal arterial tone. If it lapses from its arerage condition, the blood-pressure will decline and the flow will proceed more slowly through the wirlened vessels. In the brain, encased as it is in a rigilly walled enclosure, the slow flow will be in vesseds which cannot materially widen. Hence, the brain supply will be reduced and the maintenance of its activities threatened. It remains possible in any ordinary case to sipur the renter to renewerl action, to raise the general presire, and so to drive the blood once more with an adequate velocity through the capillaries of the brain.

Drowsiness is the subjective sign of the slowing (irculation in the remobum. In fighting it off ons resorts instinctively to the employment of extronal stimulation. This is the object attained by taking a slightly uncomfortable position, hy rasing one's ryes to the light, and by moving parts of the body. The exchusion of stimuli, (onversoly, favors the relaxation of the vascular system.

1"Trext-book of Physiology," Fifth Edition, II. B. Saunders Co, Philadrlphia, 1913. 
When we court sleep we seek quiet and darkness. By lying down we reduce to a minimum the inflowing impulses from muscles, tendons, and joints. We avoid extremes of temperature. We interrupt, so far as we may, the more vivid trains of thought. Thus, in favorable cases, we withdraw from the vasomotor center the nerve-currents which prompt it to react upon the blood-vessels, and we are rewarded by a welcome change in the character of our consciousness, if not by its actual suspension.

The fact that one can be awakened at any time by stimuli supports the theory that the immediate cause of sleep is the slackening of the blood-flow through the brain. A state of general poisoning could not be done away with on the instant by the stimulation of afferent paths. Nevertheless, the acceptance of the vasomotor hypothesis leaves a place for the toxemia theories. It is the accumulation of chemical compounds, fatigue substances, in the body fluids and perhaps in the protoplasm itself that leads up to the central failure. We have, therefore, to distinguish between the cause of the approach of sleep, which is metabolic, and that of its onset, which is mechanical. It seems to be the distribution of the fatigue substances rather than their actual amount which makes sleep a pressing necessity. We know that we may be very tired and find sleep impossible.

When the ties between the outer world and the individual consciousness are severed as one sinks to sleep there is an interesting and fairly definite order in the process. Muscular control is lost before sensation; there is an interval of delicious relaxation of which one is pleasantly aware. Shortly the cutaneous sensibility is gone, while the knowledge of the position of the extremities lingers for a little. Under such circumstances one still realizes the posture, but not the contact with the bed. Havelock Ellis $^{1}$ has suggested that this apparent absence of any support may be explained by the dreaming consciousness as the experience of floating in space or of 1 "The World of Dreams," Houghton, Mifflin \& Co., Boston, 1911. 
falling, two very rommon impresisions. Hearing is the latest means of communication between the world without and the isolated mincl. It is likewise the first chamnel to be reopened as one is roused or wakes gradually from sleep.

The depth of sleep at different times in the course of the night has often been tested. In the trials most frequently referred to, the measurement was based on the loudness of the sound necessary to awaken the sleeper. All observers have agreed that the deepest sleep, as indicated by such methods, comes quite early, probably within the second hour, if not the first. Wo know that if we are awakened within this period the experience is one of violent subjective and bodily disturbance. The nervous shock is such as to make it hard to compose one's self again. It is a very different matter to be aroused from the later and shallower sleep; then the response to a call is easily obtained, but, unhappily, it is correspondingly easy to sink back to sleep.

After the first deep sleep there is a shoaling which is about as rapid as the previous subsidenee into the depths. Within three hours of the beginning a eondition is reached in which there is marked sensitiveness to stimulation. Opinions differ as regards the hater behavior of the nervous system. Areording to one set of data there is a gradual and progressive reduction of the depth of sleep during the threc or four additional hours of its continnance. Others have noted a second deepening toward morning. 'This last deseription appears to fit in with a great deal of individual experience; a wakeful time may be passed through about 5 o'chock, and it may be harder to get up) two hours liter than it would have been at dawn. A (ierman writer, aceepting the domble-peaked curve as mormal, has refored it to the impression made mpon the erenters when the infant woke one aach nimht to be forl. Little children who no longer wale at this time are apt to show a restless interval between two periods of heary slumber. 
On any theory we should expect to find, as in fact we do, that the greatest depth of sleep would be soon reached and passed. There should be a steady gain in the direction of the sweeping away of fatigue substances and a steady improvement in the capacity for reaction, which is what we measure when we induce waking. It does not follow that

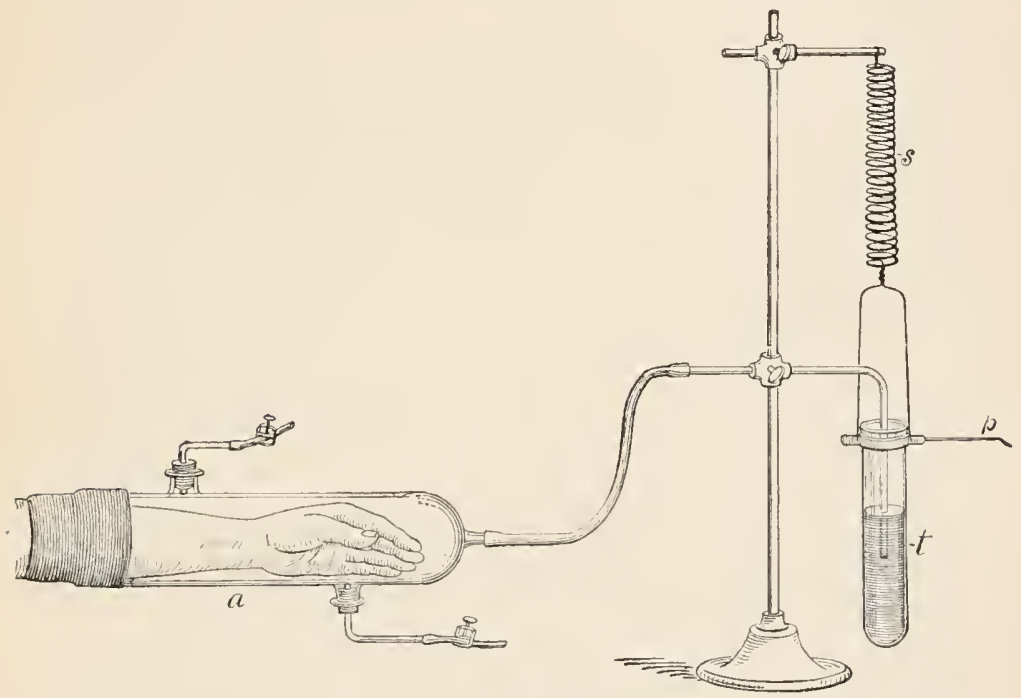

Fig. 24.-A sehematie diagram of Mosso's plethysmograph for the arms: $a$, The glass eylinder for the arm, with rubber sleeve and two tubulatures for filling with warm water; $s$, the spiral spring swinging the test-tube, $t$. The spring is so ealibrated that the level of the liquid in the test-tube above the arm remains unehanged as the tube is filled and emptied. The movements of the tube are recorded on a drum by the writing point, $p$. (Howell.)

the time passed in shallow sleep can be much shortened without detriment. The experiments cited show only that certain mechanisms require less than three hours to regain almost their full irritability; there are many more which may need a longer exemption from the remands of the waking state.

The vasomotor changes which mark the coming on of 
sleep and its departure have been demonstrated in the normal human being by an indirect, but sensitive, method. This is the use of the instrument known as the pletlysmograph (Fig. 24), which, in its usual form, is a glass cylinder designed to acemmodate the hand and forearn of the subject. A tight but comfortable rlosure at the end toward the elbow is secured and the whole is filled with water. A clelicate arge is comnected with the interior and any displacenent or drawing back of water is marle evident. A displacement must mean an increase in the volume of the arm and hand, a withdrawal must indicate a) shrinkage. Such changes in volume, when they occur at all rapidly, may be aseribed to changes in the amount of blood in the part. More gradual changes might be due to variations in the quantity of the lymph.

When a person scliools himself to go to sleep with his anm enclosed in a plethysmograph it is found that a marked dilation of the member occurs at about the time when the threshold is crosied. This testifies to a diminution of the tonic activity of the vasoconstrictor center. It has already been pointed out that such a slackening will result in a more sluggish cranial circulation. Hence it is inferred that when the record from the plethysmograpt show's a widening of the vessels in the am there is a simultaneous flagging of the blood-supply to the brain. When waking occurs there is a slarp contraction of the amm. It is very significant that extemal stimuli applied during sleep, but not sufficing to rouse the slecper, nevertheless anuse vasomotor responses. In the experiments directed ly Howell, he himself being the subject, the watcher at the berkide saw that occasional noises and viluations intermpting the quiet of the night registered themselves throngh the distincet narrowing of the vessols of the arm which they alleel forth. The reaction might le alcieribed as a therat of waking.

()n the sirle of hygiene there is munth to be said of sleep. Questions frecpurenty asked and not at all casy to answer are: How much sle(e) is lesest and low far do individuals 
differ in their requirement? How can one know whether enough sleep is taken? Is it possible to sleep too much? All these are related questions and all are important, but intelligent people will be likely to answer them in very different ways. We may attempt to deal with the last one first, and we will venture the assertion that it is possible to sleep more than is best. The fact that it is found difficult to get up in the morning is by no means a sure sign that more sleep should be taken. It may be only a sign of laziness. It is better to be guided by the evening feeling and particularly by the demand of the eyes for a release from their task.

The disciples of Horace Fletcher claim that one of the benefits realized when a low diet has been adopted is found in the fact that the hours of sleep may be shortened without making inroads upon health. The obvious suggestion is that a part of the sleep of average men is a coma, an avoidable intoxication, due to an excess of narcotizing substances absorbed from the burdened intestine. Whether this is a typic condition or not, it is probably exemplified by some heavy eaters. The picture of the carnivorous animal gorged with concentrated food and crawling away for a long sleep is familiar enough. Many young men and women who supposed that certain hours of sleep were necessary to their efficiency, have discovered, after marriage and the coming of children, that they are capable of much more work with much less sleep than they formerly believed.

With advancing age the need for sleep seems generally to diminish. In the Preacher's classic description the old person is said to "rise up at the voice of the bird." Many readers will recall the uneasy habits of the aged, who cannot lie peaceably in bed until the younger members of the family consider it time to get up, but are found bustling feebly about imaginary duties in the early hours of the morning. The nervous system in which the decomposition processes have become lessened in intensity has less need of the compensatory state. 
Is there any scientific basis for the old teaching, "Larly" to bed and early to rise"? It would seem at first as though slecp at one time should have as much virtue as at another. Still the ancient maxim may have a certain foundation. To be up early and to go "early to bed" means that the use of artificial light will be reduced to a minimum. It is not likely that any substitute for daylight an be found which will not impose a severer tax upon the eyes than does their natural form of stimulattion. Whaterer tires the eyes has a widespread and depressing influence upon the whole nervous system. Agrain, lying abed late in the morning has the disadvantage that the sleeper is likely to be affected by light and noises which may deprive his rest of some of its potency for good, even though they do not interrupt it.

Neuron Theories of Sleep.-We have regarded sleep as a state indured indirectly by fatigue substances acting upon the system and directly by the failure of an adequate eerebral circulation. Other aspects of the rondition may be selected for emphasis. All the facts of sleep might be explained by the conception of varying synaptic resistance. The cstablishing of gaps in the motor paths would remove the muscles from eentral control. Similar gaps anywhere along the paths which conduct impulses from the receptoris would cause sensory paralysis for the time. Thought, in the absence of the means of present guidance from the external world and deprived of the power to express itself through the neuromuscular mechanism, must be limited to a rehearsal of memories and should take on the character of dreaning. We should expeet that a further impaiment of intercourse among the varions regions of the cerebrum must suspend even this kind of psichic aretivity.

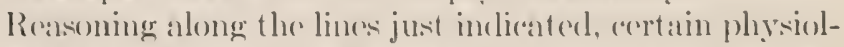
ogrists have pietured the passige from waking to sleeping as due to the interposition of extra resistance at the synapses. The idea was first expresied as a literal şnapping of comnections between the dischanging and receptive processes of the nemons, but this lats come to seem 
highly improbable. Still, the conception has a symbolic if not a literal value. We have seen in our general discussion of fatigue that the synapses may be regarded as links of low endurance, and this makes it reasonable to give them a place in our hypotheses of sleep.

It is curious to find that the idea that the junctions of the neurons may, in some sense, open and close has been used in two lines of speculation of a distinctly contrasted character. According to the more familiar view-already outlined-it is the breaking apart of the nervous units which paralyzes objective and subjective activity. Another theory, originating in Italy and not widely known here, makes precisely the contrary assumption, that sleep is the accompaniment of an extensive commingling of cell processes. The establishment of new connections between the neurons might explain the confusion and irrational combinations occurring in dreams. The general failure of reactions and, finally, of consciousness itself might be explained as due to a dissipation of the nervecurrents in so many paths that there should nowhere be any effective intensity. Waking, then, might be pictured as the resumption of intercourse among the neurons, or as the restriction of intercourse to the usual serviceable channels after a period of disorderly diffusion.

A mill is usually stopped by closing the gates and interrupting the stream that has been turning its whecls, but it could be stopped by opening sluices in the dam and diverting a large share of the water. The two possibilities correspond roughly with the neuron theories of sleep. Either a cessation or a scattering of impulses within the brain may conceivably result in unconsciousness. The second theory is better adapted to an explanation of dreams, a matter to which we must now turn. 


\section{CHAPTER XY}

\section{DREAMS}

Most people, even though they may be much interested in the achievements of science, will probably be found quite skeptical concerning the idea that dreams are worthy of any serious notice. In common judgment it is a weakness to think or talk much about the strange scenes we witness in sleep. This feeling is probably the result of cmancipation from the superstitious faith in the revealing virtue of dreams which was once universal. Tawdry books, purporting to give a basis for the interpretation of dreams and attaching an oceult significance to every (ommon object seen by the dreamer, are still cireulated. Howerer fanciful these publications may be, their purpose is not wholly unlike that of a rapidly increasing mass of sober scientific writing.

We cannot follow this subject far, but it would be unwise (6) omit all reference to dreaming, for it is fruitful of suggestions concerning hygiene. One of the most obvious has to do with the general content of the dream. Havelock Ellis' ${ }^{1}$ chasifies dreams as follows: (1) There are those which are determined by the bodily conditions existing at the moment; these may be ealled somatic, presentative dreams. (2) There are those which are shaped by stimuli areting from without; they may be alled external, presentative dreams. Other dreams are not clearly related to present ciremuntances, but are mosaies of memories. Ellis calls such dreams representative and subdivides them into two diswers, the recent and the remote. It is a matter of moment whether one's memory dreans are of the recent or the remote kind.

1 "The Work of Dreams," IIoughton, Mifflin \& Co., Boston, 1911. 
A man who is happy and not overtired, who is meeting his obligations with reasonable ease and success, is likely, when he goes to sleep, to encounter persons and scenes quite other than those he has lately known. Unexpectedness is the foremost quality of his dreaming experiences. If he is skilled in unravelling the composition when he reviews it after waking, he may be able to detect many of the sources and to convince himself that they belong to relatively distant periods in his career. It will usually be his impression that he has not been thinking at all of the matters which have been brought before him in lis dreams.

If he is seriously tired, anxious, and overwrought, he may be compelled to attend to visions of an entirely different class. Such a man may continue, in dreams, to pursue the interests of his daily life. The same problems which he had to face when waking confront him in his sleep. The chess-player who has finished a hard game shortly before going to bed may find the board again set before him and be forced to consider the possible results of each move through a long series. When he rouses himself he feels that he has not rested well. In the same way one in grief or fear may still entertain these feelings and ponder their causes while he sleeps. Now, all dreaming is partial insomnia, but there can be no question that it is better to be awake to novel and diverting thoughts than to find no release from the pressing concerns of one's routine existence. "Recent representative" dreams clearly constitute an unprofitable overtime performance on the part of some of the brain mechanisms.

The statement just made suggests that it may not be wholly whimsical to claim that dreams of the other (remote) order afford some of the elements of a vacation. The body does not find the same wholesome change of enviromment and exercise as though an actual outing were taken, but the purely mental content may be much the same. Dreams may be at least as beneficial as a moving-picture show, which, in fact, they greatly resemble. 
So long as they have the unexpected character, their occmrence does not seem to indicate that there is any failure to recuperate the powers of those nerve-complexes on which the strain of the ensuing day minst fall. It may be asserted that dromless sleep is the ideal, but we do not know surely that it is ever realized. People who say they never dream, more probably dream and forget. Wo know how uncertain at best is our recollection of most dreams. The inmersions seen to be alestroyed by the strong light of day as though they were images npon a photographic plate. Much as we have to develop our negatives in rooms dimly lighted by selected rays, we have to rehearse our dreams in the half-waking condition at dawn if we are to make them our permanent possession. This does not imply want of vividness in droums when they are first experienced; Ellis is apparently justified in his striking aphorism: "Dreams are real while they last; can we say more of life?"

The writer onee had oecasion to discover how rompletely a lapse of memory may create the impression that there has been unconscionsness. Nitrous oxid had been given for the extraction of two teeth. When he came to himsolf he told the dentist that he was much gratified by the cutire suecesis of the anesthesia. He left the office with the same feeling of satisfaction. On the street a few minutes later he recalled with appalling distinctness the pain of the second extraction. No impression of the first operation erer renmed. It is disquineting to think that one maty snffer severely and then report in good faith that one did not, but it is the same with dreaming.

The subject matter of dromms may be of considerable assistance in answering a very important question. A person who wakes dily after day with feelings of wouriness and incapacity may be cither indolent or tired. It is likely that the sensations are much the same in the two atses, and yod it is noresisaly that the two conditions shatl be distinguished. Clearly enongh, mischief will be done if one who is really fatigned and in need of more rest 
mercilessly condemms himself for laziness and redoubles his efforts to overcome the inertia. On the other hand, a man who is actually lazy and failing to make the most of himself may be led into habits of self-pity and selfindulgence by concluding that he is seriously tired. When face to face with this problem it is well to ask whether the dreams have been mostly of the recent or the remote type. If they have been filled with the cares of the day, there is good ground for assuming that cumulative nervous fatigue is developing. If they are recalled as fantastic, varied, and curious, the conclusion may be less welcome, but also less ominous.

As to dreams of the "presentative type" - those in which immediate circumstances connected with the body itself and sources of stimulation close at hand are concernedthe most interesting facts established are those with regard to symbolic depiction of the causative conditions. It is quite plain that the dreaming mind usually refers all its experiences to external affairs. It gives them an objective existence. Suppose, for example, that a man has an uncomfortably palpitating heart. When he is awake he is in no doubt of the actual nature of the case, but when he falls asleep and dreams, it is not to feel that his heart is rapid and irregular, but to view some scene suggestive of difficult action, it may be a horse struggling to draw a load up a hill or a laborer grappling with a heavy stone. The writer once lay thinking of the physiologic action of the heart as sleep drew near, and when the border-line was crossed he saw at once a huge pulleyblock. It was so good a symbol of a weight-raising device that he awoke with lively gratification.

According to the same principle, the victim of indigestion does not think while he dreams that he is suffering, but he becomes a witness of some spectacle of violence or horror. Dreams referable to distention of the bladder symbolize the real trouble in naïve and amusing ways. One who was in such a case thought that he turned on a faucet which did not run. The trivial dream perfectly 
figured the need that existed and the desirable inhibition that postponed its satisfaction, but the facts were made to appear as external to the dreamer's person. Thus we are constantly detaching portions of the self and treating them as separate objects of attention. Ellis has discerningly pointed out that this tendency is not entirely absent from the waking mind and that it may become a conspicuous one at times. This is particularly true when the temperament verges towarl the neurasthenic.

The unfortunate person who is mentally depressed is prone to charge upon others the faults which are his own. When he is quick tempered, he is convineed that they are impatient. Preciscly as the dreamer does, he fails to recognize that the matter which offends and outrages him is pat of himself. If he feels better for a while, he concludes that his housemates have become more thoughtful and kind. It is harder for him to recognize his own responsibility than it is for any of us to realize that the rising and setting of the sum are illusions due to the movement of our planet. It may be adkled that it is even more inportant to conquer the tendency to solf-deception in the first instance than in the second. The man who ean make the correct allowance for his own ups and downs while he sits in judgment on others hest deserves to be ronsidered aurake.

We are told by fertain writers of the present time that cheams are reliable sourees of information for the specialist regarding many facts of personal history and existing tendencies which the patient woukd prefer to hide. Dreams form a large share of the material nsed for diagnosis by the pryohanalysts. It woulel be presumptuous for a lay writer to criticize their principles, which have often been justified by the sucesss of their work. Neveltheless, it may be said that one who reads their expositions without special traming is likely to ronclude that psychanilysis is the art of putting the worst possible construction upon all that the subject thinks or dreams.

'Brill, "Psychanalysis," W. B. sam ders Co., Philadelphia, 1912. 
According to Freud and his school, sexual impulses are determinative in the shaping of most dreams. In the troubled consciousness of the dreamer there are present at once the current of desire and the sense of the restraint which is habitually imposed upon it. Both are disguised almost beyond recognition, for the dreaming mind is curiously disingenuous and indirect. The concealment is so effectual that the average reader does not readily accept the interpretations placed upon the dream imagery by the modern successors of Joseph and Daniel. It seems as though people of an introspective turn might do themselves serious injustice by applying too rigorously the Freudian ideas to self-examination.

For such there are certain consoling considerations. First of all, it may be stated that the relation between the waking and the dreaming life of a man who is approximately normal is one of contrast rather than one of resemblance. Therefore, if a man seems to display a tendency to cowardice, frivolity, deceit, or sensuality in his dreams, it may be hecause these evil traits have been decisively subordinated in his waking hours to their very opposites. It is only when the will is in abeyance that they can be brought to the fore. It is the best of us that goes to sleep most soundly, and if there is a shocking deficiency in generosity and renunciation in the apparent character of the dreamer, it may be that the instruments of these faculties are plunged into a narcosis which is the sign of their continuous exercise during the day. It is reasonable to suppose that in health the parts of the complex mechanism which are most employed while one is awake will be most profoundly restrained from action when sleep has come.

For similar reasons it is unjust to conclude from the unworthy impulses of a man in delirium that his previous life has been one of hypocrisy and duplicity. It may well be that he has been master of the situation until his fine powers have been temporarily dissipated. We must bear in mind that virtue does not consist in the inability 
to eonerive of misconduct, but rather in the strength to refrain from it and to "overome evil with good." This is eminently true of the sexual life, and, even if the elaims of Freud are fully aceepted, it cloes not follow that men need lose self-respect or become eynical regarding the high principles by which the lives of their associates are governed.

We have quoted the statement that sleep is inattention. By contrast, the state of complete waking may be regarded as one of attention, and, more precisely, of attention of the active order. Psychologists distinguish active from passive attention, the former requiring the voluntary selection of its objects and the removal of their competitors by a process of inhibition. Passive attention is that which is involuntarily vielded to stinuli which we are unable to ignore. This is alearly the ase when we dream; we are not able to follow up the features of the dream which interest us, but are compelled to shift our thought to other: which, in turn, elude onr scrutiny. Ellis has said that dreams have always the character of dissolving views. Objects which excite our curiosity persist in fading away and becoming overlaid by new ones seemingly mrelated to the first.

We have spoken chiefly of the part played in dreams by menories and bodily conditions. The special sense organs doubtless bear their part. This is true even of the eyes, which are soures of vague sensition even when elosed. It is believed by many, including Bergson, that the glinimering effert which anyone nay notice on shutting the cyes is quite influential in suggesting the scenery of dreams. It may be thought a very linited source for such elaborite phenomena, but, at Bergson points out, it is our habit when awake to fill in the details of what we see in seant outline. I)reams influeneed by sombds atre rather (ontmonom, and serve to raise interesting guestions as to whether wo recall our dreatus ats they artually orrurred or arrange their rontents in a new onder. 'To use an illustration from Ellis: A man cheams that he culists in 
the army, goes to the front, and is shot. He is awakened by the slamming of a door. It seems probable that the enlistment and the march to the field are theories to acrount for the report which really caused the whole train of thought, though it seemed to be its latest iten.

A dentist made the following experiment twice with the same results: While a patient was inhaling nitrous oxid the names of the stations on a local railroad line were repeated to him. When consciousness returned he was asked what he had dreamed. In each case the reply was, "I thought that I went on a long railroad journey and at last met with a terrible accident." One cannot doubt that the catastrophe was the dreamer's interpretation of the violent extraction of a tooth.

The dreaming state is one which usually has little or no motor expression. Ellis has called attention to the fact that in dreams we may either think that we move with extraordinary ease and speed, or we may have the sense of inability to command the muscles. Of course, the second state is one in which we have a more correct impression of the actual situation. The author eited thinks that it is always associated with shallow sleep when there are sensory signs of the immobility of the limbs. With deeper sleep these signs would disappear and the dreamer would not be deterred from imagining remarkable indulgences in locomotion and aviation.

The lack of brightness in the ocular sensations possible to one with closed eyes may account for the report commonly made that dream scenery is colorless and sober. This is not necessarily the case; the writer often experiences surprise and pleasure when, after a winter day, he finds that in his dream country the grass is brilliantly green, the sky intensely blue, and the sunshine as gokden as that of a Sorolla landscape. It is generally agreed that sensations of taste and smell are rarely noted in dreams. 


\section{CHAPTER XVI}

\section{CAUSES OF NERVOUS IMPAIRMENT}

When we look into the faces of men and women as we neet them on the street-cars we are painfully impresised with the widespread prevalence of ill health. The average expression is not one of comfort, hope, and good-will, but of depresion, anxiety, and absorption in self. The exceptional face which is radiant of strength and benevolence is conspicuous in the dreary succession. The temptation is to pass a larsh judgment upon those who seem so unhappy and infriendly and to condemn them for not being otherwise. Reflection convinces one that this is unjust. They are the victims of heredity, of malnutrition, of poverty, and, not seldom, of voluntary sacrifices. It is not for the casual spectator to say how far they are suffering from personal dereliction which should have been avoided. Whatever the past facts have been, the present diffienly with most of these people is imperfertion of nervors equipment.

A consilerable share of this may be charged to neurotic inheritance. Every one can think of families in which. nervous instability is exemplified in various forms by the different members. These are the families which are given to (fuareling and recrimination at home, but unite with even greater pugnacity against the ontsider who has incurred their elispleasure. They make themselves miscrable, but seem mable to help it. Where the taint is graver, there is dowmight neurasthenia. From such stock come certain individuals with marked talent, but hampered hy relf-conscionsness and exersive sensitiveness. The temperament is not a modern development, as commonly asimmel, but as old as the time of Plato, 
who is said to have described it with great precision and to have declared such persons to be "undesirable citizens" for his republic.

But the proportion of people who fall far below the normal in courage and perseverence, in kindliness and contentment is too large to allow us to say of every case that the inheritance was much to blame. We must pass on to the circumstances affecting the individual. These may be divided into those which are strictly physical and those which ean be described as unfortumate mental habits. Among the physical factors are some which are bodily and some which are environmental.

We may conveniently mention first disturbances of nutrition. The opinion is commonly held that many powerful personalities have been perverted by dyspepsia. This is said, for example, of Carlyle. Of course, it is hard in such instances to say which is cause and which is effect. The indigestion may be the result of the inefficiency of a nervous system in which pessimism is a congenital characteristic. This is a difficulty of interpretation which we constantly encounter in all discussions of this kind. But whether despondency and cynicism are primary or secondary, there is no reasonable doubt that when they are once established they continue to impair the digestive capacity, and the alimentary trouble tends to intensify the nervous deficiency. Thus, we have an illustration of what is known to physicians as a "vicious cycle."

The reaction of a disordered stomach and intestine upon the brain is not solely by means of nerve-impulses such as result in general sensation. It is now believed that the influence exerted is largely due to chemical products originating in abnormal fermentation processes in the canal. Entering the blood, these deleterious compounds are borne to all parts of the body, but they have an especially marked effect upon the central nervous system. The condition in which these poisons are circulated and become productive of mischief is spoken of as auto-intoxication. It is favored by overeating, especially 
of nitrogenous fooks (meats, ('ggss, and legumes). But it may develop also when the dict is scanty, for it has become clear in recent times that underfeeding may so enfecble the reactions of the organs of digestion that they lo not (are for the food so well as they would for a larger and more stimulating ration.

Auto-intoxication is frequently associated with anemia, and this condition-a diminution of the oxygen-carrying substanee in the blood-ahwas threatens injury to the nervous systen. It implies limited endurance in every pursuit. Just how the anemia of auto-intoxication is ratused is not always plain. In some eases it is probably due to the continuous formation in the intestine of a poison which is destructive to the red (orpuscles.

Among the bodily sources of nervous damage we do well to emphasize eye-strain. Attention has already been called to the primacy of the eye among the receptors through which the organism is stimulated. It follows that exessive use of the eyes or their employment under difficulties must be harmful in a ligh degree. A little space may be here devoted to a comparison of the eommon visual rleferets as eauses of central trouble. The nomml eye may be abused-as by reading with poor light or in situations where there is vibration (in the cars)-but it is of special importance to ciseuss the near-sighterl, the farsighted, and the astigmatic conditions.

Noar-sight is a defect ordinarily referable to too great depth of the ryoball. The effect upon the retinal image is the same that is produced in a camera when the distance between the lens and the plate is male greater than it should be for landscape work. The distant view beeomes blurred and indistinct, while oljecets at short range: are sharply dofined. So in the nestr-sighted eyo no clear pieture of the distanes is ohtaminble, but things close hy are seen with a minimm of effort. What is ealled the nomul cye is used without strain for observing things at a distance, and applied to near work with a certain sustained contraction of what is known as the aceommodation 
muscle. Moderate near-sightedness adapts one to read or sew with even less fatigue than if the eyes were strictly normal. Nevertheless, the condition has serious disadvantages.

If a child is at all near-sighted it may be predicted that the defect will grow graver during the period of school life. The actual nervous strain involved is slight, but the indirect results may be deplorable. The boy who cannot see well at a distance cuts a ludicrous figure in vigorous outdoor sport, and, being subjected to ridicule, abandons the attempt to take part in it. At first he is sensitive and aggrieved. Later he convinces himself that athletics are not worth while and he inclines to become a bookworm, with a serious lack of physical stamina. It is fortunate if he is not a conceited prig in the bargain.

Far-sight, so far as its cause is concerned, is the exact opposite of near-sight. The eyeball is not deep enough. A simple experiment with a camera will serve to show that such a relationship between lens and screen will result in a failure to focus anything sharply, though the distance will be better imaged than the foreground. By an effort such as one with normal vision makes to see objects near by, the far-sighted person secures clear vision for distance; to read or do other close work he must subject the accommodation muscle to an additional strain. Thus, his eyes are never at rest when they are being used at all. Yet he can see quite well anything to which he turns his attention, and it may be hard to make him accept the fact that he has a visual defect calling for glasses. Headaches, indigestion, and general nervous disturbances may result from this condition.

Regular astigmatism is an imperfection of the cornea or anterior surface of the eye. In the majority of cases the trouble is an excess of curvature up and down as compared with that from right to left. This has been well described as spoon-shaped cornea; in geometric terms this important refracting surface of the eye is ellipsoirl instead of spheric. The purely optical consequences 
need not be set forth; the word "astigmatism" means litcrally "not pointedness," and the reference is to the fact thist with surh curvatures a point outside can never be imlaged as a point upon the retina. Vision an never be sitisfactory, but at a given moment certain linear features of the scene will he clealer than others which have a different direction. The attempt to change the degree of arcommodation so as to have a better definition for the second set of lines results in sacrificing the sharpness of the first. Hence, there is a restless flutter of the accommodation meclanism, a perpetual attempt to gain a comprehensive view, which is destined always to be baffled.

The effects of common astigmatism upon health are much like those of far-sight. The glasses used to correct the deficiency must themselves be astigmatic, but in a sense opposite to that in the eyes to which they are added. They must have their least curvature in the mericlian in which the cornea has its greatest. The mounting of such lenses is evidently a matter of importance, for there is only one position in which they can fulfil their purpose.

Somnd heredity, successful nutrition, and eyes free from hurtful strain go far toward securing an efficient nervous systen, but we have ret other factors to reckon with. All bodily conditions which eause discomfort must be recarded as possible soures of central injury. It is probable, moreover, that many peripheral derangements which we think we can ignole or which may even have eseaped our recognition, may be productive of much harm. We have seen that this is true of far-sight. An eminent surgeom, C. IV. ("rile, has furnished striking evidence that this may be frequently a fart. The foundation of his exposition is the body of information we possess with respect to amesthesia.

When ether or chloroform is introduced into the blood and carried to the hrain there is an interruption of certain processes in the nourons which modifies or destroys consciollsulsis, but we have no warrant for assuming that

${ }^{1}$ Boston Merlical and surgical dournal, 1910, clxiii, s92. 
ordinary anesthesia suspends all the many eentral activities. In fact, we know that it does not, for it would be fatal if it did. The presumption is that certain synapses are much more easily affected than others, whence it follows that we can subdue cortical currents to a considerable extent without paralyzing the respiratory center. Now, it is the belief of Crile that when an operation is conchucted under ether or chloroform, streams of impulses ascend to the brain from the seat of the cutting and cauterizing. These would produce terrible pain in the conscious subject and reflex struggling of the most desperate intensity. In the actual case the pain is avoided and the reflexes are greatly reduced. But are we to suppose that the afferent impulses are wholly without effect upon the brain? Crile contends that they continue to work injury to the central gray matter even in the absence of consciousness and reflexes.

Experimental evidence has been secured by making microscopic studies of the brain tissue in animals which have undergone severe operations under the common anesthetics. Cellular changes are described which are of the same nature as those long held to denote profound fatigue. Such alterations are not seen in the brains of animals which have merely been etherized for a long time without operation. Hence, Crile refers them to the inflow of impulses from the parts that have been so powerfully stimulated.

All this may seem to be a technical digression, but we shall find that it opens certain considerations of the most practical kind. It will be noted that the central fact in Crile's thesis is this: Sensation does not constitute a reliable measure of the damage done to the nervous system by afferent currents. To disregard a source of such impulses is not to nullify their influence. It is ahways better to remove the cause than to seek to suppress the cerebral echo. Using a text like this, we may indict the principles of psychotherapy under any of its various names when it seeks to treat organic disease. It under- 
takes to abolish pain, and this it may do with surprising success. But this is a species of naleosis and earries with it no certain assurance that the nervous system is not to suffer progresive injury from the subconscions stimulation.

This critieism should not be lamnched without giving larger recognition to the usefulness of psychotherapeutic measures, even where the trouble is an organic one. Freedom from pain favors sleep and mutrition. Hence, it may casily prove to be the only condition which is needed to initiate a recovery. Again, the banishment of pain is always benefieent when the disease is incurable. But when the peripheral cause of distress can be corrected, it is always better to attend to it.

One can readily think of a rather large number of physical lesions which are apt to be tolerated or eren forgotten which are possible sources of injurions stimulation. Defective teeth afford an example. Many trombles asiociated with the feet, such as corns, broken arches, or even

- badly fitted shoes, belong in the same clissis. Nasal obstructions may have the same influcnece. Hemorrhoids and uterine displacements are more serious conditions and have a like tendency, only more obviously effective. Surgical operations for the relief of such conditions may hring about what is little less than a regeneration of the character of the individual. Among temporary canses of imperfortly realized nervoms strain may be mentioned the wearing of orthodontia appliances. Children obliged to submit to these instruments may not complain of great distress, but they are likely to be made irritable and tired by the constant wear and tear. An arlditional factor in some (ases is found in the loss of pleasure in eating which the appalatus is likely to entail.

A word of eriticism may be introduced leere regarding (omrent viows roncerning ventilation. The simple and stmmuary doetrine prevails that air camnot be bad unlest it is too warm. The odors hy which we msually gage the suceesis or failure of a system are lienlety treaterl. It is 
said that we soon cease to perceive them, and that, therefore, they do not signify anything of moment. Is this not a dangerous assumption? An odor is the sign of a chemical agent working upon the nervous system; we have no right to say that this agent has ceased to act when we have ccased to feel its immediate effects. Such a claim is equivalent to the assertion that nothing can influence a sleeper unless it wakes him.

Less attention is usually paid to the bodily sources of nervous impairment such as we have been discussing than to the influence of oceupation, surroundings, and the mental life. Nervous break-downs are most frequently attributed to overwork. But according to the judgment of the ablest specialists work in itself is not often the sole cause of these disasters. Work may be hard and fatiguing, but if it is congenial and at all successful, if it does not encroach upon the hours of sleep, and if it is not a subject of anxiety which the worker cannot easily dismiss, it is not likely to do him harm. If, on the other hand, the work involves worry and discouragement, if it so fills the mind that it cannot be put aside at will, it does become a menace to the poise and efficiency of the nervous system.

If work is of an unwelcome kind and is performed in a rebellious spirit, so much the worse for the subject. The question may be asked: What of the mill-operatives, with their monotonous and uninteresting tasks, are they particularly subject to nervous disease? One would at first say that they must be so, but there are certain factors which favor their protection against it.' They are not obliged to think of their work at all beyond the hours assigned to it. Unless they are doing piece-work they have no ambition to increase speed. Moreover-and this is a very important point-they do not have at short intervals to make choices between different duties which demand attention. There is a restful clement in having but one definite thing to do and being freed from the anxiety

${ }^{1}$ But see Goldmark, "Fatigue and Efficieney," New York Charities Publication Committee, 1912. 
lest some other minter shomld have had the precerlence. The sense of being presied by numerous eoneerns of nearly equal mrency is probably a root of much evil in the life of the "careful and troubled" housewife.

The elash of antipathetic personalities is a most serious element anong the (auses of nerve-fag. It is one which becomes steadily more potent for injury when a certain measure of fatigue has arrived, for added irritability means more and more grievous friction. It is a rare family in which the atmosphere is not improved by temporary separation of the house-mates. The entertaining of visitors scrves a good pupose when the guests absorb attention that would otherwise be bestowed exelusively upon members of the home eirele and in a critical spirit. It is a lamentable fact that in most families there is more restraint in speech and more consideration in conduct when outsiders are present; this suggests another valuable serviec rendered hy company. Neurasthenia is, in a certain sense, a contagious discase: one case fully developed may give rise to others, though the seconclary ones are ordinarily less severe.

Some one lass shrewdly pointed out that one fruitful soure of mischief in the nervous system consists in what may be suecinctly described as not minding one's own business. People easily fall into the habit of fretting over the beliefs and the behavior of their associates in matters in which individual liberty ought to be respected. Among the uneducited this results in the aftempt to dictate, and futile contention follows. Higher in the social seale a man or woman who (“ommits this error may not be so aggrexive, but will brood unh hippily over the principles or aletions held in such stronge (lisipporovil. It is much better not to be the "Drother's kecpere" moless the interest is clearly philanthropice. Why should a man distress himself becanse a fellow-being is fond of cherese, which he does not like? or goes to (hurell, which he does not wish to do? It is sound hygiene to live and let live. The world, indeed, neods reformers, but their task is one which calls for so 
much personal sacrifice that they should be sure the cause is worthy of the expenditure. A sense of humor is a saving grace for those in whom the impulse to regulate the lives of others is a powerful one.

Let us summarize the conditions we have named as helping to maintain the nervous system in a normal state and so to keep the individual happy and efficient. We have recognized that a sound inheritance goes far to secure this end. Any neurotic tendency of the stock is a handicap and makes it the more imperative that other unfavorable influences shall be avoided. Physical defects are to be corrected wherever possible, even though it may seem easy to put up with them. Environmental factors, such as fresh air, well-regulated illumination, and quiet for the hours of sleep, must receive attention. A moderate but not a harassing variety of. occupation and thought is to be recommended. And no responsibility which it is not clearly a duty to bear-no gratuitous anxiety-is to be assumed.

Sometimes people exhaust themselves in what is judged to be purely unselfish and sacrificing devotion. To such it may be necessary to say that future as well as present usefulness must be considered. The sum total of service that can be rendered to the family or other associates is likely to be greater when there is some deliberate sparing of one's self, some reservation of time for rest and recreation, than when the offering of labor and sympathy is absolutely unsparing. Of course, there are exceptional crises when any thought of self would be base, but, as a rule, the greatest contribution can be made by those who practise a wise conservation of their resources.

Reference must be made once more to the inestimable value of the Seventh Day for the preservation of the nervous system. The deepest degradation to which the Sabbath can be subjected is to fill it with odd jobs left over from the week's routine. The compulsions of Sunday should be from within, not from without. So far as possible the day should bring complete release from 
habitual petty cares and scope for the idealistic life. A certain parallel may be suggested between the renewing function of the Sabbath and the benefit to the eyes that proceeds from relaxing the muscle of accommodation. We necessarily bestow much of our attention upon objects close at hand and rapidly changing. We rest our eyes by looking away to the inountains with their unvirying outlines. So the nervous system, after making its swift adaptive changes to meet the inmumerable little exigencies of the six days, may well be permitted on the seventh to find a profoundly restful relation to "the things which are not seen." 


\section{CHAPTER XVII}

\section{NEURASTHENIA}

In the previous chapter we have attempted to catalog some of the factors which tend to subject the nervous system to gradually deepening injury. We have now to devote some space to the ways in which this injury is usually manifested. "Nervous fatigue," "nerve fag," "nervous prostration," "nervous exhaustion"-- these are expressions used to denote different degrees of a condition which is covered by the word "neurasthenia." It is an example of what is called a "functional disorder." By this term physicians characterize diseases in which no structural change in the tissues can be demonstrated postmortem. Ordinary neurasthenia is thus brought into contrast with those perversions of nervous reaction which are caused by obvious abnormalities of the brain-paralyses, manias, epilepsies, etc., due to hemorrhages, tumors, infections, and the like. The adjective organic is the one chosen to set over against the term "functional."

The distinction between functional and organic troubles is often a helpful one, but it may be criticized as unscientific. There is a medical maxim which says, "There is no psychosis without a neurosis," that is, the nervous system will not act in an abnormal way unless it is physically abnormal. All its disorders are, therefore, organic in the best sense, and a functional disease is a fiction. All that can be claimed for the so-called functional disturbances is that the derangement is chemical rather than structural, molecular rather than molar. It follows, however, that recovery is much more probable in the functional cases.

1 The word is often restricted to cases of a certain type. It is here used more inclusively, but in a way which does no violence to the root meaning. 
If a layman is to enter at all upon a theme which properly belongs to the practitioner, he should (ite the authority from which he draws most freely. The rhief soure' of the following alecount is Courtney's "The ('onculest of Nerves." I The book ean be commended to all who seck an analysis of neurasthenia at once scientific and sympathetic, with many same suggestions for its relief. The same author has contributed the section on the nervous system in Pyle's "Personal Hygiene," where a more condensed presentation of similar material may be found.

The nervous system seens to suffer from fatigue of two orders. First, there is that which may be called the claily type, from which complete recovery oceurs in the course of a night's sleep. This has been sufficiently discussed (sce ('hapter XII). Another type of fatigue is that which is cumulative from day to day, and which cannot be quickly rompensated. It results from the coexistence of some or all the factors mentioned in the last chapter, and when it is far enough developed it is recognized as neurasthenia. There is a single principle which proves to be the key to the problem: it is the fact that in nervous fatigue of the rentral order there is a large element of hypersensitiveness and consequent excessive activity.

We usually think of fatigue as a distinct depresion of capacity for action. This is true in a general way of the neuromuscular system, though even with the simplified conditions of laboratory trials it has been shown that a moklerate anount of contraction increases the working power of muscle. Lee has interpreted this as meaning that the metabolic prochets of the contratetile process, the sime compounds wheh in larger culuntities will limit the performanee of the merhanism, act at first as stimulants. This seens to be much more distinctly the ease with the netrons of the brain and cord.

We can often observe in people tired hy a day of excitement-perhaps of sightsecong-that there is an appear-

${ }^{1}$ Macmillan, New York, 1911.

2IV. B. Saundrers Co., Philadelphia. 
ance of stimulation. They are talkative and demonstrative. They laugh easily and with abandon. Their state suggests a mild intoxication. It may be that the condition is more like an intoxication than we should be inclined to think. We account for the garrulity of banqueters by saying that the alcohol has acted as a narcotic, selecting the inhibitory centers for its primary action and so giving the outward and subjective signs of stimulation. The influence of the fatigue substances upon the brain may be much like this. Whether the secret of the influence consists in a general stimulation or in the withdrawal of desirable inhibitions, the obvious result is augmented activity.

Once before we have alluded to the fact that the tired nervous system craves employment, though it needs repose. Many people will appreciate the following instance cited by J. J. Putnam: An overwrought woman had appealed to an old physician for advice. He had told her that she must rest. Her reply was that she did not feel tired and could not bring herself to be still. "Madam," said the doctor, "you will have to lie down until you are tired and then rest." A hyperexcitability like this is unhappily common in children, who nowadays have less training in the exercise of inhibition than fell to the lot of earlier generations. We may now go on to see how consistently the neurasthenic exemplifies this heightened nervous activity in every department of his organization. It is easy to recognize that a vicious cycle is involved, the overaction intensifying the fatigue and yet failing to bring automatic relaxation.

Guided by Courtney, we shall consider the signs of neurasthenia as they appear in four realms. These are: (1) The motor mechanism, (2) the sensory equipment, (3) the autonomic or visceral field, and (4) the temperament. The connections of all these are such that disturbances in one must be expected to overflow upon the others. The reflex principle makes this inevitable. In order that an organism shall be properly adjusted to 
its normal enviromment its central nervous system must lave a mechum degree of resistance to the transmiscion of impulses. If the resistance is raised, as by anestlesiat, the result is too great inertia; if the resistance is unduly lowered, there are wasteful and exhausting reactions in response to stimuli which might as well have failed to produce any discharge of energy.

1. In the realm of the skeletal muscles nervous fatigue expresses itself in the familiar form of restlessness. The victim has less than his usual endurance and may be consciously tired by his own umprofitable activity, but he ramnot keep still. He crosses and unerosses his legs, fumbles with his watch-chain, twirk his moustache, wallis about aimlessly, and tries one chair after another. Courtney has acutely noted the predilection of the neurasthenic for rockers, which give an outlet to his uneasiness. In some sanitariums the trouble is attacked along this line; hard and simple manuil work is prescribed and pushed to the point of weariness, that primitive exhaustion which is pleasant by contrast with the other and which brings sleep as its reward.

2. The sensoly symptoms are just what we might expect if the central characteristic is one of lowered resistance. Stimuli which are not noticed by one in health are felt unpleasantly, and sensations reaclily ignored by the normal man become torment. This is true for the cutaneous sensations; the neurasthenic is dissatisfied with the feeling of his clothes and his bed. He is morbilly sensitive to changes of temperature. When other's would say merely that the room had grown a trifle wam, he says that it is unbearably loot. When it is really a little cooler than is idcal, he feek thoroughly rhilled. He is much affecterl hy all changes of weather and may conceive an aversion for erertain wincls, proving his kermuess of jurlgment by ammouncing carle chatnge.

The eyes shate the general stlpersensitiveness. Strong light is objerefomable and the shrmking from it may grow into photophobia. The after-inmeres, those spots of rom- 
plementary color which anyone may observe after looking fixedly at bright objects, become persistent and disquieting. The entoptic appearances, the shreds and spots in the humors of the eye and the twinkling corpuseles in the capillaries of the retina, obtrude themselves upon the attention. Johannes Müller was at one time greatly distressed by the loss of the power to exclude these things from his consciousness. They may be seized upon as symptoms of ocular or brain disease.

As it is with the eye, so it is with the ear. Sounds become wearisome; sometimes the loud ones are particularly irritating, so that the subject camnot bear to hear children at play, sometimes the greatest annoyance proceeds rather from slight and repeated noises, like the ticking of a clock or the gnawing of a mouse within the bedroom wall. Olfactory stimuli may have an intensified effect and the detestation of certain odors may seem unreasonable. The sensory relations of the neurasthenic should serve to make clear to a well person how desirable it is to be protected against so many of these possible sources of discomfort by the height of the normal "threshold." The same external forces assail the vigorous and the weakened subjects alike, but the sufferer from nervous fatigue is like a man without a cuticle-everything is felt too keenly.

3. As the admission of impulses into the central fabric is too free, so the outpouring that follows is too profuse. We have seen how this is expressed through the neuromuscular system as unrest. We have now to turn to the autonomic system. Impulses sent out over the paths of this system may have either inhibitory or excitatory effects. We find evidence of their action upon the heart, the blood-vessels, the digestive tract, the genito-urinary organs, and the sweat-glands. The list might readily be extended to include still other responding elements.

Heart symptoms in the neurasthenic are common. They may be due in part to the direct flow of impulses of undesirable intensity from the medulla to the organ; they 
are very likely to be angmented by reflex influences from a disordered alimentary canal. Irregularities of the heart-beats are likely to be noticed and there are uneasy sensations of abnormal mobility about the heart, feelings "as though it turned over," ete. The acerleration during muscular activity may seem greater than it should be and the vietim may become fearful of local organic defects. Along with the cardiac misbehnvior there will probably be vasomotor instability. It is the duty of the vasomotor system to maintain a proper and nearly steady arterial pressure. Failure to do this may result in feclings of faintness and vertigo, perhaps, at other times, in headache.

To the perverted action of the vasomotor system we may ascribe the exaggerated judgments of warmth and cold already mentioned. If the nervous mechanism is in such a "hair-trigger" condition that a slight rise of the external temperature eatses an intense flushing of the skin, while a slight depresion renders it anemie, these impressions are to be expected. It is to be remembered that the temperature which we feel is that of the skin and not that of the air. The waxingsand waning of the cutaneous blood-flow will have ats much to do with the sensation as the state of the air outside. In the neurasthenic the vasomotor ehanges which aceompany emotion are excesive. Extraorlinary outbrealis of perspiration are frequent.

The symptoms arising from the functional derangement of the almentary canal are of expecial importance. It wats stated in an earlicer rhapter that this essential system lats surele a regres of automaticity that in many ases it might work better with no intereourse with the lomin and corel than it is actually observerl to do. Foster speaks of the improvenent of digestive eapacity often noted in the aned. As the nerve-enters become less dominant the stomach and infestino do their duty in a more reliable mamner than they did under more constant regulation, and the former ilyspeptic "eats with the rourage and suceess of a boy." In view of such facts we can under- 
stand that the organs of digestion in the neurasthenic are suffering from too much intermeddling.

The central influence is so largely inhibitory that the chief effect may be characterized as a general retardation of the activities of the tract. This includes a loss of positiveness in movement and a withholding of secretions. The stomach retains its contents longer than it should, and instead of being acted upon by a strong and antiseptic gastric juice, they are fermented by micro-organisms. What happens in the stomach is continued with minor variations in the intestine. The extensive decomposition may well give rise to definitely poisonous bodies and so to auto-intoxication, which is thus both a cause and an effect of neurasthenia. Another annoying result of the fermentation is the voluminous production of gas. This feature of nervous prostration is so marked that some physicians have thought that the quantity of the gas could not all be due to bacterial action. They have considered whether it might not come in part from an actual secretion of carbon dioxid from the blood into the tract. At any rate, it becomes a source of discomfort, even of sharp pain, while the distention is likely to occasion reflex disturbances of heart action. The picture is a familiar one, particularly in the country, where there is less thought for appearances - the sallow, angular dyspeptic, with frequent sighs and yawns and noisy belching of gas.

With deficient tone and peristalsis, constipation is to be anticipated. It may be extreme and is a matter much brooded over by the sufferer. He may be much given to experimenting with cathartics and enemata. On the other hand, constipation may actually exist and yet be unrecognized, for, if there are massive accumulations in the colon which the relaxed muscles fail to displace, the local irritation may set up a catarrhal condition with liquid discharges made urgent by the ever-present gas and simulating diarrhea. There are two places in the large intestine where fecal retention is likely and which may become the seat of pain. One is near the spleen 


\section{THE NERVOCS SISTEM AND ITS CONSERYATION}

(close to the lower ribs on the left sicke) and the other is at the sigmoid flexure lower down on the same side. Severe pain is said to arise from the overloaded sigmoid and to be referred to the left groin and hip-joint.

These various pains are not readily attributed by the neurasthenic to their ignoble and commonplace cause. He is half-anxious to find grounds for the belief that he is suffering from a mortal discase, and he prefers the irleat of a cancer to constipation of nervous origin. Courtney says incisively that his fears lead only to an anticlimaxhe is very likely to develop hemorrhoids.

The genito-urinary tract does not escape the influences of the overactive centers. The concentration of the urine varies in an erratic way between extremes. When it is seanty and high colored, depositing sediment on standing, the subject may diagnose his case as Bright's (lisease. If, a little later, it becomes pale and profuse, he may decide that he has diabetes. There is plenty of pernicious arbertising matier to confirm any of his conchusions. The bladker is likely to be irritable and micturition frequent. The reactions of the reproductive organs come in for a share of anxious surveillance, especially in the youmg. Here, even more than with the kirheys, the insidions suggestions of quacks sent broadeast in their repulsive literature may stimulate agonies of fear.

4. Many entimpses of the subjective state in neurasthenia have already been afforded. It is one of egotism, disregard of others, and self-pity. We have most of us reason to eherish memories of men and women who have gone with splendid heroism and unselfishness through sessons of suffering and eren to death. Ire know of sainted invalids. But these ases which move us so deeply to reverent atdmiration are the ones in which the nervous system in its higher parts has been left relatively mustulhed. When it is disordered we an no more expect an exhibition of fine and strong charatefer than we can cxpect beatiful music from an instrument which is altogerther ont of tune. The neurasthenic is not his best self. 
When this is said, the question arises, Is there a sharp line between the temporary warping of disposition that we see in the neurasthenic and the irresponsibility of definite insanity? A recent writer has set a standard which is an attractive one if we can be wise enough to apply it rightly. It is this: The neurasthenic differs from the psychasthenic, as we may call the graver defective, in the fact that he fabricates nothing, but merely exaggerates and distorts. There is some foundation for all his complaints. $\mathrm{He}$ is not insane until he is in touch with things which have no existence for other people. Fortunately, in the vast majority of cases, he is destined to recover his poise and not to cross the sinister boundary.

There are few things more difficult than to deal humanely and yet firmly and consistently with neurasthenia. A tolerant and even mind is called for-one that shall possess all the temperance and perspective which for the time being are so sadly wanting in the patient. The most cruel anguish which must be endured is in experiencing the enfeeblement of affection which has overtaken the stricken husband or wife. Cutting words from the once loyal companion, bitterness that would never be exhibited to a stranger, must be borne without remonstrance. The superiority of the sanitarium to the home in most cases may be traced to the usual failure to live up to such exactions. In the institution some restraint is imposed upon the patient by the strangeness of his contacts, while the trained attendants maintain a uniform attitude instead of alternating between caresses and angry argument.

It must not be forgotten that the suffering described by the neurasthenic is as real as any that life brings. It merits sympathy. Yet the free expression of much sympathy sinks the victim in deeper despondency and encourages him to invent new theories to account for his misery. It also makes his future appear darker than ever. Even the most earnestly phrased sympathy will not seem adequate to the pity-consuming neurasthenic. He remains skeptical as to the possibility that anyone can really appre- 
ciate his woe. He is likely to wish that his friend might feel just what he feels, showing in this the marked contrast between his own state and that of the sufferer with rhemmatism or tubereulosis, who is glad that others are well if he eammot be.

The studied withholding of sympathy from neurasthenic's has often had remarkable results. It is doubtless practised in many sanitariums, and there is one institution in particular in which it is a chief measure of treatment. The broken-down business man who comes to this resort does not wait long before he attempts to set forth his tale of hopeless suffering, but each attendant cuts short his expatiating with brusque or jocular rejoinders. The spirit of the neurasthenic is deeply womnded and, at first, his self-pity is intensified. Perhaps he casts himself upon his bed and weeps in his desolation, tuming his face to the wall like the undisciplined Hebrew ling.

If we bear in mincl that the central fact in neurasthenia is excess of nervous activity, we shall foresee that correction must come from inhibition. Now, one of the first steps towarl the attainment of self-rontrol is taken when the patient becomes assured that he eamnot obtain the sympathetic response which he so greatly raves, and begins to hold his tongue. Another reaction which is sometimes beneficial is the provocation of the invalid to anger. At the sanitarimm referred to, the larsh attitude maintained by the attendants leads readily to the loss of temper on the part of the sufferer. If he forgets himself so far as to lay hands mpon his nurse, he is vigorously handled. Insulted and humiliated, he deseends to the uttermost depths after such a pasiage at amms. But if the experienee is repeated at intervals, the regular habits and general hygienic conduct of the institution having their effect in the meantime, the emotion of anger gradually eomes to bring with it a sense of power instead of impotence. The return of self-relianes and self-government is said to be splendid to witness. If a diyy annes when the convalesent demonstrates that he an put his tormentor ont into the corriclor, 
he rejoices with a liveliness that he had never expected to realize again.

Plainly, this systematic piquing of the nervous invalid to restore both the capacity for inhibition and for vigorous performance cannot be practised successfully upon those who have organic disorders as an important element of their condition. Medical or surgical treatment is appropriate in all such cases. Attractive meals and acceptable forms of recreation are of great importance. Courtney protests against the common error of sending neurasthenics into the country, where they find a degree of stagnation that is as distressing to them as the excess of action from which it is planned to have them escape. A medium condition is to be chosen, in which both the sense of pressure and the sense of enforced idleness may be avoided. If the patient is willing to be lazy for a while, this is very fortunate, but it is more likely that he will demand some variety of interests.

Exereise is a definite need of the neurasthenic, but it is desirable that it shall be interesting and not merely mechanical. Courtney recommends hunting, because it is so well calculated to take one out of self and fix the attention on the world outside. The more the mind can be made to concern itself with the messages of the special sense organs, the less it can dwell upon the misbehavior of the body. Much may be said in favor of walking in mild or incipient cases. Long tramps in the country are not quite so refreshing as they were before the automobiles filled the roads with dust and stenches and woke the echoes with their raucous and insulting horns, but it is still possible to choose routes over byways which are rarely invaded by motor cars. The most stimulating element in a walk is novelty. The country should not be well known to the walker. He will then have a delightful series of surprises as the unexpected landscapes open to his view, broad prospects from the hill-tops and glimpses of rushing brooks in shaded valleys.

A vigorous walk of a hundred miles in four days taken 
when one lats reengnized signs of nervous fatigue will often exert a prolonged and favorable influence on one's condition. It is hard to find a congenial companion for such an excursion, and on some aceounts it is not a bad plan to go alone. There ean then be no clash of wishes, and it may be profoundly restful not to be obliged to talk. The gentle mental stirring which attends the uneertainty regarding the course and ending of each stage is exceedingly wholesome. Equally so on the physical side is the profuse outpuring of perspiration and the compensatory water drinking. Village hotels rather than farmhouses are to be recommended as stopping-places. They do not impose the obligation of sociability upon the tired wayfarer and they usually offer him the luxury of a hot bath.

Sea-voyages are often beneficial to those who lack rigor for more active recreation. There is hardly another situation in which individual responsibility is so successfully annulled and one's fortumes so absolutely committed to others. But the life on shipboard does not appeal to all temperaments. The scenic aspect of the ocean presents abundant variety to the observer who loves it, but another fincls it monotonous.

We have previonsly maintained that intellectual interests ought to make for stability of nervous organization. It should now be elear that what the neurasthenic most lacks is sense of proportion. His own concerns are magnified unduly, and the present cireumstances are allowed too greatly to outweigh those which have obtained in the past and may retum in the future. It is a mark of mental soundness to be able to overrule such a tendency. If a mam passing through temporary troubles am live orer the happier erents of an carlier time, and can realize the prob)ability that they will again be realized, he is sustained by these ties as the Alpone tomrist is held safe hy the other members of his party.

Sone knowlerlge of secence is well caleulated to fortify one agininst rgotism, It is hard to see how anyone who possesses the scientist's grasp of time and space ean fall 
into the habit of overemphasizing his own importance to the universe. Yet he should not think meanly of himself. The poise that springs from having a scientific perspective is compounded of belief in the value of individual effort and the restful conviction that when such effort flags through weariness the creative currents of nature flow on in other channels.

This comes very near to religion, at least to Matthew Arnold's faith in "a power not ourselves that makes for righteousness." This has been called the irreducible minimum of religion. For the vast majority of mankind the philosophic belief is not a commanding motive until it is warmed with an infusion of devotion and personality. But whatever the clothing of the central idea, its inestimable power to sustain health and efficiency has been recognized in every age. At the present time it is familiarly associated with Christian Science.

To an outsider the leadership of this cult appears dominecring and mercenary. The adherents seem utterly inconsistent. We see them yielding to hunger, fatigue, cold, and heat. They grow old, sicken, and die. Yet we may not doubt that they maintain on their course an exceptionally high average condition. If a touch of fanaticism encourages them in the belief that the same achievements are denied to those who hold other creeds, we can understand that this very defect is a source of positiveness and conviction. Bigotry is better for man than indifference, though we may well seek to combine earnestness with generosity and tolerance. 


\section{CHAPTER XYIII}

\section{SOME MATTERS OF GENERAL HYGIENE}

IT will be well to supplement the suggestions already made with some others that do not readily find their place mader the titles of previous chapters. Emphasis has been placed on the fact that all that favors the well-being of the nervous system goes to support the general health. But there is danger of a one-sided view if the opposite assertion is not admitted; namely, that all that ministers to the other systems helps to preserve the nervons mechanism.

Five heads may be suggested which shall fairly cover the requirements of hygiene. These are: (1) A sound inheritance, (2) successful nutrition, (3) suitably varied activity in all departments of organization, (4) rest properly adjusted to the foregoing, and (5) a wholesome environment. When we eonsider the kast-named subject we find that it covers some matters for which the individual is responsible and some which rest upon the community. Sufficient attention has already been bestowed upon some of these topies; others may now be granted a little space.

The teachings of modern science concerning heredity may have confused the thinking of some intelligent readers, and it may be worth while to venture a few comments. The widespread intorest in eugenies makes people who are intellectually honest anxious to be rightly informed as to how far they cam influence the physical and mental estate of their children. The average man will probably be fomd to have a very definite betief in this comnection. He thinks that his moral victories secure stamina in the offspring, and that his lapses woaken his progeny. He is likely to think that athletic training on his part will endow his son with a superior musculature. 
Similarly, he may assume that scholarly achievements of his own will make similar attainments easier for his children.

When a man holding views like these first hears that scientists generally deny "the inheritance of acquired characters" he is likely to feel that his moral responsibility has been gravely impaired. The immediate impression is that conduct is without significance in heredity, and that a very strong and noble motive for self-restraint has been abolished. Reflection will convince one that such impressions are not wholly warranted. One's obligations are scarcely impaired.

In the first place, there are at least two consequences of transgression which are still believed to pass on from father to son. Syphilis is one of these. The other is the complex of effects induced by alcoholism. Therefore, deterrents from the two commonest forms of intemperance remain in full force. Gonorrhea is not strictly inherited, but the peril of infection at birth and the inclusion of the wife in the calamity leave every possible ground for continence unshaken.

It may now be pointed out that in matters less specific than these the individual may still have reason to consider carefully what manner of life he has led when he contemplates parenthood. His acts may not have modified the stock, but we now regard them as illustrating its properties. These properties are regarded as having great stability. The son resembles the father not because of certain acts which the father performed, but because the inheritance common to both makes them likely to behave in a similar way under similar circumstances. Some one has expressed the fact picturesquely by saying that "the son is not a chip of the old block, but father and son are both chips of the same old block"-the immemorial ancestry which they share.

This being the case, a man reviewing his career and having in mind the probable future of his children may reason somewhat as follows: "My indulgences and my denials 
have searcely affected the capacities of the stock. But my indulgences have exhibited its inherent weaknesses and my self-restraint has shown its strength. My failures are ominous and my victories reassuring, for the like are to be expected in the life of my son." The grave and final question is whether the stock onght, on the whole, to be perpetuated. This is complicated by the consideration that the son will owe half his inheritance to the mother. "He is his father's half-brother by a different mother." While it is fair to give due weight to this fact, it is likely that many men have trusted too frecly to the maternal stock to neutralize their shorteomings. ${ }^{1}$

The data of eugenies are easily subjected to ridicule, while, at the other extreme, too much may be expected from the new science. We can already see that at least one valuable service may be rendered by it. The workers in this field are showing that hereditary defects are of two classes, those due to lack and those dne to positive features of the germ plasm. A lack can be made good by proper mating; a positive property will taint the offspring whatever partner may have been secured, and so can never be neutralized. It is agreeable to find that the majority of abnomalities are deficiencies, and theoretically (ain be bred out of the race instead of being allowed to die ont. Practically, however, the strong and efficient can hardly be expected to forego mating with their equals to redeem the weaker stodis.

Since reference has been made above to the damage done by alcohol, we may pursue the subject further and say something of its individual as well as its hereditary results. Two opposing views of the general problem are maintainerl. Most writers assume that alcohol is a chief ranse of degeneratey. On the other hamel, it is ingenionsty maintained that the indulgence is as much a sign as a (anuse of the conditions: with which it is assonelated. According to this conception, a drunkard is a man who would

1 Jordan, "The Heredity of Richard Roe," The American Unitarian Association, Boston, 1911. 
have been a worthless fellow even if he had never discovered the consolations of liquor. This we can readily grant for eertain cases, but we can think of others where we feel sure that nothing but alcoholic intemperance has stood in the way of useful or even brilliant attainment.

One thing which we do not much like to remember is that none of us are many generations removed from ancestors who were frequently intoxicated. Only the Mahometan can claim that his case is otherwise. Reid Hunt, comparing the toxicity of grain alcohol and wood alcohol as determined upon the lower animals, found that while wood alcohol is more poisonous than the other the difference is much less than for man. His suggestion is that the human race is habituated to grain alcohol by ages of drinking. It has never gained any such tolerance for wood alcohol largely because it has not often employed it as a beverage.

Keeping the welfare of the nervous system in the foreground, let us consider the action of alcohol as experienced by those who take it very moderately. It is popularly held to be a stimulant, and the claim has a measure of scientific support. But most students emphasize its depressant property, pointing out-what has been said elsewhere - that to depress the inhibitory centers is to "take off the brakes" and to create an appearance of stimulation. The most impressive articles that have been written in defense of the retention of alcohol have come from writers who did not recommend it as a stimulant, but as a means of promoting mental relaxation and social ease. It is disquieting to the advocate of total abstinence to find that the great majority of the most original and, on the whole, the most admirable men have valued alcohol as a social reagent. It begins to seem as though a reaction were setting in, but it will evidently be a long time before the representative gatherings of leaders in politics, letters, and even in education will forego their wines without complaint.

The temperamental change induced by alcohol in 
moderate quantities is highly characteristic. It may be described as intellectual myopia, a condition in which all that is near at hand-the present company and the inter('sts of the hour-will be found dominant, and all that is remote from these will tend to be exchuled. Thus, the cares that weighed upon the banqueter before he came to the feast and the problems he must face next morning are forgotten. We have insisted that this detachment is most desirable and hygienie. But the ideal is to compass it at will without the employment of a chemical artifice. One who can relinquish care as a voluntary act can take it up again promptly and earnestly. The banishment of obligation by aleohol does not permit the same decisive resumption of responsibility. It is well for the man who is heact of a family, when he reviows some eomvivial oecasion, to ask himself whether the wife and rhildren at home did not recede farther from the forefront of his' ('onsciousness than he would have chosen to have them. Perhaps the bachelor need not be so exacting in his introspective judgment.

It seens wellnigh impossible to write without bias of the social use of alcohol. Those who uphold it charge their (opponents with a want of charity and with a disposition to demand needless remunciations of pleasure. They would probably assert that the typieal moderate drinker is a kindlier man than the typical abstainer and that he is not less efficient. To be quite just to those who maintain this position one should read the pleas of such writers as Holmes, Münsterbere, and Heinemann.'

If it is a difficult matter to pass judgment upon those who use alcohol, what shall be said of caffein, the active principle of tra and coffer? This is an agent which we sometimes hear unsparingly condemued, but most vigorously by those who have substitutes to offer. Many

"Holnes, "The Autorrat of the Breakfast Table," Riverside Elition, Joughton, Mifllin \& (oo., Boston, p. 1 s it seq. Münsterbere, "Americin Problems from thre Point of Viow of a l'syehologist," Meffat, lard \& Co., New lork, 19I0. Heinemann, "The Rule of Not 'Tor Much," Chicago, 1912. For counter-arguments, ece Crooker, "Shall I Drink"?" The P'ilgrim l'ress, Boston, 1914. 


\section{1}

SOME MATTERS OF GENERAL HYGIENE

experimental studies have consistently shown that caffein is a true stimulant, actually increasing the capacity for muscular and mental work. The advisability of resorting to a stimulant must depend largety upon the extent of the after-effect and upon possible cumulative injury.

A most painstaking investigation of the properties of caffein was reported recently by Hollingworth. ${ }^{1}$ It was conducted upon a considerable scale, a staff of 7 trained workers gathering data from 16 subjects (of whom 10 were men and 6 women). In all trials of this kind it is necessary to keep the subjects in ignorance of the times at which they receive the drug to be tested. Hollingworth gave them at intervals gelatin capsules many of which were blanks, while others contained measured doses of caffein. The heaviest dose equalled the quantity in two large cups of coffee. Ingenious tests were made as a matter of daily routine, whether the caffein was given or not. Speed, dexterity, discrimination, and mental alertness were observed.

The results of the research were almost entirely favorable to caffein. Gains were recorded in all the capacities investigated. The tests made with the typewriter were of the most practical interest. When caffein had been received by the worker the copying was accomplished somewhat more rapidly and with fewer errors than at other times. Moreover, when mistakes were made, they were more often recognized on the instant. It is instructive to compare these facts with those that have been secured with alcohol. Both alcohol and caffein probably inspire the user with confidence in his ability to do his best. But there is a divergence in the actual performance, alcohol failing to give the promised reinforcement, and caffein confirming the subjective impression quite decisively.

We naturally assume that a period of stimulation will be followed by one of corresponding depression, as the 1 "Archives of Psychology," The Science Press, New York, April, 1912. 
trough of a wave follows the "rest. Hollingworth has failed to find evidence of any such reaction. Nothing in the report is more uncexpected or more important if it shall be sustained. If it is possible to enhance working power and not entail any extra fatigne, we must conelude that the part played by the stimulant may be quite imnocent and desirable. Sereral years ago a wise teacher suggested that a whip is appropriate for the lazy, but not for the tirecl, horse.'

In spite of Hollingworth's impressive findings, it would be unsafe to conclude that all people can advantageously use tea and coffec. Many exceptions are apparent. Even among the members of Hollingworth's squad the karger doses raused some feverish conditions, headache, and sleeplesiness. If such reactions were markert and long continued, there cin be no doubt that the favorable effects of caficin would soon be exchanged for detrimental ones. Only three or four of the subjects were non-users of caffein before the experimental periorl. It is probable that there are a good many abstainers from coffee who have learned by disagreeable experience that they must rlo witlout it.

While we may not rondemn in a swepping fashion the taking of eaffein, nor even the gurarded indulgence in alcohol, there is no room for two opinions regarding the dimeres of more active drugs. All use of morphin, cocain, and their congeners is perilons. Temperane in their employment is conceivable, but serms scarcely ever to be realized. The tendency to increase the dosage is almost irresistible. There is hardly a spectacle so tragie as that of the drug victim, stearlily deteriorating in character, until his moral cowardice, dishonesty, and lack of self-respert are incerelible to the members of his family. Fome one has said that "the drumkind turns night into day and the morphinist turns day into night." The influence of cocain serems to rescumble that of alcohol rather more than that of

' Hongh and singwick, "The Human Mechanism," (inn \& (o., Buston, 1!)hi, (hilp). xx. 
morphin; it leads to reckless and violent crime. There is a popular impression that the habit-forming alkaloids produce delightful subjective states. This seems rarely to be the case after the first foolish ventures; the most that the unhappy wretch reports later is that the drug relieves - and often incompletely - the misery of abstinence.

A final word may be added concerning the attitude which we should maintain toward medicine and the medical profession. Physicians were once held in high respect by all civilized people. At the present time, when the attainments and principles of the profession merit, far more than ever before, popular esteem and admiration, a hostile and skeptical spirit is often manifested. Several causes for this are evident. The fact that drugs are less relied on to remedy discased conditions than was formerly the case has encouraged the hasty conclusion that they have no value at all. Errant schools, using peculiar therapeutic methods, have fiercely attacked the main body of practitioners. Patients who have been benefited by these special measures have joined heartily in denying the virtue of other kinds of treatment. Psychotherapy has led to the same reaction in spite of the broad views urged by its ablest exponents. Certain periodicals have made incessant, malicious attacks upon the profession, charging mercenary aims, unwarranted experimentation upon human subjects, and failure to effect cures. It is amusing - even while it is irritating-to note that those who write such articles charge the physician with being unwilling to adopt new methods, and in the next paragraph cry out against his innovations. The dignified silence maintained by medical men in the face of these attacks is not properly appreciated by a thoughtless public.

When it is suggested that physicians and surgeons ask excessive fees there are two or three reflections that should modify judgment. It is a trite saying that restoration to health has a value not easily expressed in money. Second, we should consider the investment of time, strength, and means which has equipped the doctor for his respon- 
sible service. Third-and this is often overlooked-it is the generous payments of those who can afford them which make it possible for the practitioner to give his best skill frecly to the poor.

Too many intelligent people have failed to read of the achievements of medical science. It is only when the former insecurity of life is contrasted with its present conservation that our indebtedness to the profession is realized. The stories of the conquest of small-pox and yellow ferer are among the most thrilling that can be found in lumman annals. The discovery of the chief methods of anesthesia and of the way to avoid surgieal infection-these have almost an equal power to grip the reader. A little acquaintance with the literature of serenty-five years ago suffices to make one realize the horror of epidemies, particularly of yellow fever and cholera. Typhus fever, which once ravaged the steerages of emigrant ships, has become a rare and curious discase. Pessimists often lay stress upon the increasing prominence of certain causes of death. They forget that since man is mortal, the individuals who escape one malady must later be counted among the vietims of another. The happy fact is that they have lived through longer, more vigorous, and more rewarding lives. 


\section{INDEX}

Accelerators, cardiac, 117

Accomplishments, 54

Adjustors, 18, 33, 52

Idrenal bodies, 92, 109, 170-172

Afferent paths, 75-82, 99, 143

type of neuron, $31,32,78,79$

Ige, $156,157,181$

Alcohol, 217-220

Alimentary canal, 125, 208

All-or-none law, 90

Amputation, 45

Anemia, 194

theory of sleep, 175-177

Anesthesia, 196

Anger, 168, 212

Animals, decerebrate, 129-133, 174

Ant, 47

Antagonistic muscles, 94

Anticipation, 159, 160

Aphasia, motor, 147-149

Association areas, 150, 151

fibers, 151

Associative memory, 128, 129

Astigmatism, 195, 196

Ataxia, 99

Auditory area, 145

nerve, 73,81

Auto-intoxication, 193, 194, 209

Lutomatic property, 20

Autonomic system, 114-126, 17 . in emotion, $170-172$

in neurasthenia, 207-210

Axis of nervous system, 66,67

Axis-cylinder or axon, 26
Bell's law, 62

Brain, circulation in, 175

frog's, $60-65$

gray matter in, 70

rabbit's, $65-67$

ventricles of, 64

Breathing, 99, 100

Burnett on decerebrate frogs, 130, note

CAFfein, 220-222

Camis on reflexes, 93

Cannon on emotion, 165-167, 170,171

Cardiac accelerators, 117 nerves, 116-11s

Cavities of eentral nervous system, 62-64

Cell theory, 22

Cells, 22-24

Cerebellum, 65, 68, 96-99, 128

Cerebral hemispheres. Sce Cerebrum.

Cerebrospinal fluid, 61

Cerebrum, 64, 70, $88,127-155$

lobes of, 71

Chiasma, 73

Chorda tympani, 119

Christian Science, 215

Cireulation in brain, 175

City life, 167

Cold, sensation of, 78

Coneentration and detachment, $15 \mathrm{~S}$

Conduction, 25, 79 
Congestion, 121, 122

Connective tissue, 11

Constipation, 209, 210

Contractile tissue, 12

Convolutions, 70

Coörlination, 14, 93

Corporal quadrigemina, 66

Corpus callosum, 70)

Cortex, 70, 136

Coughing, 50

Courtney on neurasthenia, 204213

Cranial nerves, 60, 71-74

Crile on unfelt injury, 196-199

Crura cerelori, 69)

Cytoplasm, 2.1

\section{D.ancisa, 109}

Dirwin's use of limited strength, 159

Decerebrate animals, 129-133, 17.4

child, 132

Degeneration, 35

Delirimm, 92

Dendrites, 29

Dendrons, 29

Depth of sleep, 178

Descartes on memory, 136 on reflexes, 49

Diaphragm, 10:3

Diet, influence of, 112

Dreams, 151-191 clasified, 1st

ryes in, 190

sensitions in, 197

symbolism in, 187

viseeral symbols in, 187

Drugs, 222

EARLY eonceptions of nerve action, 37
Effectors slefined, 18

Elbow, 42

Electric phenomena, $17,39,171$

Ellis on clreams, 177, 184-191

Emotion, 161-172

Epilepsy, 1 12

Epithelial tissue, 12

Equilibrium, s1, 97

Escape (of heart), 117

Eugenics, 216-21s

Evolution of nervous system, 19

Eye-muscles, it

Eyes in clreams, 190

Eye-strain, 194-19ti

FAR-Signt, 195

Fatigue and (1reams, 15.j-187 general, 203-205 neuromuscular, 101-110 synaptic, 10.5

Fatigue-products, 101, 102

Fibers, association, 151 regeneration of, 3.) secretory, 126

Fibrils, 26, 34

Fingers, so

Flatulence, 209

Flechsig on association areas, 151

Fletcher on hours of sleep, 1S1

Flourens, pioneer experiments, 130, 133

Forbes on fatigue, 10:-107

Foster on ollel age, 156, 208

lireud on dreams, 1s?

Frietion, domestic, 200

Frog's nervols system, 60-65)

Functional and organic disorlers, 203

Gage, Phineas, 152

Gall, phrenologist, $13 t$ 
Ganglia, 27, 115, 116 of (lorsal roots, 78

Ganglion, Gasserian, 80

Genito-urinary symptoms, 210

Glands, nervous control of, 126

Goltz's decerebrate dog, 132

Gordon on infant mind, 154

Gradation of muscular responses, 89-93

Gravity and the circulation, 123 , 124

Gray and white matter, 26-28

matter in brain, 70 in cord, 68

Growth of muscles with use, 111 Gyri, 70

Habits, $54,155,156$

Hearing, 81

Ifeart, 116-118, 120, 121, 208 inhibition of, 117

Heredity, 192, 216-218

Hollingworth on caffein, 221, 222

Howell on sleep, 176, 180

Hunt on alcohol, 219

Hygiene, 15.5-163, 167-170, 180$182,185-187,200-202,213-224$

Hypnotism, rapport of, 56

INDIVIDUAL, $16,47,127$

Infancy, 153-155

Inhibition, 20, 21, 157, 209, 212 of heart, 117

withdrawal resembles stimulation, 20, 205, 219

Inhibitory influence on centers, 104,108

Integration, 16

Intelligence, 127, 146

Intercellular substance, 24

Intoxication, 205
JAMES on emotion, 167, 168 on habits, 155,156

James-Lange theory, 164, 171

Jordan on heredity, 218

LANGUAGe, 147-150

Law, all-or-none, 90

Bell's, 62

Lee on fatigue, 102, 204

Lincoln's power of detachment, 158

Lingle on tonus, 91

Lobes of cerebrum, 71

Localization, 133-152

Loeb on localization, 139

Lucas on muscular action, 89-93

Martin et al. on sensory threshold, 162

Medicine, 223, 224

Medulla, 63, 128, 143

Mellus on the cortex, 150

Memory, 137, 161, 186 associative, 128, 129

Meninges, 61,62

Midbrain, 64

Monotony, 160

Motor aphasia, 147-149 areas, $135-143$ end-plates, $87,102,104,112,166$ neurons, 33,85

Müller, 43, 207

Miillerian principle, 44,76

Münsterberg on free agency and mind, 141

Muscle-fibers, 85

Muscles, antagonistic, 94 eye-, 74

NeAr-Sight, 194, 195

Nerve action, early conceptions of, 37 
Nerve, auditory, 73, 81

impulses, 37-40, 43

olfactory, 65,71

in fish, 129

optic, 65,72

trigeminal, 73 , so

vaugus, 73

restibular, $S 1$

Nerve-eenters, 53

Nerve-fibers, 25, 26;

Nerves, 25

cardiac, 116-11s

(ranial, 60, 71-74

spinal, 60

Neurasthenia, 185, 2013-215

sensitions in, 206, 207

Neurasthenic temperament, 18s, 210

Neuromuscular fatigue, 101-110 unit, 86,57

Neuron, afferent type, 31, 32, is, 79

Neurons, motor, 33, 85

postganglionic, 115

preganglionic, 115

Neuropile, 34

Newborn, 54

Nodes of Ranvier, 26;

Nucleus, 24

Nutritional (listurbances, 193

Occepation, 199

())factory area, 145

n(rvoe, (i.5, 71

in fish, 12?

Optic rhi:Lmat 73

nerve, 6.5, 72

Orthortontial, 19s

(Overwork, 19!)

P'.1. 1!)

Paths of easy transmission, 4ti
Perikiaryon, alteration through activity, 41, 197

definerl, 30

reinforcing funetion, 41

relaterl to mutrition, 34

Phrenolongy, 13.4, 13.5

Pilomotor action, 12.5

Play atut work, 110

Plethysmogr:aph, 17!?

Pons, tis .

Post gamglionic nemurons, 115

Posture, 12:3, 121

Preganghonic neurons, 115

Prince on memory, 137

Prof:unity, 1.4s

Projection fibers, SS, 143

Protoplasm, 2t

Psychanalysis, 185-190

Psychathenia, 211

Psycholongy, 16, 140

Piychotherapy, 197, 198, 21.;

f'unctiform sensibility, 7

Putnam on fatigue, 20:3

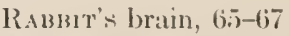

Ranvier, norles of, 26

Rapport of hypnotism, .56

Reaction-tinc, is

Reading are:1, 14:

Receptors, 18,76

Reciprocal innervation, 95,96

Reflexps, 19-59, si

eomlitioned, is

type of atl nervous action, 139

Regencration of tibers, 3.5

Religion, 163. 2102, 21:5

Respiratory center, 100)

Restlesinese, 20)i

Right-hameterl comslition, 146

Roots, dorsil and vent ral, 6i2

Ruts, 11 , 156 
SabBath, 161-163, 201, 202

Science, 214, 21j

Sea-royages, 214

Secretory fibers, 126

Sonsations, 44, 76-84, 104 general and special, 83, 84 in dreams, 191 in neurasthenia, 206, 207 Sensibility, punctiform, 77

Sensory threshold, 162, 207 Sexual life, 189, 190, 217

Sherrington on coördination, 9496

Singing, 170

Skill, 113

Skin, 75, 121

s'leep, 173-1s:3

anemia theory of, $175-177$

lepth of, $17 \mathrm{~S}$

toxemia theory of, 175-177

sinell, 81

Speceh center, 147-150)

Spinal cord, 60, 69, 127 gray matter in, 70

Spontaneity, 131

Starling on cercbrum, 127

Stcdman on Lincoln, 15s

Stimuli, 17, 36, 37, 82

Strain, cyc-, 194-196

Sulci, 70

Symbolism in (lreams, 1S7

Sympathetic system, 116, 170

Sympathy, 168, 211

withlolding of, 212

Synapse, $28,33,88$

valve action of, 29,30

symaptic fatigue, 105

resistance, 46, 182

TASTE, 81

Temperature and blood-flow, 121, 208
Thom on on aphasia, 148 on sleep, 174

Tissues, 11-14 connective, 11 contractile, 12 epithelial, 12 nervous, 13

Tolerance, 200

Tonus, 55, 119

Toxemia theory of sleep, 175177

Training, 91, 110-113

Treppe, 102

Trigeminal nerve, 73,80

Vacis nerve, 73

Valve action of synapse, 29, 30

Vasoconstrictors, 118

Vasodilators, 119, 120

Vasomotor reactions, 55, 118125, 208

Velocity of nerve-impulse, 40

Ventilation, 198, 199

Ventricles of brain, 64

Vestibular nerve, 81

Visecral muscle, 114 symbols in dreaums, 187

Vision, 80

Visual areas, 140,144

Vital resistance, 123

Voluntary action, 53, 58, 87

WALKING, 53, 98, 213

Waste-products of nerve, 39 (and note). Sec Fatigue.

Wells and Forbes on electric disturbances, 171

Wink, 50

Women, dull lives of, 169

Writing, 149 





\section{COLLEG TERTIBORS PUBLISHED BY}

\section{W.B.SAUNDER COMPANY}

West Washington Square Philadelphia

London: 9, Henrietta Street, Cov́ent Garden

\section{Daugherty"s Economic Zoölogy}

Economic Zö̈logy. By L. S. Daugherty, M. S., Ph. D., Professor of Zoïlogy, State Normal School, Kirksville, Mo.; and M. C. Dadgherty. Part I-Field and Laboratory Guide: I 2 mo of 237 pages, interleaved. Cloth, \$1.25 net. Part II-Principles: I $2 \mathrm{mo}$ of 406 pages, illustrated. Cloth, $\$ 2.00$ net.

There is no other book just like this. Not only does it give the salient facts of structural zoölogy and the development of the various branches, but also the natural history-the life and habits. It emphasizes the economic phase throughout, showing the beneficial or harmful tendencies of each animal in the life of man. The illustrations are helpful.

Prof. V. E. Shelford, University of Chicago: "It has many merits and is the best book of the kind on the market."

\section{Striles}
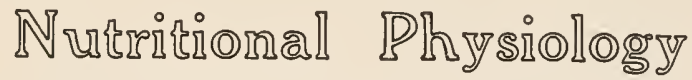

Nutritional Physiology. By Percy G. Strles, Assistant Professor of Physiology in Simmons College; Instructor in Physiology and Personal Hygiene in the Massachusetts Institute of Technology, Boston. $12 \mathrm{mo}$ of $27 \mathrm{r}$ pages, illustrated. Cloth, $\$ \mathrm{r} .25$ net.

Dr. Stiles' new work expresses the most advanced views on this important subject. It takes up each organ, each secretion concerned with the process of digestion, discussing the part each plays in the physiology of nutrition-in the transformation of energy. In fact, the keynote of the book throughout is "energy"-its source and its conservation. The illustrations and homely similes are noteworthy.

Prof. M. E. Jaffa, University of California: "The presentation of the matter is excellent and can be understood by all." 


\section{MeFarland's Biology}

fiolugy: General and Medical. By Josliph McFakland, M.I., l'rofessor of Pathology and hacteriology, Medico-Chirurgical (o). lege, Philadelphia. 12 mo of 440 pages, illustrated. Cluth, \$1.75 net.

This work is particularly adaptable to the requirements of scientific courses. There are chapters on the origin of life and its manifestations, the cell and cell division, reproduction, ontogenesis, conformity to type, divergence, structural and blood relationship, parasitism, mutilation and regeneration, grafting, senescence, etc.

Prof. W. R. McConnell, Pennsylvania State College: "It has some admirable features, the most valuable of which is the careful résumé of the subjects of heredity and evolution."

\section{Drew's Inver?ebrąe Zoölogy}

Invertebrate Zoology. By GuMAN A. DREw, Ph. D., Assistant Director of the Marine Biological Laboratory, Woods Hole. Mass. $12 \mathrm{mo}$ of 213 pages. Cloth, S1.25 net. Vew (2d) Edition.

Professor Drew's work gives the student a working knowledge of comparative anatomy and leads him to an appreciation of the adaptation of the animals to their environments. It is a practical work, expressing the practical knowledge gained through experience. The type method of study has been followed.

Prof. John M. Tyler, Amherst College: "It covers the ground well, is clear and very compact. The table of definitions is excellent."

\section{American Pocker Dictionary}

American Pocket Melical Dictionary. Edited by W. A. NEw. MAN WORLAND, MI. D. 677 pages. Flexible leather, \$1.00 net; thumb index. $\$ 1.25$ net.

Eighth Edition.

A clictionary must be full enough to give the student the information he seeks, clearly and simply, yet it must not confuse him with detail. The editor has kept this in mind in compiling this Pocket Dictionary, and he has produced a work of great value to the student. There are over 100,000 American Medical Dictionaries now in use.

I. V. S. Stanislaus, M.D., Merlico-Chirurgical College: "We have been strongly recommencling this little book as being the very best." 


\title{
Buchanan' V eterinary Bacteriology
}

\author{
Viterinary Bactiriology. By RoBert E. Buchanan, Ph. D., \\ Professor of Bacteriology in the lowa State College of Agriculture \\ and Mechanic Arts. Octavo of 516 pages, 2I 4 illustrations \\ Cloth, $\$ 3.00$ net.
}

Professor Buchanan's new work goes minutely into the consideration of immunity, opsonic index, reproduction, sterilization, antiseptics, biochemic tests, culture media, isolation of cultures, the manufacture of the various toxins, antitoxins, tuberculins, and vaccines.

B. F. Kaupp, D. V.S., State Agricultural College, Fort Collins: "It is the best in print on the subject. What pleases me most is that it contains all the late results of research."

\section{Sisson's Vererimary Anatomy}

Veterinary Anatomy. By Septimus Sisson, S. B., V. S., Professor of Comparative Anatomy, Ohio State University. Octavo of 826 pages, 588 illustrations. Cloth, \$7.00 ret. The Standard.

Here is a work of the greatest usefulness in the study and pursuit of the veterinary sciences. This is a clear and concise statement of the structure of the principal domesticated animals-an exhaustive gross anatomy of the horse, ox, pig, and dog, including the splanchnology of the sheep, presented in a form never before approached for practical usefulness.

Prof. E. D. Harris, North Dakota Agricultural College: "It is the best of its kind in the English language. It is quite free from errors."

\section{Sharp's}
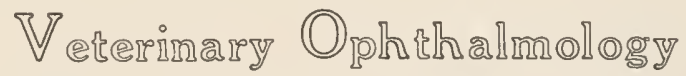

Ophlhalmology for l'eterinarians. By WaLter N. SHARP, M. D., Professor of Ophthalmology, Indiana Veterinary College. I 2 mo of 210 pages, illustrated. Cloth, \$2.00 net.

This new work covers a much neglected but important field of veterinary practice. Dr. Sharp has presented his subject in a concise, crisp way, so that you can pick up his book and get to "the point" quickly. He first gives you the anatomy of the eye, then examination, followed by the various diseases, including injuries, parasites, errors of refraction, and medicines used in ophthalmic therapeutics. The text is illustrated. 


\section{Pylès Personal Hygiene}

Personal Hygiene. Edited by WAltro L. Pyle, M. D., Fellow of the American Academy of Medicine. $12 \mathrm{mo}$ of 515 pages, illustraied. Cloth, \$r.5o net.

Fifth Edition.

Dr. Pyle's work sets forth the best means of preventing disease-the best means to perfect health. It tells you how to care for the teeth, skin, complexion, and hair. It takes up mouth breathing, catching cold, care of the vocal cords, care of the ey'es, school hygiene, body posture, ventilation, house-cleaning, etc. There are chapters on food adulteration (by Dr. Harvey W. W'iley), domestic hygiene, and home gymnastics.

Canadian Teacher: "Such a complete and authoritative treatise should he in the hands of every teacher."

\section{Galbraith's Esercise for Women}

Personal Hygiene and Physical Training for Women By Anna M. Galbraith, M. D., Fellow New York Academy of Medicine. $12 \mathrm{mo}$ of $37 \mathrm{x}$ pages, illustrated. Cloth, $\$ 2 . \infty$ net.

Dr. Galbraith's book meets a need long cxisting-a need for a simple manual of personal hygiene and physical training for women along scientific lines. There are chapters on hair, hands and feet, dress, development of the form, and the attainment of good carriage by dancing, walking, running, swimming, rowing, etc.

Dr. Harry B. Boice, Trenton State Normal School: "It is intensely interesting and is the finest work of the kind of which I know."

\section{MeKenzie on Emercise}

Exercise in Education and Medicine. By. R. TAIt MchuNzıE, M. I., P'rofessor of Physical Fducation, L'niversity of Y'ennsyl. vania. Octavo of 406 pages, with 346 illustrations. Cloth, \$3.50 net. Adopted by U.S. Army.

Chapters of special value in college work are those on exercise by the different systems: play-grounds, physical education in school, college, and university.

D. A. Sargent, M. D., Hemenway Gymnasium: "It should be in the hands of every physical educator." 


\section{rinll's Nommal ristology}

Normal Histology and Organography. By Charles Hill, M. D. I2mo of 468 pages, 337 illustrations. Flexible leather, $\$ 2 . \infty$ net. Second Edition.

Dr. Hill's work is characterized by a brevity of style, yet a completeness of discussion, rarely met in a book of this size. The entire field is covered, beginning with the preparation of material, the cell, the various tissues, on through the different organs and regions, and ending with fixing and staining solutions.

Dr. E. P. Porterfield, St. Louis University: "I am very much gratified to find so handy a work. It is so full and complete that it meets all requirements."

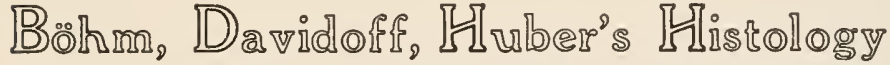

Histology. Py A. A. Böнm, M. D., and M. von Davidoff, M. D., of Munich. Edited by G. Carl Huber, M. D., Professor of Embryology at the Wistar Institute, University of Pennsylvania. Octavo of 528 pages, 377 illustrations. Flexible cloth, $\$ 3.50$ net.

Second Edition.

This work is conceded to be the most complete text-book on human histology published. Particularly full on microscopic technic and staining, it is especially serviceable in the laboratory. Every step in technic is clearly and precisely detailed. It is a work you can depend upon always.

New York Medical Journal: "There can be nothing but praise for this model text-book and laboratory guide."

\section{Reisler's Embryology}

Embryology. By J. C. Heister, M. D., Professor of Anatomy, Medico-Chirurgical College of Philadelphia. Octavo of 432 pages, 205 illustrations. Cloth, $\$ 3.00$ net.

Third Edition.

A book of the greatest teaching value. The subject is taken up systematically, treating the development of each tissue, each organ, each region and system in a most thorough way. There are frequent allusions to certain facts of comparative embryology.

Journal American Medical Association: "The text is concise, and yet sufficiently full for a text-book." 


\title{
Jordan's Genera! Bacteriology
}

General Bacteriology'. By luwin O. Jordan, Ph. D., Professor of Bacteriology, University of Clicago. Octavo of 623 pages, illustrated. Cloth, $\$ 3.00$ net.

Third Edition.

This work treats fully of the bacteriology of plants, milk and milk products, dairying, agriculture, water, food preservation; of leather tamning, vinegar making, tobacco curing; of houschold administration and sanitary engineering. I chapter of prime importance to all students of botany, horticulture, and agriculture is that on the bacterial diseases of plants.

Prof. T. J. Burrill, University of Illinois: "I am using Jordan's Bac. teriology for class work and am convinced that it is the best text in existence."

\section{Eyre's Backeriologic Technic}

Bacleriologic Technic. By J. W. II. EYRE, M. D., Bacteriologist to Guy's Hospital, London. Octavo of 525 pages, illustrated. Cloth, \$3.00 net. Second tidition.

Dr. Eyre gives clearly the technic for the bacteriologic examination of water, sewage, air, soil, milk and its products, meats, etc. It is a work of much value in the laboratory. The illustrations are practical and serve well to clarify the text. The book has been greatly enlarged.

The London Lancet: "It is a work for all technical students, whether of brewing, dairying, or agriculture."

\section{Gorkam's Laboratory Bacteriology}

\author{
Laboratory Bacteriolugy. By liredertc P. Gorkan, A. M., \\ Associate Professor of linlogy, Brown Jniversity, Providence. \\ 12 mo of $1 \geqslant 2$ pages, illustrated. C'oth. \$1.25 net.
}

The subjects of special interest to scientific students are the identification of bacteria of water, milk, air, and soil. Professor Gorham has succeded in making his instructions clear and easily graspecl by the student. The text is illustraterl.

Science: "The author has descrilecd small points of technic usually" left for the student to learn hinself." 


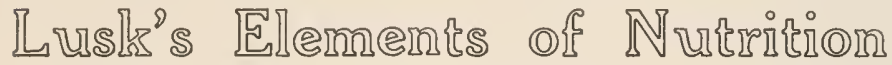

Elements of Nutrition. By Graham Lusk, Ph. D., Professor of Physiology, Cornell Medical School. Octavo of 402 pages, illus trated. Cloth, \$3.oo net.

Second Edition.

The clear and practical presentation of starvation, regulation of temperature, the influence of protein food, the specific dynamic action of food-stuffs, the influence of fat and carbohydrate ingestion and of mechanical work render the work unusually valuable. It will prove extremely helpful to students of animal dietetics and of metabolism generally.

Dr. A. P. Brubaker, Jefferson Medical College: "It is undoubtedly the best presentation of the subject in English. The work is indispensable."

\section{凡owel|'s PRysiology}

Physiology. By William H. Howell, M. D., Ph. D., Professor of Physiology, Johns Hopkins University. Octavo of Iozo pages, illustrated. Cloth, $\$ 4.00$ net.

Fifth Edition.

Dr. Howell's work on human physiology has been aptly termed a "storehouse of physiologic fact and scientific theory." You will at once be impressed with the fact that you are in touch with an experienced teacher and investigator.

Prof. G. H. Caldwell, University of North Dakota: "Of all the textbooks on physiology which I have examined, Howell's is the best."

\section{Bergegy's rygriene}

Hygiene. By D. H. Bergey, M. D., Assistant Professor of Bacteriology, University of Pennsylvania. Octavo of $53^{\circ}$ pages, illustrated. Cloth, \$3.00 net.

Fourth Edition.

Dr. Bergey gives first place to ventilation, water-supply, sewage, industrial and school hygiene, etc. His long experience in teaching this subject has made him familiar with teaching needs.

J. N. Hurty, M. D., Indiana University: "It is one of the best books with which I am acquainted." 


\section{Morrow? Care of Injurred}

Immediate Cizre of the Injured. Bу Ацввка S. Moкиоw, M. D., Acljunct Professor of Surgery, New York Polyclinic. Octavo of 360 pages, 242 illustrations. Cluth, \$2.50 net. Second Edition.

Dr. Morrow's book tells you iust what to do in any emergency, and it is illustrated in such a practical way trat the idea is caught at once. There are chapters on bandaging, practical remedies, first-aid outfit, hypodermic injections, antiseptics and disinfectants, accidents and emergencies, hemorrhages, inflammation, contusions and wounds, burns and scalds, the injurious effects of cold, fractures and dislocations, sprains, removal of foreign bodies from the eyc, ear, nose, etc., poisons, and their antidotes. There is no book better adapted to first-aid class work.

Health: "Here is a book that should find a place in every workshop and factory and should be made a text-book in our schools."

\section{American Illustrated Dictionary}

American Illustrated Medical Dictionary. By W. A. Nвwsin Dokland, M. D., Member of Committee on Nomenclature and Classification of Diseases, American Medical Association. Octavo of 1107 pages, with 323 illustrations, 119 in colors. Flexible leather, \$4.50 net; thumb indexed, \$5.00 net. Seventh Edition

If you want an unabridged medical dictionary, this is the one you want. It is down to the minute; its definitions are concise, yet accurate and clear; it is extremely easy to consult; it defines all the newest terms in medicine and the allied subjects; it is profusely illustrated. This new edition alone defines over 5000 new terms not defined in any other medical dictionary-bar none. There is no other medical dictionary that will meet your needs as well as The American Jllustrated. Why not then get the best?

John B. Murphy, M. D., Northwestern University: "It is unquestionably the best lexicon on medical topics in the English language, and, with all that, it is so compact for ready reference."

DESCRIPTIVE CIRCULARS OF ALL BOOKS SENT FREE 


702 
